LUCIANO CAVALLINI CYRILLO

\title{
GESPRODS - UM MODELO DE GESTÃO DE PROJETOS DISTRIBUÍDOS DE SOFTWARE
}

Dissertação apresentada à Escola Politécnica da Universidade de São Paulo para obtenção do título de Mestre em Engenharia. 
LUCIANO CAVALLINI CYRILLO

\section{GESPRODS - UM MODELO DE GESTÃO DE PROJETOS DISTRIBUÍDOS DE SOFTWARE}

Dissertação apresentada à Escola Politécnica da Universidade de São Paulo para obtenção do título de Mestre em Engenharia.

Área de Concentração:

Engenharia Elétrica

Orientador:

Prof. Dr. Kechi Hirama

SÃO PAULO

2005 


\section{FICHA CATALOGRÁFICA}

Cyrillo, Luciano Cavallini

GesProDS - um modelo de gestão de projetos distribuídos de software / L.C. Cyrillo. -- São Paulo, 2005.

$114 \mathrm{p}$.

Dissertação (Mestrado) - Escola Politécnica da Universidade de São Paulo. Departamento de Engenharia de Computação e Sistemas Digitais.

1.Desenvolvimento distribuído de software 2.Gestão de projetos distribuídos 3.Gestão de projetos I.Universidade de São Paulo. Escola Politécnica. Departamento de Engenharia de Computação e Sistemas Digitais Il.t. 


\section{DEDICATÓRIA}

À minha esposa Juliana, por seu apoio e carinho, que foram determinantes para a conclusão deste trabalho. 


\section{AGRADECIMENTOS}

Ao Prof. Dr. Kechi Hirama, pelo excelente trabalho de orientação, pelo apoio, dedicação e estímulo prestados ao longo deste período e pela oportunidade única de aprendizagem proporcionada.

Ao Prof. Dr. Ítalo Vega, pelo incentivo ao ingresso na carreira acadêmica.

Ao Prof. Dr. Jorge Luis Risco Becerra e à Profa. Dra. Lúcia Vilela Leite Filgueiras, pela grande contribuição no exame de qualificação.

À minha mãe Denise, pelo incentivo e pelo grande exemplo de dedicação à carreira acadêmica.

Ao meu pai Francisco, grande amigo, que sempre esteve presente e me apoiou nos momentos difíceis.

À minha irmã Fernanda, pelo exemplo de dedicação e persistência para alcançar os objetivos.

Aos meus familiares, pelo apoio e pelo interesse demonstrados pela minha carreira.

Aos meus gestores do Unibanco e BSI Tecnologia, Marta, Nelson, Aurélio e Soraya, que me incentivaram e permitiram que me dedicasse ao mestrado.

E a todas as outras pessoas que, de forma direta ou indireta, me ajudaram na elaboração deste trabalho. 
"Se as coisas são inatingíveis...ora! Não é motivo para não querê-las... Que tristes os caminhos, se não fora A mágica presença das estrelas!"

Mário Quintana 


\section{RESUMO}

Este trabalho apresenta um modelo para gestão de projetos distribuídos de software. Inicialmente, são apresentados os principais problemas identificados na literatura em relação ao Desenvolvimento Distribuído de Software. Em seguida, são analisados alguns modelos de gestão especializados neste tipo de desenvolvimento e também modelos tradicionais de gestão. Uma comparação entre os modelos é realizada para identificação do nível de atendimento de cada um em relação aos principais problemas identificados para este contexto de desenvolvimento. As melhores práticas de gestão em ambientes de Desenvolvimento Distribuído de Software são identificadas e utilizadas para compor um modelo de Gestão de Projetos Distribuídos de Software (GesProDS). O detalhamento do modelo envolve a descrição dos papéis, responsabilidades das organizações e recursos envolvidos. Além disso, a estrutura da organização envolvida e os processos de gestão identificados são descritos.

Palavras-Chave: Desenvolvimento Distribuído de Software; Gestão de Projetos Distribuídos; Gestão de Projetos. 


\begin{abstract}
This work shows a model for management of Global Software Development projects. Initially the main problems identified in literature for this kind of projects are presented. After that, some specialized models of project management are discussed. A comparison between the identified models and the most known models of project management in relation to the main described problems for this context is also carried through. From the described information, the best practices of project management are identified and used to compose a project management model (GesProDS) for Global Software Development Projects. This model is described including its roles, responsibilities of organizations and required resources. Further more, the structure of the virtual organization and management processes are described.
\end{abstract}

Keywords: Global Software Development; Distributed Project Management; Project Management. 


\section{LISTA DE FIGURAS}

Figura 1. Organização Virtual. Cyrillo e Hirama (2005) .................................................19

Figura 2. Tipologia de projetos. Evaristo e Fenema (1999) ...............................................21

Figura 3. Modelo CMMI. Representação por estágios. CMMI (2002)................................23

Figura 4. Modelo CMMI. Representação contínua. CMMI (2002) ....................................23

Figura 5. Ciclo de vida de projetos. PMBoK (2000). ........................................................

Figura 6. Modelo CPMA. Chen, Romano e Nunamaker (2003a) ......................................33

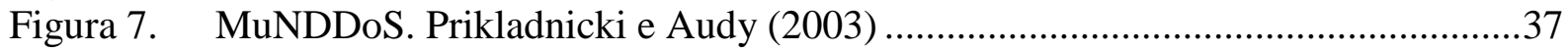

Figura 8. MILOS. Goldmann, Münch e Holz. (1999b)......................................................

Figura 9. Hexágono de gerenciamento de processos. Burlton (2001) . ..............................43

Figura 10. IDEF0. Diagrama de contexto. Burlton (2001)..............................................44

Figura 11. IDEF0. Representação de subprocessos. Burlton (2001).................................45

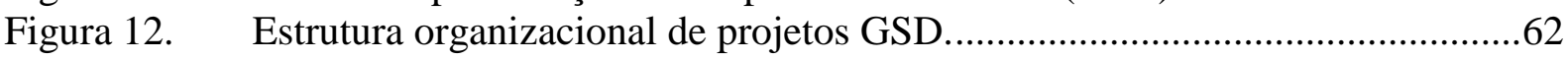

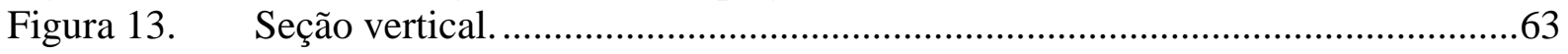

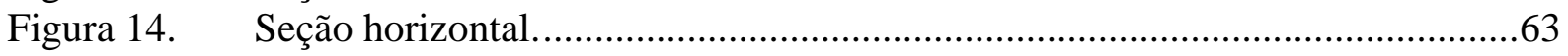

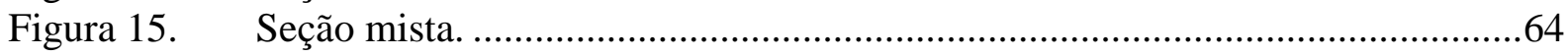

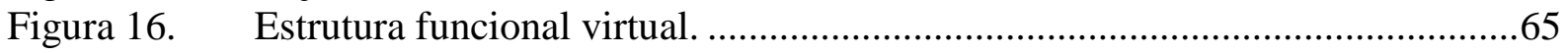

Figura 17. Diagrama de Contexto do modelo GesProDS. ...............................................68

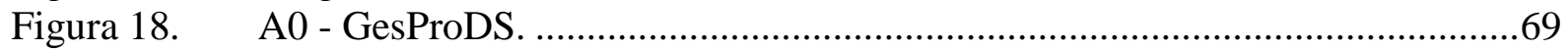

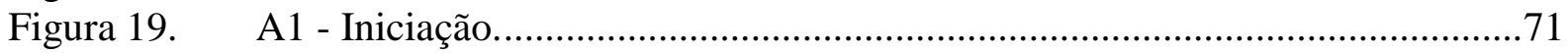

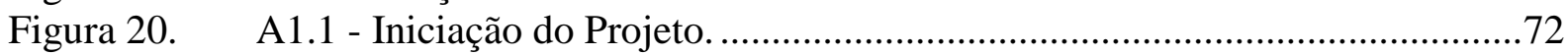

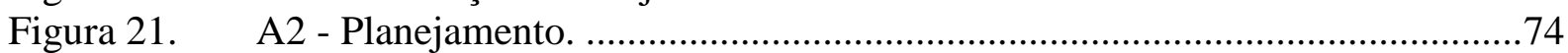

Figura 22. A2.1 - Avaliação de Riscos de Distribuição..................................................75

Figura 23. A2.2 - Meta-Planejamento do Tempo do Projeto............................................79

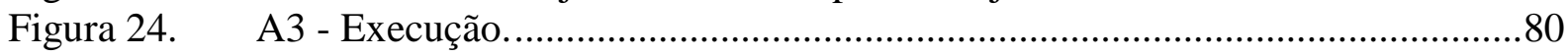

Figura 25. A3.1 - Gestão da Colaboração entre as Equipes Virtuais.................................82

Figura 26. A3.2 - Gestão do Conhecimento Colaborativo.................................................86

Figura 27. A3.3 - Gestão do Ambiente Físico de Desenvolvimento Distribuído. .............88

Figura 28. A3.4 - Suporte ao Entendimento de Conceitos do Projeto. ..............................92

Figura 29. A3.5 - Gestão da Distribuição de Informações do Projeto. ...............................94

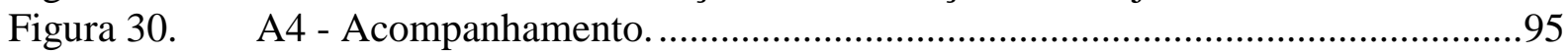

Figura 31. A4.1 - Controle de Mudança de Escopo. ......................................................98

Figura 32. A4.2 - Controle de Cronograma. .............................................................. 101

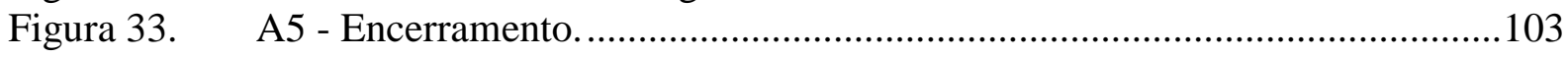

Figura 34. A5.1 - Encerramento do Projeto................................................................ 104 


\section{LISTA DE TABELAS}

Tabela 1. Relação entre problemas identificados e modelos de gestão...............................51

Tabela 2. Atributos da Iniciação do Projeto. ..................................................................... 71

Tabela 3. Atributos da Avaliação de Riscos de Distribuição. ...............................................75

Tabela 4. Atributos do Meta Planejamento do Tempo do Projeto. .......................................77

Tabela 5. Atributos da Gestão da Colaboração entre as Equipes Virtuais. ...........................81

Tabela 6. Atributos da Gestão do Conhecimento Colaborativo. ..........................................84

Tabela 7. Atributos da Gestão do Ambiente Físico de Desenv. Distribuído.........................87

Tabela 8. Atributos do Suporte ao Entendimento de Conceitos do Projeto. .........................91

Tabela 9. Atributos da Gestão da Distribuição de Informações do Projeto..........................93

Tabela 10. Atributos do Controle de Mudança de Escopo. ................................................97

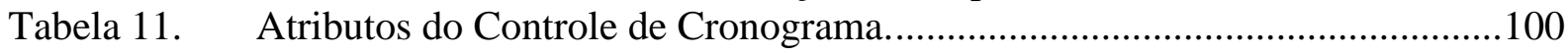

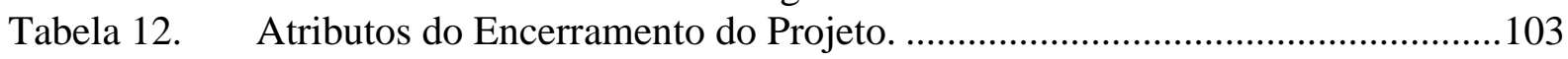




\section{LISTA DE ABREVIATURAS E SIGLAS}

CASE - Computer Aided Software Engineering

CMMI - Capability Maturity Model Integration.

CPMA - Collaborative Project Management Architecture.

DFG - Deutsche Forschungsgemeinschaft. Fundação de Pesquisa da Alemanha.

DPM - Distributed Project Management.

GesProDS - Gestão de Projetos Distribuídos de Software.

GSD - Global Software Development.

HICSS - Hawaii International Conference on System Sciences.

KPI - Key Performance Indicator.

MBWA - Management By Walking Around.

MILOS - Minimally Invasive Long Term Organizational Support for Software Development.

MuNDDoS - Maturidade No Desenvolvimento Distribuído de Software.

NSERC - Natural Sciences and Engineering Research Council of Canada.

PMBoK - Project Management Body of Knowledge.

PMI - Project Management Institute

PSP - Personal Software Process

SWEBoK - Software Engineering Body of Knowledge.

UP - Unified Process 


\section{SUMÁRIO}

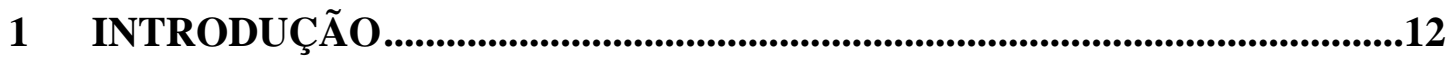

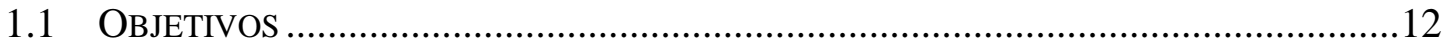

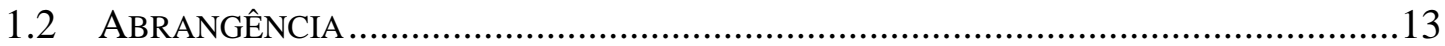

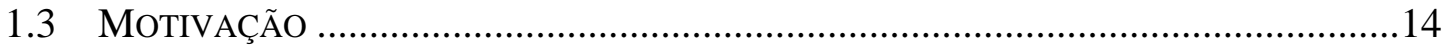

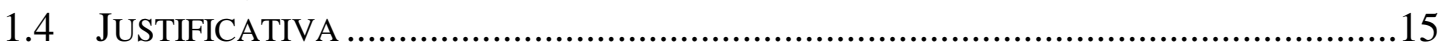

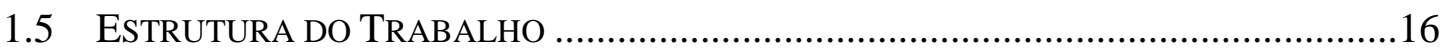

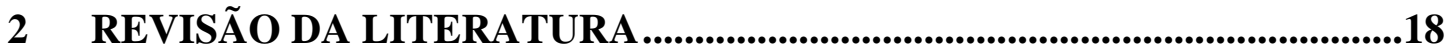

2.1 DESENVOLVIMENTO DistRIBUÍDO DE SOFTWARE................................................18

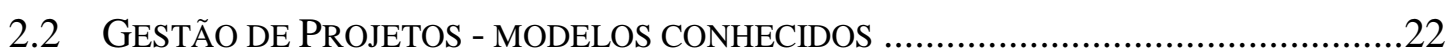

2.2.1 Capability Maturity Model Integration - CMMI...........................................22

2.2.2 Project Management Body of Knowledge - PMBoK....................................26

2.2.3 Software Process Improvement and Capability dEtermination - SPICE .........31

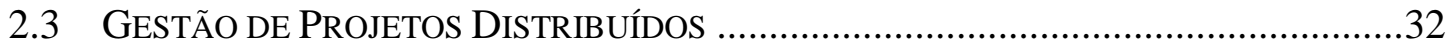

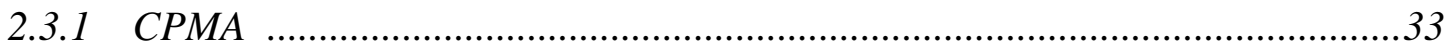

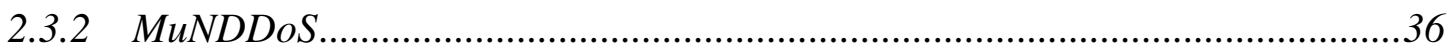

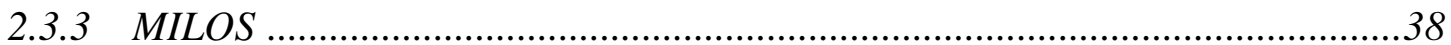

2.4 METOdOLOGIA PARA DESCRIÇÃO DE PROCESSOS ..............................................42

3 ANÁLISE DAS BASES CONCEITUAIS.......................................................46

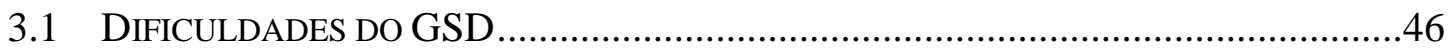

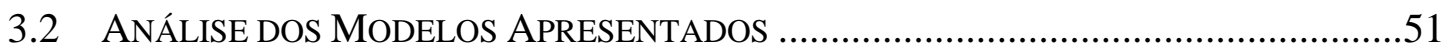

3.3 Boas Práticas PARA Gestão de Projetos Distribuídos ...............................54

4 GESPRODS - MODELO DE GESTÃO DE PROJETOS DISTRIBUÍDOS DE

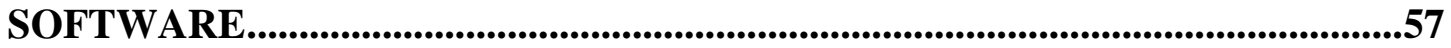

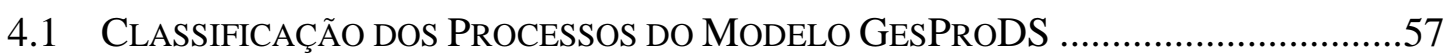

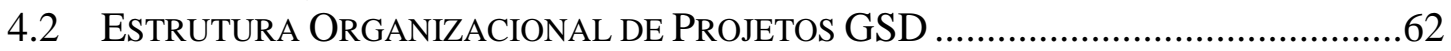

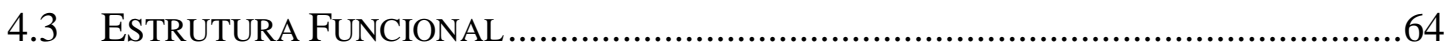

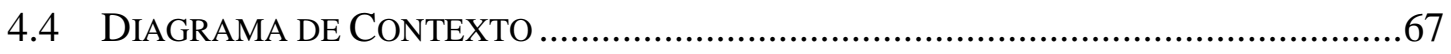

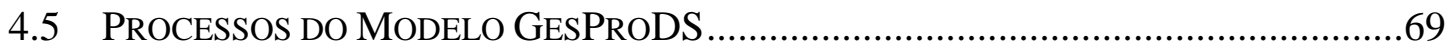

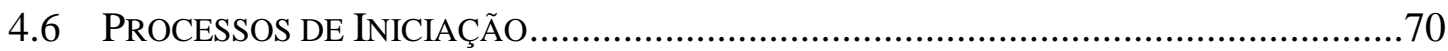

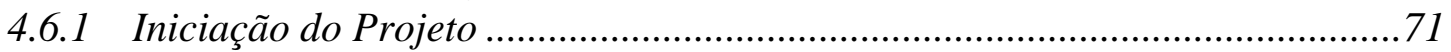

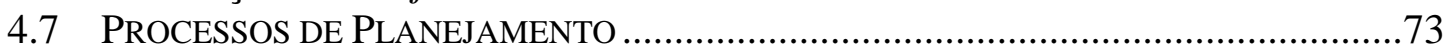

4.7.1 Avaliação de Riscos de Distribuição de Projetos e Equipes Virtuais ..............74

4.7.2 Meta-Planejamento do Tempo do Projeto.........................................................77

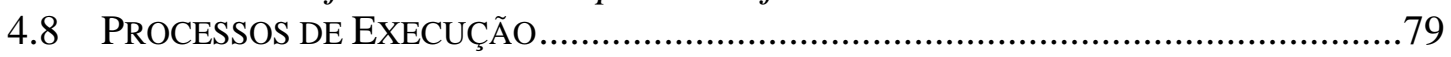

4.8.1 Gestão da Colaboração entre as Equipes Virtuais ........................................81

4.8.2 Gestão do Conhecimento Colaborativo.......................................................8

4.8.3 Gestão do Ambiente Físico de Desenvolvimento Distribuído ..........................86

4.8.4 Suporte ao Entendimento de Conceitos do Projeto ..........................................90

4.8.5 Gestão da Distribuição de Informações do Projeto ..........................................93

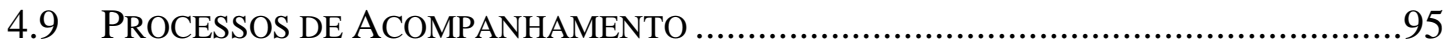

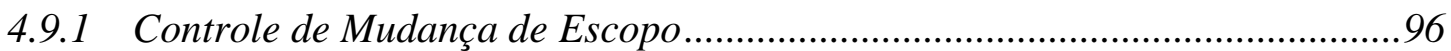

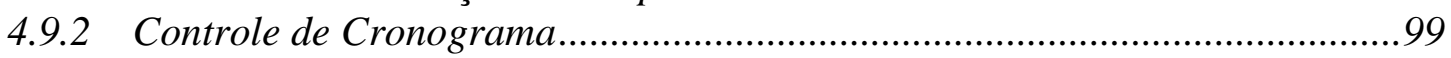

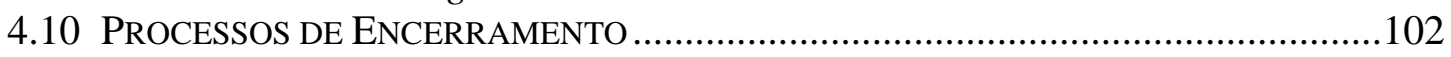




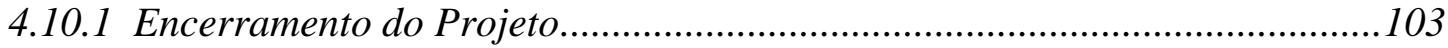

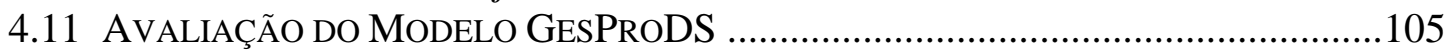

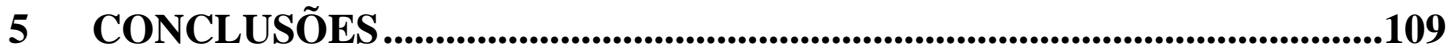

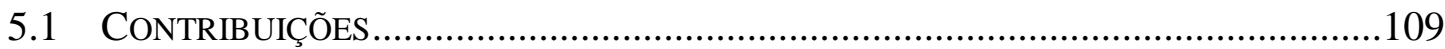

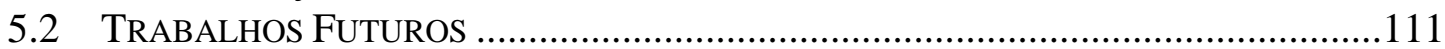

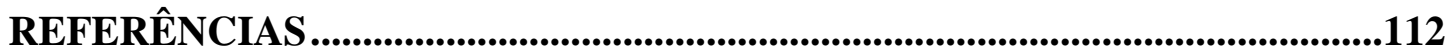




\section{Introdução}

Este capítulo apresenta o contexto geral do trabalho por meio do detalhamento dos seguintes tópicos: objetivos, abrangência, motivação, justificativa e estrutura do trabalho.

\subsection{Objetivos}

O principal objetivo deste trabalho é apresentar uma proposta de modelo de processos para Gestão de Projetos Distribuídos de Software (GesProDS). Conforme o PMBoK (2000), Project Management Body of Knowledge, um projeto é um trabalho temporário realizado para produzir um único bem ou serviço. Um projeto distribuído ou virtual, segundo Evaristo e Fenema (1999), envolve pessoas cooperando em locais geograficamente distribuídos e em diferentes organizações. Por proposta de modelo de processo, entende-se a especificação das atividades, métodos, técnicas, papéis e indicadores necessários para atingir as metas descritas para cada processo do modelo.

Este trabalho adota a definiç̧ão de Burlton (2001) para processo de negócio, neste caso referido como processo. Um processo inicia-se por um evento externo envolvendo um participante do processo; é composto de todas as ações necessárias para prover as saídas esperadas associadas aos eventos de negócio; transforma as entradas em saídas de acordo com regras e políticas e com o suporte de recursos; possui passos lógicos que percorrem horizontalmente áreas funcionais e unidades de uma organização; possui indicadores de desempenho e entrega produtos e serviços a um interessado externo ou a outro processo interno. 
A estratégia para o desenvolvimento do modelo de processo consiste na identificação na literatura de experiências e estudos de caso a respeito de projetos GSD (Global Software Development ou Desenvolvimento Distribuído de Software) que são conduzidos através de um conjunto de empresas ou departamentos de empresas distribuídas geograficamente. São identificados os principais problemas e dificuldades na gestão de projetos GSD para compor as principais questões a serem tratadas em um modelo de gestão.

Além disso, é realizada uma pesquisa a respeito dos principais modelos de gestão de projetos existentes na literatura sobre projetos GSD. A partir deste levantamento é possível realizar um cruzamento entre os principais problemas identificados e os processos de gestão descritos em cada modelo, de forma a identificar as carências de cada um.

Por fim, identificam-se as principais práticas a serem adotadas para aumentar a eficiência na gestão de projetos GSD e então compor um modelo de processo para gerência de projetos deste contexto.

\subsection{Abrangência}

O modelo de processo que constitui o resultado deste trabalho tem como objetivo apoiar na gestão de projetos de software conduzidos de forma distribuída.

Como o tema gestão de projetos é bastante abrangente, identificam-se ao longo do trabalho as áreas de conhecimento mais importantes no contexto de projetos GSD. O modelo PMBoK (2000) é utilizado como ponto de partida para a análise de processos de gestão através de suas áreas de conhecimento, já que se tornou nos últimos tempos um modelo amplamente aceito pela comunidade científica e pela indústria de software.

Em relação aos aspectos de gestão, percebe-se que do ponto de vista do GSD, duas áreas de conhecimento do modelo PMBoK são muito importantes: Gerência das 
Comunicações do Projeto e Gerência da Integração do Projeto. Entretanto, a princípio, todas as áreas de conhecimento do modelo são discutidas.

Os processos de gestão de projetos dos modelos CMMI (2002) (Capability Maturity Model Integration), ISSO/IEC 15504 (1998) e PMBoK (2000) também são considerados em virtude de que tratam da questão de gestão de projetos de software. Alguns modelos de gestão de projetos distribuídos também são analisados e comparados com os modelos atuais mais utilizados atualmente.

\subsection{Motivação}

A indústria de desenvolvimento de software está sofrendo grandes alterações nos últimos anos. A grande concorrência existente devido à globalização dos negócios está exigindo que empresas de desenvolvimento apresentem soluções de baixo custo em prazos curtos de entrega.

Devido ao aspecto global e ao avanço da tecnologia da informação, os sistemas tornam-se mais complexos. Neste contexto, o GSD surge como uma importante estratégia de desenvolvimento que é adotada cada vez mais pela indústria de software.

O GSD apresenta importantes características que podem aumentar a competitividade de uma ou um conjunto de organizações. Seguem algumas características mencionadas por Prikladnicki e Audy (2003):

- $\quad$ Parcerias entre empresas com especializações diferentes.

- $\quad$ Alocação de recursos humanos com diferentes perfis e custos.

- Utilização de jornadas diárias de 24 horas baseadas em equipes distribuídas geograficamente. 
A gestão destes tipos de projeto enfrenta grandes dificuldades não identificadas em projetos desenvolvidos em uma única localidade. Espera-se apresentar um modelo que permita viabilizar este tipo de desenvolvimento.

Apesar de modelos atuais, como o PMBoK (2000), não tratarem claramente deste tipo de projeto, Oppenheimer (2002) afirma que não existe algo de novo a ser tratado que não exista nestes modelos. Alguns modelos específicos para gestão de projetos GSD já foram propostos, porém não existe um consenso na comunidade científica a respeito de sua aplicabilidade.

A análise das propostas existentes comparadas ao PMBoK e o confronto destas com experiências de projetos GSD identificadas na literatura, permite identificar as lacunas entre os modelos de gestão existentes e apresentar uma proposta de modelo. Espera-se poder sedimentar conceitos relacionados ao GSD e descrever um modelo de processo com as melhores práticas para a gestão deste tipo de projeto.

\subsection{Justificativa}

A gestão de projetos GSD, além de ser um tema bastante atual, também é um tema pouco explorado pela comunidade científica brasileira. Este trabalho espera agregar conhecimento em relação a este tipo de projeto e direcionar novas pesquisas na área. Atualmente, os principais modelos relacionados a desenvolvimento de software e gestão de projetos não tratam explicitamente de ambientes distribuídos de desenvolvimento. Desta forma, este trabalho apresenta uma discussão em torno dos modelos existentes e propõe um modelo de gestão para projetos GSD.

A partir dos resultados deste trabalho será possível compreender o modelo GSD e identificar boas práticas para a gestão deste tipo de projeto. O GSD habilita as nações em 
desenvolvimento a participar de projetos globais. Países como Brasil e Índia que possuem mão de obra de baixo custo e qualificada são fortes candidatos na indústria de software. Espera-se com este trabalho instrumentar e apoiar empresas brasileiras a tornarem-se participantes em projetos globais.

\subsection{Estrutura do Trabalho}

Este trabalho inicia-se com a revisão da literatura a respeito de modelos para gestão de projetos e apresenta os principais modelos para gestão de projetos em um contexto de projetos GSD. Os principais problemas em um contexto GSD são identificados e relacionados aos modelos descritos. A partir dessa análise, é derivado um modelo de gestão para projetos GSD. O último capítulo descreve as principais contribuições e trabalhos futuros.

Apresenta-se a seguir a estrutura de capítulos detalhada da dissertação:

- $\quad$ Primeiro capítulo: Este capítulo apresenta a introdução do trabalho com os objetivos, abrangência, motivação, justificativa e estrutura do trabalho.

- $\quad$ Segundo capítulo: Neste capítulo são apresentadas as bases conceituais deste trabalho. São descritos os conceitos de GSD, modelos atuais de gestão de projetos e modelos de gestão de projetos GSD.

- $\quad$ Terceiro capítulo: Este capítulo compara os principais modelos de gestão de projetos existentes atualmente e os focados em projetos distribuídos em relação aos principais problemas existentes neste contexto. Identificam-se boas práticas para este tipo de projeto.

- Quarto capítulo: Este capítulo apresenta o modelo GesProDS. Este modelo é uma proposta para gestão de projetos GSD. A aplicabilidade do modelo é discutida. 
- Quinto capítulo: Este capítulo apresenta as conclusões do trabalho. As considerações finais, principais contribuições e trabalhos futuros são descritos.

- Sexto capítulo: Este capítulo apresenta as referências utilizadas neste trabalho. 


\section{Revisão da Literatura}

Este capítulo faz uma revisão da literatura a respeito dos principais temas para o contexto do trabalho. O primeiro item apresenta o conceito de Desenvolvimento Distribuído de Software (GSD) que é a base para o modelo de gestão proposto. Os dois próximos itens discutem os principais modelos existentes, os mais utilizados pela indústria de software e os focados na gestão de projetos GSD. O último item discute uma metodologia para descrição de processos que será utilizada neste trabalho para descrição do modelo proposto GesProDS.

\subsection{Desenvolvimento Distribuído de Software}

Este item apresenta as principais características do GSD e também as suas diferenças em relação ao desenvolvimento tradicional de software. Em um ambiente GSD, segundo Carmel (1999) e Karolak (1998), os seguintes aspectos são muito importantes: comunicação, coordenação, colaboração, integração, confiança entre equipes e diferenças culturais.

O GSD ainda é um tema pouco explorado pela comunidade científica brasileira, porém seu uso está em crescente evolução na indústria de software mundial. Ele é caracterizado pela formação de uma Organização Virtual composta por equipes situadas em locais geográficos distintos. Estas equipes são chamadas de Equipes Virtuais.

A Organização Virtual tem como objetivo atender a uma determinada necessidade de um cliente através da elaboração dos produtos de software necessários. A Organização Virtual existe enquanto durar o ciclo de vida do projeto. Após a sua conclusão, a organização é desfeita e os participantes voltam a buscar novas oportunidades para formar outras Organizações Virtuais, conforme Karolak (1998). 
Segundo Zesar et al. (1998), uma Organização Virtual é formada por um grupo de empresas ou departamentos de uma empresa, localizados em regiões geográficas distintas e que desenvolvem seu trabalho em conjunto através de uma infra-estrutura em rede para atingir os objetivos de negócio.

A Figura 1 descreve a composição de uma Organização Virtual, conforme Cyrillo e Hirama (2005).

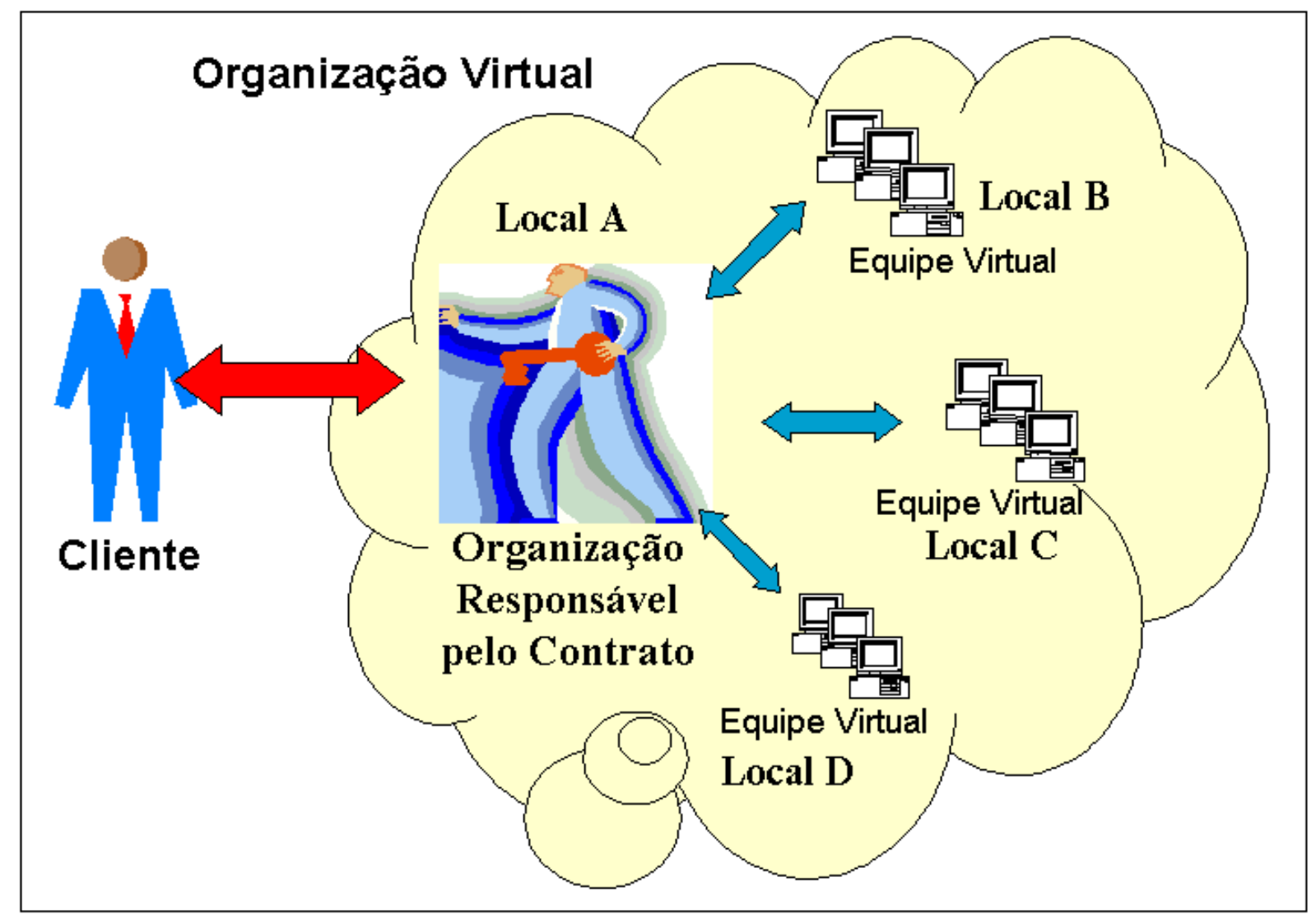

Figura 1. Organização Virtual. Cyrillo e Hirama (2005)

Normalmente, existe uma empresa ou departamento que é chamada de "Organização Responsável pelo Contrato". Esta organização realiza a parte comercial junto ao cliente. As principais atividades são: elaborar o contrato, obter as especificações do projeto e entregar os produtos do projeto. 
Esta organização também é responsável por formar a Organização Virtual. Isto ocorre a partir da seleção de empresas e departamentos que se enquadram na estratégia adotada para o projeto. Esta estratégia é desenvolvida a partir das características do projeto (tecnologia, regras de negócio, orçamento, prazo, etc...) e das características das empresas e departamentos (conhecimentos, disponibilidade, custos, infra-estrutura, etc...) que podem formar a Organização Virtual do projeto.

Uma importante característica que diferencia uma Organização Virtual de uma empresa que faz a subcontratação de partes de um projeto a outras empresas é o senso de propriedade do projeto. Todos os envolvidos são responsáveis pelo projeto inteiro e devem cooperar para atingir os objetivos do projeto e satisfazer o cliente. Em uma subcontratação, cada envolvido está focado em desenvolver a sua parte. Além disso, o tempo de uma parceria de subcontratação é determinado pelo contrato de prestação de serviços que independe do ciclo de vida do projeto. Uma Organização Virtual existe desde a formação da organização até o momento de encerramento do projeto.

Com objetivo de identificar os tipos de projetos e a complexidade existente na gestão de projetos, Evaristo e Fenema (1999) desenvolveram uma tipologia para classificação dos tipos de projeto possíveis. Esta classificação é uma das mais referenciadas na academia em relação ao tema Desenvolvimento Distribuído de Software.

A tipologia está baseada em duas características de projetos: tipo de projeto (Projeto ou Programa) e distribuição geográfica das equipes do projeto. Variando estas características, foram encontrados sete tipos de projetos que estão representados na Figura 2.

1. Projeto tradicional. Projeto executado em apenas uma localização.

2. Projeto distribuído. Projeto executado em mais de uma localização.

3. Múltiplos projetos distribuídos: Localização discreta. Programa formado por um conjunto de projetos executados em mais de uma localização. Cada localização possui Equipe Virtual que trabalha em apenas um projeto distribuído. 
4. Múltiplos projetos distribuídos: Localização compartilhada. Programa formado por um conjunto de projetos executados em mais de uma localização. Pelo menos uma localização possui Equipe Virtual que trabalha em mais de um projeto distribuído e compartilhado com localizações diferentes.

5. Múltiplos projetos tradicionais. Programa formado por um conjunto de projetos que são executados em localizações diferentes.

6. Programa localizado. Conjunto de projetos relacionados que são executados em uma mesma localização.

7. Múltiplos programas localizados. Múltiplos programas em que cada programa é composto por um conjunto de projetos executados em uma única localização.

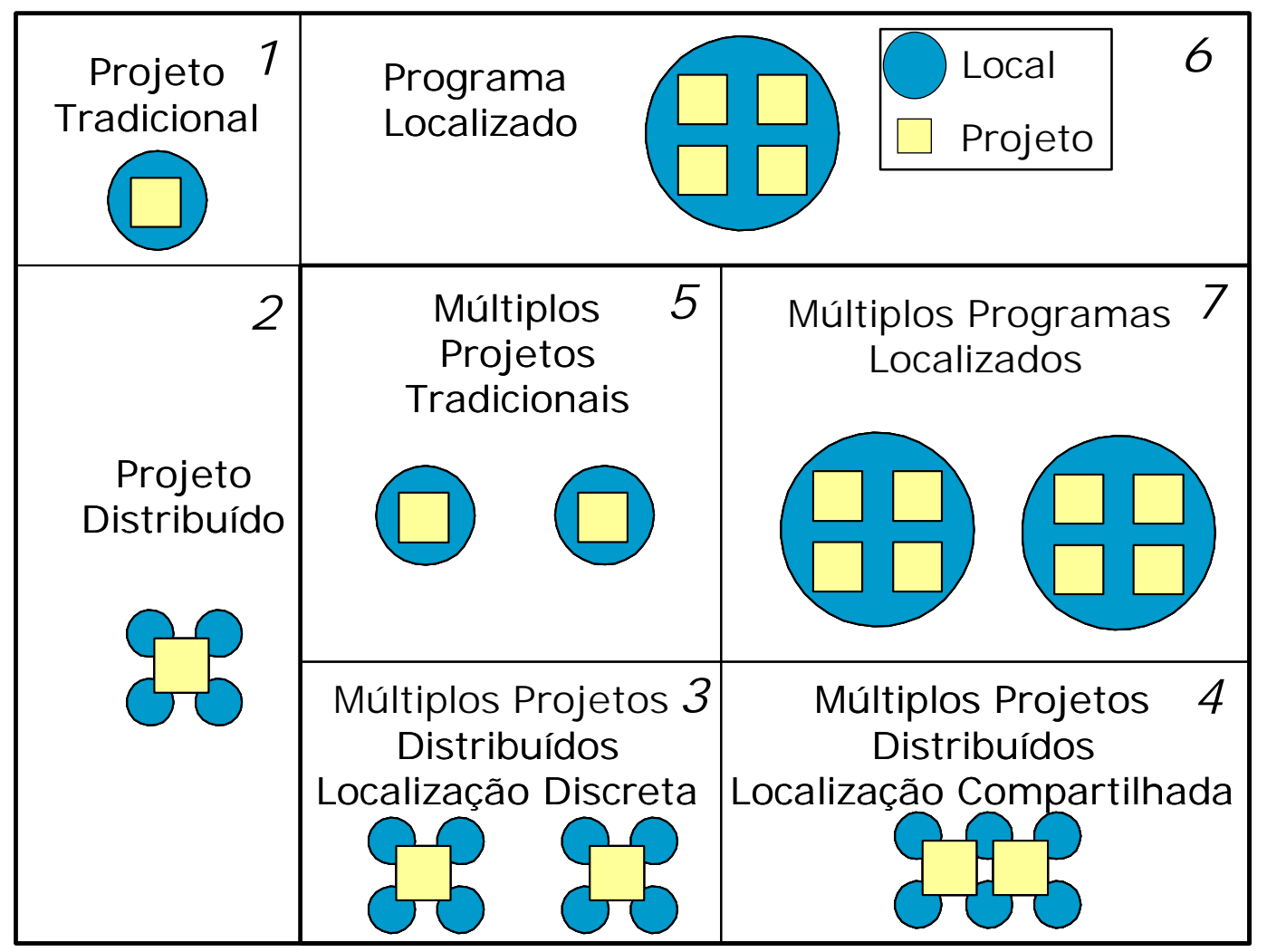

Figura 2. Tipologia de projetos. Evaristo e Fenema (1999)

Segundo os autores, a evolução na utilização dos tipos de projetos apresentados deve ser feita de forma gradual. Passar de um "Projeto Tradicional" (tipo um) diretamente para um projeto do tipo três, quatro ou sete significa aumentar a complexidade do projeto em dois sentidos: quantidade de projetos e quantidade de localizações. Apesar do último nível 
proposto (projetos tipo três e quatro) apresentar maior ganho em termos de produtividade, também requer maior esforço no sentido de comunicação e coordenação de atividades. Desta forma, a sugestão de Evaristo e Fenema (1999) é a de que o caminho para se atingir este tipo de projeto seja feito em progressivos aumentos de escala de complexidade.

\subsection{Gestão de Projetos - modelos conhecidos}

Este item apresenta alguns modelos atuais que de alguma forma tratam a questão de gestão de projetos. Além disso, alguns autores importantes que também contribuíram para identificação de boas práticas para gestão de projetos também são discutidos:

\subsubsection{Capability Maturity Model Integration - CMMI}

Uma importante referência quando se trata de assuntos relacionados a gestão de projetos é o modelo CMMI (2002). Apesar de não ser focado em gestão, ele apresenta importantes elementos para o planejamento e controle de projetos.

O CMMI é um modelo que permite avaliar o nível de maturidade do processo de desenvolvimento de software de uma empresa. Existem dois tipos de representação do modelo. A representação por estágios e a contínua.

$\mathrm{Na}$ primeira opção, existem cinco níveis de maturidade. Cada nível possui um determinado número de áreas de processo que possuem metas específicas e genéricas. Para se atingir uma meta genérica, é necessário implementar todas as práticas específicas descritas que estão organizadas em características comuns (compromissos, habilidades, diretivas de implementação e verificações). A Figura 3 apresenta a representação do modelo CMMI por estágios. 


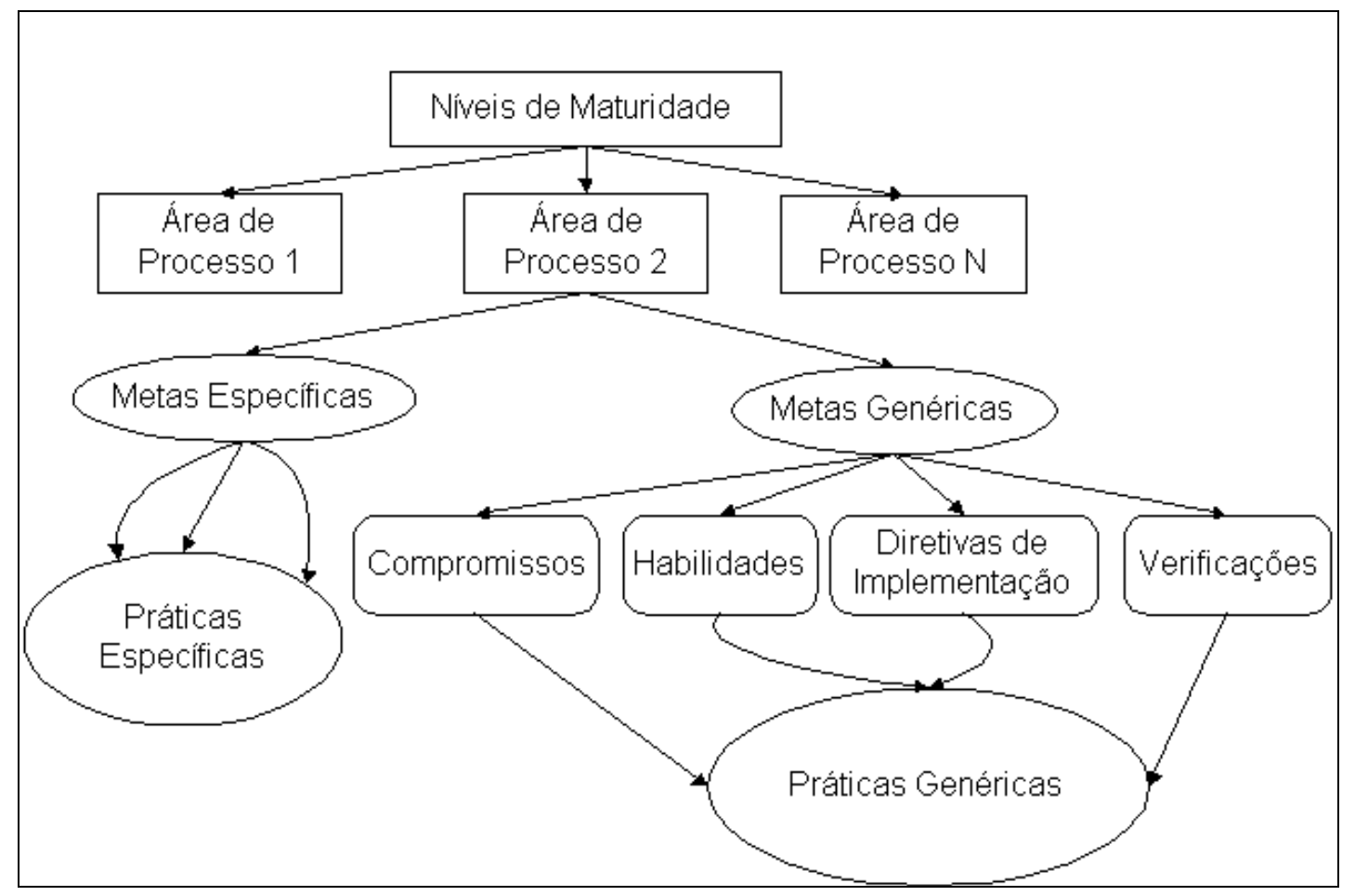

Figura 3. Modelo CMMI. Representação por estágios. CMMI (2002).

$\mathrm{Na}$ representação contínua, as áreas de processo possuem metas genéricas e específicas e cada meta é composta por práticas. A Figura 4 apresenta o modelo contínuo do CMMI.

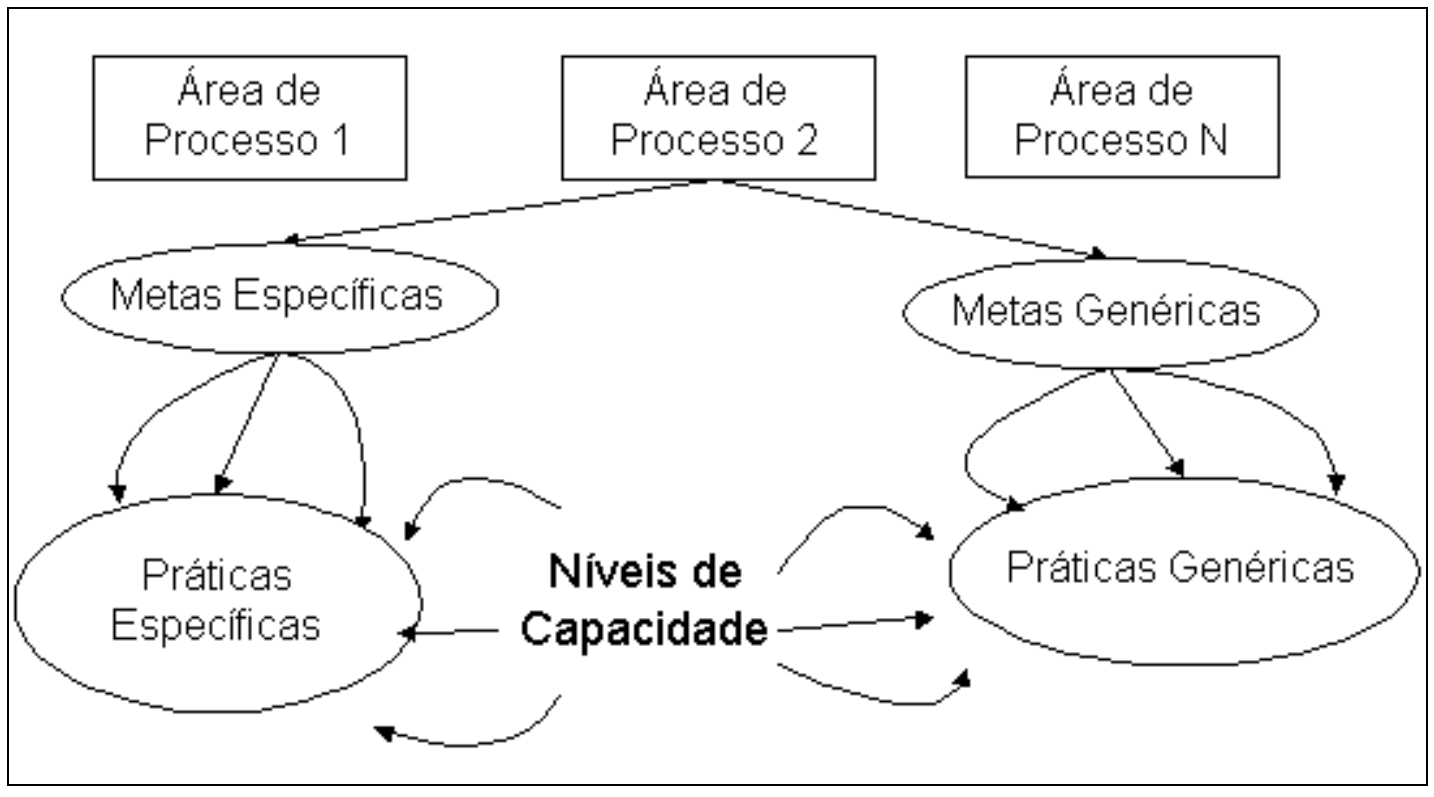

Figura 4. Modelo CMMI. Representação contínua. CMMI (2002) 
A principal diferença entre as duas representações consiste na forma como se aumenta a capacidade dos processos da organização.

Na representação contínua, o aumento da capacidade ocorre dentro de cada área de processo. Conforme se implementa as práticas, o nível de maturidade é maior (incompleto, executado, definido, gerenciado, quantitativamente gerenciado e otimizado).

$\mathrm{Na}$ representação por estágios, o aumento da capacidade da organização é dado quando se implementa as práticas de um conjunto de processos de um determinado nível. $\mathrm{O}$ próximo nível é atingido com adoção de novas práticas de outras áreas de processo.

Dentre os processos especificados no modelo, as seguintes áreas de processo possuem características relevantes para o tema deste trabalho:

- "Planejamento de Projeto". O objetivo desta área de processo é estabelecer e manter os planos que definem as atividades do projeto a serem executadas. Esta área de processo envolve as atividades de elaboração do plano, obtenção de compromisso pelos envolvidos no projeto e manutenção do plano conforme evolução do projeto.

- "Monitoração e Controle de Projetos". O objetivo desta área é acompanhar a evolução do projeto de forma a dar visibilidade do progresso, permitindo a tomada de ações corretivas quando o projeto se desvia significativamente do plano.

- "Gestão de Acordos com Fornecedores". O propósito desta área é gerenciar a aquisição de produtos de fornecedores externos. As principais atividades envolvem a definição do tipo de fornecimento, seleção de fornecedores, estabelecimento e manutenção dos acordos com os fornecedores e avaliação e aceite de produtos recebidos.

- “Gestão Integrada de Projeto”. O objetivo desta área é estabelecer e gerenciar o projeto e os envolvidos no projeto de acordo com um processo integrado e definido. As atividades desta área envolvem o controle das atividades dos envolvidos no 
projeto de forma que eles trabalhem de forma coordenada e sincronizada para obtenção dos objetivos do projeto.

“Gestão de Riscos”. O objetivo desta é identificar potenciais problemas antes que eles ocorram, de forma que seja possível planejar, mitigar e acompanhar estes riscos para evitar impactos no projeto.

- Gestão Integrada de Equipes”. O objetivo desta área é formar e manter uma equipe do projeto que desenvolva os produtos de trabalho necessários.

- "Gestão Integrada de Fornecedores". O objetivo desta área de processo é identificar produtos que podem ser utilizados para atender os requisitos do projeto e gerenciar os fornecedores selecionados de modo a melhorar a produtividade e qualidade dos serviços prestados. Isto é obtido através da análise periódica e avaliação dos fornecedores envolvidos no projeto, alterando os acordos e a forma de trabalho com objetivo de aumentar a produtividade do relacionamento.

- "Gestão Quantitativa de Projetos". O propósito desta área de processo é gerenciar e acompanhar de forma quantitativa indicadores do processo definido de forma para atingir as metas de qualidade e performance estabelecidas.

- “Ambiente Organizacional para Integração”. O objetivo desta área é prover uma infra-estrutura de produtos e processos para integração e também gerenciar os envolvidos no projeto de modo a facilitar a integração do projeto. Estes objetivos são obtidos através do estabelecimento de uma Visão Compartilhada do Projeto que se constitui em um mecanismo de manutenção e divulgação dos principais conceitos, regras, missões e objetivos do projeto. Além disso, outra atividade importante é o estabelecimento de um ambiente integrado de trabalho que possua uma infra-estrutura de hardware, software e telecomunicações que habilite a colaboração entre os membros do projeto. 
As principais diretrizes destas áreas de processo e que são relevantes para este trabalho são:

- $\quad$ Registrar estimativas de tamanho dos produtos de trabalho de software.

- $\quad$ Prover visibilidade do progresso de desenvolvimento de um projeto.

- $\quad$ Registrar medidas dos trabalhos de software.

- $\quad$ Armazenar histórico dos projetos.

- Identificar, estimar, avaliar, categorizar, priorizar e mitigar riscos.

- Selecionar, estabelecer, manter, executar e verificar acordos com fornecedores.

- $\quad$ Prover os recursos necessários e propiciar a colaboração externa e interna entre os colaboradores que maximize a produtividade das equipes.

- $\quad$ Estabelecer um ambiente de trabalho integrado.

- $\quad$ Estabelecer procedimentos de operação para facilitar a interação e aumentar a integração efetiva de esforço.

- $\quad$ Estabelecer uma Visão Compartilhada do Projeto com valores e diretrizes da organização.

- $\quad$ Estabelecer uma estrutura de equipes integradas que desenvolvam suas tarefas de forma coordenada para atingir os objetivos do projeto.

- Gerenciar as dependências do projeto. Identificar, negociar e acompanhar dependências críticas do projeto entre os interessados no projeto.

\subsubsection{Project Management Body of Knowledge - PMBoK}

Outra importante referência em relação a gerência de projetos é o modelo PMBoK (2000) do PMI (Project Management Institute) que reúne um conjunto de boas práticas de gestão de projetos separadas por áreas de conhecimento. 
O modelo PMBoK abrange nove áreas de conhecimento. As áreas de conhecimento de "Gerência da Integração do Projeto" e "Gerência das Comunicações do Projeto" possuem características de grande importância quando tratamos do tema Desenvolvimento Distribuído de Software. Devido à questão de distância imposta por este tipo de projeto, a comunicação e a integração dos processos e dos produtos são bastante impactadas. Desta forma, estas áreas de conhecimento são mais detalhadas. Segue descrição das áreas de conhecimento.

- Gerência da Integração do Projeto. O objetivo da área de Gerência da Integração do Projeto é garantir que os diversos elementos do projeto estejam coordenados. Esta área é composta pelos processos "Desenvolvimento do Plano do Projeto", "Execução do Plano do Projeto" e "Controle Geral de Mudanças". O plano de projeto elaborado nesta área de conhecimento é um plano integrado de projeto que é composto por um conjunto de documentos. Os planos de tempo, escopo e custo fazem parte do plano integrado. As decisões, estratégias do projeto, estimativas de custos, linhas de base (baselines) e principais marcos também fazem parte do plano integrado do projeto. A "Execução do Plano do Projeto" é o processo responsável por garantir a execução coordenada das atividades do projeto. Para tanto, é apoiado pelo processo de "Controle Geral de Mudanças". Este tem como objetivo garantir que mudanças do projeto sejam tratadas de forma sincronizada e coordenada entre as áreas de conhecimento de "Gerência de Escopo do Projeto", "Gerência do Tempo do Projeto", "Gerência do Custo do Projeto", "Gerência da Qualidade do Projeto" e "Gerência dos Riscos do Projeto".

- Gerência do Escopo do Projeto. Esta área tem como objetivo garantir o correto entendimento do que precisa e o que não precisa ser executado no projeto. Desta forma possui processos para definir, detalhar, verificar e controlar mudanças no Escopo do Projeto. 
- Gerência do Tempo do Projeto. A Gerência do Tempo do Projeto tem como objetivo definir e manter o cronograma do projeto. O cronograma do projeto é o mecanismo que permite ao gestor do projeto acompanhar o andamento e tomar as medidas necessárias para que o projeto seja implementado no tempo previsto. Os seguintes processos compõem esta área de conhecimento "Definição das Atividades", "Seqüenciamento das Atividades", "Estimativa da Duração das Atividades", "Desenvolvimento do Cronograma" e "Controle do Cronograma".

Gerência do Custo do Projeto. O objetivo desta área de conhecimento é garantir que o projeto será executado dentro do orçamento aprovado.

- Gerência da Qualidade do Projeto. A Gerência da Qualidade tem como objetivo garantir que o projeto será executado dentro dos padrões estabelecidos de qualidade. Para isso, possui processos para planejamento e definição dos padrões de qualidade a serem obtidos e também processos para monitoração e garantia da qualidade. A monitoração e garantia da qualidade é realizada através da avaliação do desempenho do projeto em relação aos padrões estabelecidos.

- Gerência dos Recursos Humanos do Projeto. A área de Gerência dos Recursos Humanos do Projeto tem como objetivo possibilitar o uso efetivo das pessoas envolvidas no projeto. Esta área possui processos para planejamento, montagem e desenvolvimento da equipe do projeto.

- Gerência das Comunicações do Projeto. Esta área de conhecimento tem como objetivo garantir a efetiva coleta, distribuição, armazenamento e controle das informações do projeto. Os seguintes processos compõem esta área de conhecimento: "Planejamento das Comunicações", "Distribuição das Informações", "Relato de Desempenho" e "Encerramento Administrativo". O planejamento das comunicações envolve a identificação de quais informações são importantes para o 
projeto, quem necessita da informação, qual o melhor meio de comunicação e quando a comunicação deve ser executada. A distribuição é a efetivação da comunicação. O processo de relato de desempenho é a efetivação da comunicação de informações específicas de desempenho do projeto. O último processo de encerramento administrativo também se caracteriza pela efetivação da comunicação de um tipo de informação específico. Neste processo, o encerramento de fases do projeto ou do próprio projeto é comunicado. Esta comunicação envolve a aceitação formal de produtos intermediários ou do produto final e registro de lições aprendidas.

- Gerência dos Riscos do Projeto. Esta área de conhecimento está fundamentada na identificação, análise e planejamento de respostas aos riscos com objetivo de minimizar eventos negativos e maximizar os eventos positivos.

- Gerência das Aquisições do Projeto. A área de Gerência das Aquisiçõos do Projeto tem como objetivo prover meios para planejar e preparar as aquisições do projeto e também auxiliar na identificação, seleção e administração de fornecedores do projeto.

O ciclo de vida de um projeto é composto dos seguintes processos: Iniciação, Planejamento, Execução, Controle e Encerramento. A Figura 5 representa o ciclo de vida de projetos, segundo o PMBoK (2000). 


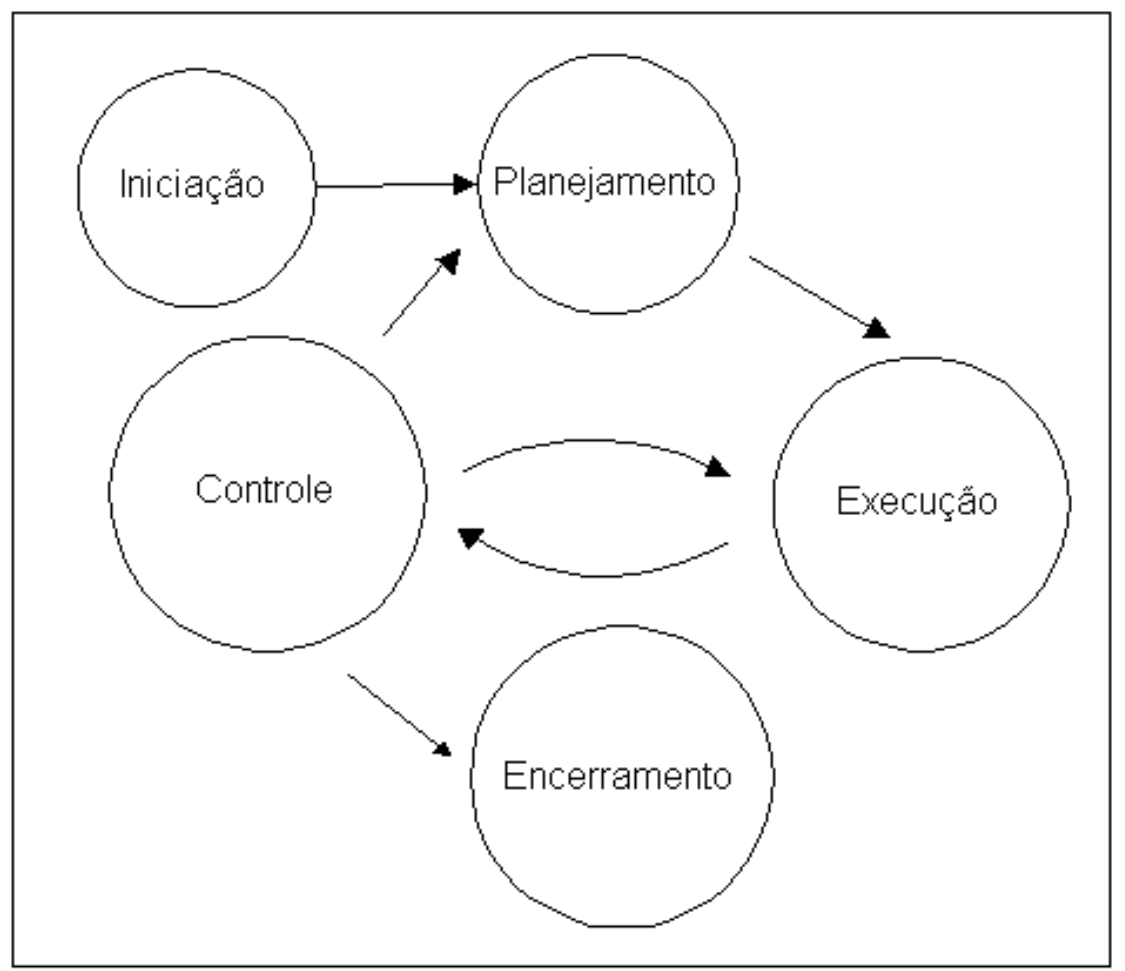

Figura 5. Ciclo de vida de projetos. PMBoK (2000).

O processo de Iniciação tem como objetivo permitir o reconhecimento de que um projeto ou fase deva ser iniciado. Neste processo, o gerente do projeto é identificado, as necessidades de negócio, premissas e restrições são registradas.

O processo de Planejamento é responsável por manter e gerenciar um esquema de trabalho que permita atingir as necessidades de negócio do projeto.

O processo de Execução corresponde às necessidades de gerenciamento dos recursos de acordo com o planejamento do projeto.

O processo de Controle tem como objetivo garantir os objetivos do projeto através da medição do progresso do projeto e da tomada de ações corretivas na ocorrência de desvios em relação ao plano do projeto.

O processo de Encerramento tem como objetivo formalizar a aceitação do projeto ou da fase pelos envolvidos no projeto. 
O ciclo de vida descrito anteriormente, além de ser executado no âmbito do projeto, também ocorre em cada fase do projeto. Desta forma, o ciclo de vida de um projeto também é composto por pequenos ciclos sucessivos até a entrega do produto final.

Além disso, cada atividade descrita nas áreas de conhecimento também se enquadra em um dos processos do ciclo de vida de um projeto.

Um ponto importante em relação ao PMBOK é que ele está focado em práticas de gestão de projetos genéricas que podem ser aplicadas a qualquer tipo de projeto. O modelo CMMI está focado em práticas para projetos que envolvem software.

\subsubsection{Software Process Improvement and Capability dEtermination - SPICE}

O modelo ISO / IEC 15504 (1998), da mesma forma que o CMMI, estabelece uma estrutura para avaliação do processo de desenvolvimento de software de uma organização. Os processos da organização são divididos nas seguintes categorias:

- $\quad$ Fornecimento ao cliente: Processos que impactam diretamente o cliente.

- Engenharia: Processos de especificação, implementação ou manutenção do produto de software.

- $\quad$ Suporte: Processos de suporte a outros processos.

- $\quad$ Gestão: Processos utilizados por pessoas que controlam atividades.

- $\quad$ Organização: Processos que estabelecem objetivos de negócio da organização.

Cada processo é avaliado em um nível de capacidade conforme um conjunto de atributos definidos. O objetivo é verificar o grau de maturidade de cada processo. 
Dentre as categorias descritas anteriormente, a categoria de Gestão é a que representa maior importância para o GSD. Desta forma, segue descrição de algumas características dos processos do modelo SPICE relacionadas à categoria de gestão:

- $\quad$ MAN.1. Gestão. Atividades e tarefas precisam ser identificadas, desempenho das atividades deve ser monitorado e produtos devem ser revisados.

- MAN.2. Gestão de Projetos. Escopo de trabalho do projeto deve ser definido, tarefas e recursos devem ser estimados, planos para execução do projeto devem ser desenvolvidos e implementados.

- $\quad$ MAN.3. Gestão da Qualidade. Monitorar a qualidade de produtos e serviços com objetivo de garantir a satisfação do cliente. Estabelecer metas de qualidade baseadas nos requisitos dos clientes, desenvolver estratégia para obtenção das metas, monitoração da qualidade corrente do projeto e tomada de ações corretivas na ocorrência de desvios de qualidade em relação às metas.

- $\quad$ MAN.4. Gestão de Riscos. Identificar e mitigar continuamente os riscos do projeto. Determinar escopo dos riscos, estratégias para gestão dos riscos, análise e priorização de riscos, métricas e ações corretivas na ocorrência de riscos.

Os processos de gestão do modelo SPICE não tratam de todos os aspectos previstos no modelo PMBoK. As áreas de conhecimento "Gerência das Comunicações do Projeto" e "Gerência da Integração do Projeto" não estão cobertas. Os processos do SPICE reforçam a necessidade de planejar e acompanhar escopo, prazo, qualidade e riscos do projeto.

\subsection{Gestão de Projetos Distribuídos}

Este item apresenta modelos para gestão de projetos GSD identificados na literatura. 


\subsubsection{CPMA}

O modelo CPMA (Collaborative Project Management Architecture) foi desenvolvido por pesquisadores das universidades do Arizona e de Oklahoma. Os primeiros conceitos do modelo foram publicados por Briggs, Romano e Nunamaker (2001) no congresso HICSS2001 (Hawaii International Conference on System Sciences). Foi apresentada uma infraestrutura (framework) para colaboração e gestão do conhecimento para projetos GSD.

A colaboração entre funcionários ocupa a maior parte do tempo do esforço em projetos e a tecnologia pode aumentar substancialmente a produtividade da colaboração em projetos distribuídos. Estas hipóteses foram verificadas nos estudos de caso de Nunamaker et al. (1989a, 1989b). Chen, Romano e Nunamaker (2002, 2003a, 2003b), apresentam uma evolução a respeito dos tipos de colaboração existentes e também uma arquitetura de processos para gestão e suporte para projetos do tipo GSD. A Figura 6 apresenta o CPMA.

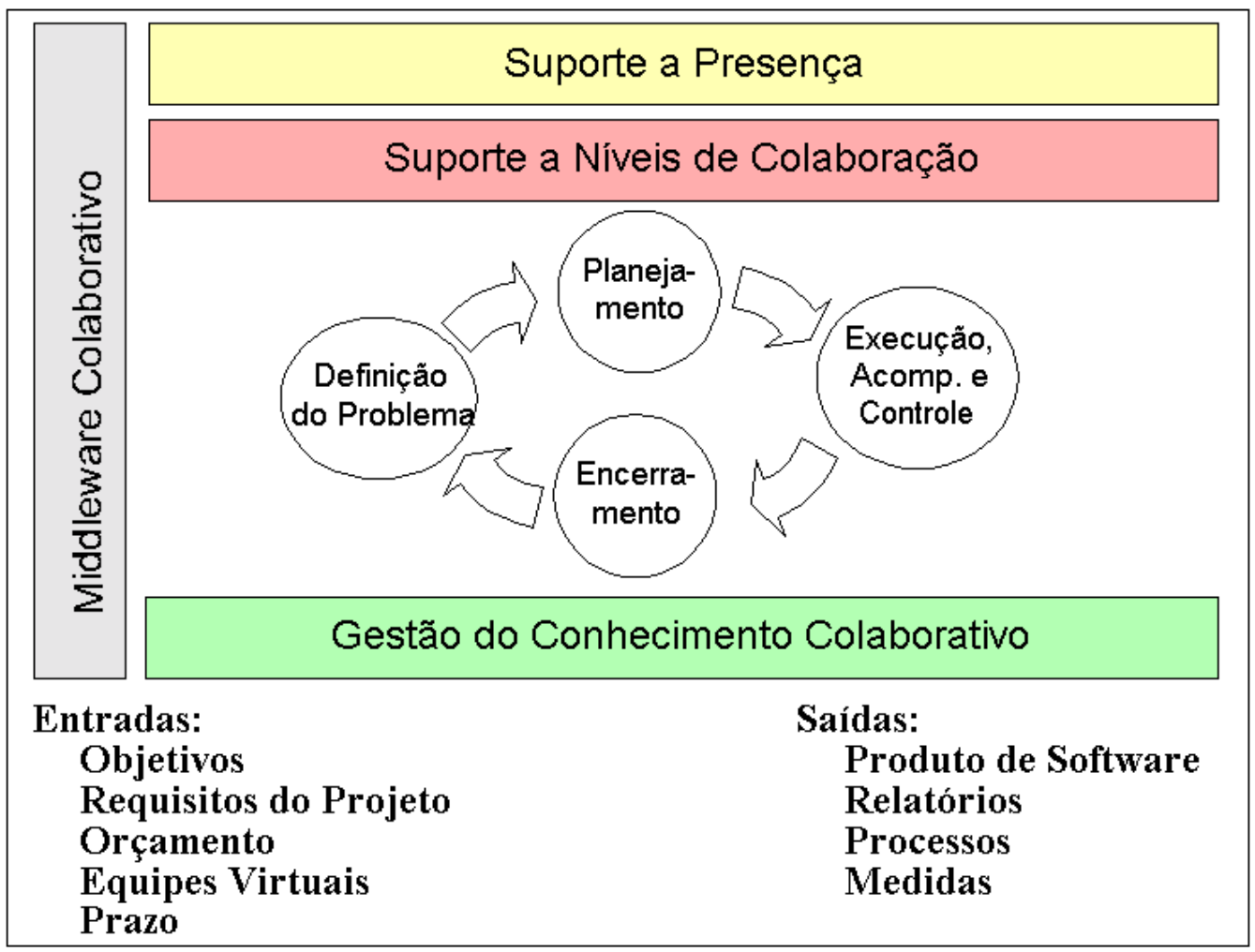

Figura 6. Modelo CPMA. Chen, Romano e Nunamaker (2003a). 
O CPMA proposto por Chen, Romano e Nunamaker (2002, 2003a, 2003b) é composto por quatro camadas e define um ciclo de vida de projeto parecido com o ciclo de vida proposto pelo PMBoK (2000). Esta arquitetura recebe como entrada os objetivos, requisitos, orçamento e prazo do projeto além das Equipes Virtuais que participam do projeto. As saídas obtidas com esta arquitetura são relatórios e medidas de progresso do projeto, processos e o produto de software.

O Middleware Colaborativo constitui um conjunto de sistemas e ferramentas que permite a um membro do projeto interagir com a Organização Virtual, seus participantes e seus recursos. Estas ferramentas são necessárias para dar suporte às atividades do projeto e aumentar a eficiência da colaboração entre as equipes. Exemplos: workflow, gestão de cronograma, suporte a tomada de decisão, elicitação de requisitos, editoração colaborativa, inspeção, ensino a distância, comunicação, etc.

O objetivo do processo de Suporte a Presença é promover a visibilidade do contexto do projeto para toda a organização através da representação do conhecimento. Devido à distância imposta em projetos GSD, é difícil identificar e entender conceitos do projeto se eles não estão bem representados e divulgados. Assim, o intuito é facilitar a visualização de conceitos do projeto através da identificação, registro e divulgação destes conceitos. Exemplos: Dicionário de projeto, regras e políticas de negócio, informações de contexto do projeto como prazo, orçamento, equipamentos e recursos.

Segundo Chen, Romano e Nunamaker (2003a), uma arquitetura de gestão de projetos distribuídos precisa suportar a colaboração entre as Equipes Virtuais. Por colaboração entende-se qualquer troca de informação ou atividade realizada em conjunto. $\mathrm{O}$ modelo identifica os seguintes tipos de colaboração: esforço individual (collected work), esforço coordenado (coordinated work) e esforço sincronizado e conjunto (concerted). Uma organização virtual deve ter mecanismos para suportar todos os níveis de colaboração 
existentes. Cada atividade de um projeto requer um determinado nível de colaboração que deve ser identificado e gerenciado.

O processo de Gestão do Conhecimento Colaborativo prevê o acúmulo de conhecimento através dos projetos desenvolvidos pela Organização Virtual. Este conhecimento armazenado pode auxiliar na identificação de problemas ocorridos e diminuir a chance de que eles ocorram em outras oportunidades. A Gestão do Conhecimento Colaborativo fornece informação para tomada de decisão em futuros projetos e também permite identificar padrões para utilização em novos projetos. Em um contexto de projetos distribuídos, este processo é fundamental. Se não existir uma forma de manter o conhecimento, este acaba se perdendo pela Organização Virtual.

O ciclo de vida de projetos proposto ocorre em vários níveis do projeto. As fases do ciclo de vida são identificadas tanto no nível macro do projeto como também em cada fase que é realizada. Segundo Chen, Romano e Nunamaker (2003a), se forem identificados grupos de atividades e produtos de cada fase descrita do ciclo de vida e o tipo de colaboração necessário em cada atividade, será possível padronizar o processo de desenvolvimento e utilizar tecnologia disponível para facilitar a execução das atividades. O ciclo de vida de projetos é constituído das seguintes fases:

- Definição do Problema. Nesta fase, as principais atividades são: definição de escopo, identificação dos objetivos do projeto, identificação dos principais envolvidos no projeto, determinação das diferenças entre a situação existente e a desejada e estimativa de recursos para obter o correto entendimento do projeto.

- $\quad$ Planejamento. Nesta fase, um plano de projeto é elaborado para permitir atingir os objetivos descritos na fase anterior. As principais atividades são: dividir o projeto em atividades gerenciáveis, identificar dependências entre as atividades, formar a 
equipe do projeto, alocar recursos às atividades, planejar e gerenciar riscos e comunicação do projeto.

- $\quad$ Execução, Acompanhamento e Controle. Esta fase é a parte central do projeto. Ela ocorre com duas subfases em paralelo. Enquanto o projeto é desenvolvido, os gestores realizam o acompanhamento e controle das atividades do projeto. As principais atividades são: execução das atividades do plano, coleta de progresso das atividades do projeto, gerenciamento dos riscos e mudanças, atualização e manutenção da documentação do projeto.

- $\quad$ Encerramento. Nesta fase, identifica-se o momento de conclusão do projeto. As principais atividades são: avaliar os resultados do projeto, comparar os resultados com o planejamento inicial, identificar possíveis melhorias para projetos futuros.

\subsubsection{MuNDDoS}

O modelo MuNDDoS é fruto de uma parceria entre a Escola de Ciências de Computação da PUC do Estado do Rio Grande do Sul e a empresa Dell Computer Corporation através de sua divisão da América Latina. Zanoni e Audy (2003) descreveram dois estudos de caso sobre GSD que foram realizados com Equipes Virtuais cooperando a partir da cidade de Porto Alegre no Estado do Rio Grande do Sul e de Austin nos Estados Unidos da América.

Zanoni e Audy (2003) realizaram uma comparação entre o modelo PMBoK (2000) e o Processo Unificado (Unified Process), proposto por Jacobson, Booch e Rumbaugh (1998), em um contexto GSD. Identificaram que o suporte a ambiente distribuído não é atendido em nenhum dos dois modelos. 
O modelo MuNDDoS (Maturidade No Desenvolvimento Distribuído de Software), proposto por Prikladnicki e Audy (2002, 2003), está focado em gestão de projetos e detalha processos de planejamento estratégico, tático e operacional de um projeto GSD. Ele também estabelece o processo de Avaliação de Realimentação para armazenamento de lições aprendidas no processo de Desenvolvimento Distribuído de Software.

A Figura 7 apresenta o modelo.

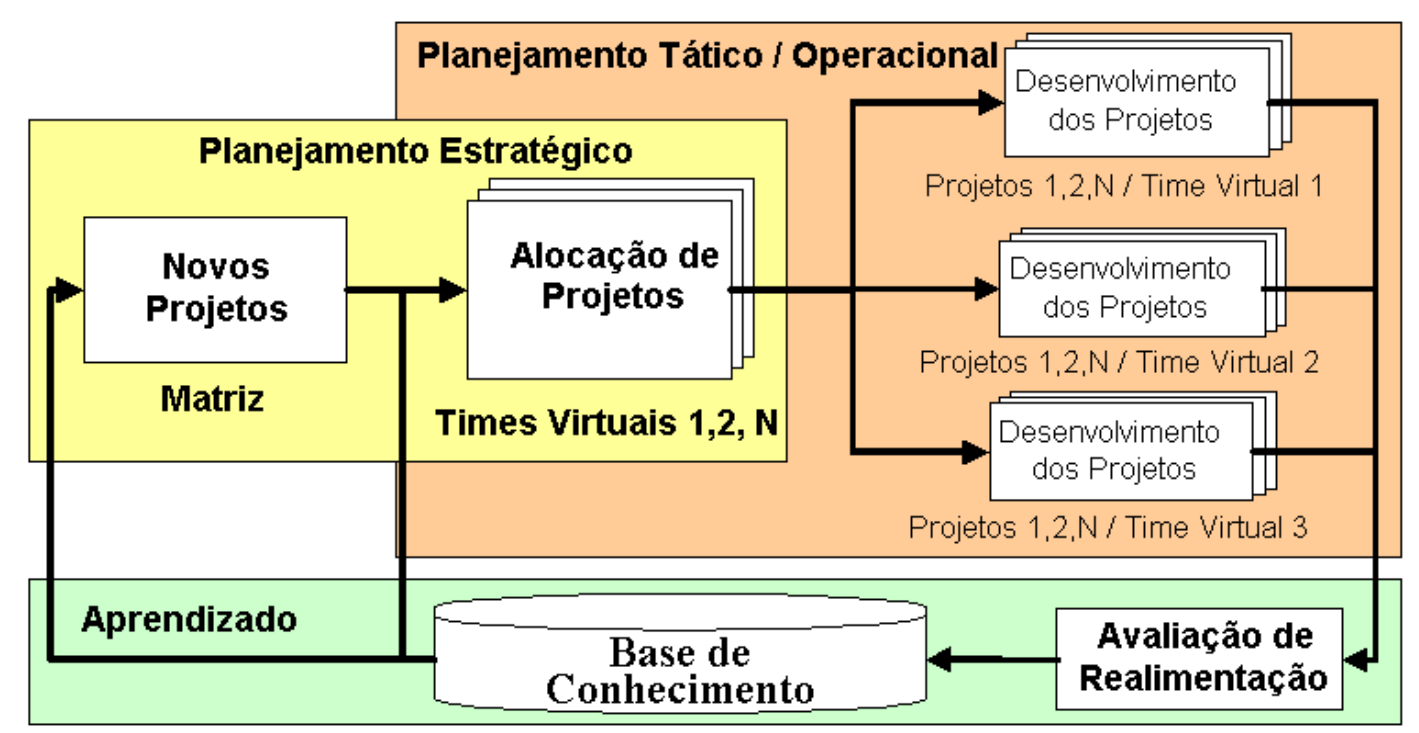

Figura 7. MuNDDoS. Prikladnicki e Audy (2003)

Segundo Prikladnicki e Audy (2003), o planejamento estratégico envolve a identificação e priorização de novos projetos a serem desenvolvidos. Além disso, cabe aos participantes deste planejamento o alinhamento estratégico entre as perspectivas e objetivos de cada Equipe Virtual com relação aos objetivos, estratégias e políticas a serem seguidas.

Neste processo, as demandas de projeto são analisadas quanto a sua possibilidade de distribuição considerando os riscos envolvidos na distribuição do projeto. Caso o projeto seja escolhido para a distribuição, começa um processo de análise de risco de cada Equipe Virtual e seleção das equipes mais apropriadas para integrar o projeto. 
O Planejamento Tático é de responsabilidade final dos coordenadores de cada Equipe Virtual.

O Planejamento Operacional envolve a gestão do projeto de desenvolvimento de software, centrado na coordenação geral das atividades entre os diversos colaboradores, interfaces entre as equipes, comunicação, entre outros. Neste processo, o foco é na condução do projeto de desenvolvimento de software. Ele ocorre no âmbito das Equipes Virtuais e nele estão contidos aspectos de planejamento e gestão das atividades das equipes e também na comunicação e colaboração com outras Equipes Virtuais do projeto.

O processo de Avaliação de Realimentação diz respeito à avaliação das atividades realizadas e estratégias adotadas durante o projeto. O objetivo é coletar dados e informações dos projetos para compor a Base de Conhecimento da organização e realimentar as etapas iniciais do modelo fornecendo subsídios para tomada de decisão em novos projetos de GSD.

\subsubsection{MILOS}

Segundo Richter e Maurer (2003), o modelo MILOS foi iniciado em 1992. Ele foi desenvolvido por dois grupos de estudos conduzidos pelos professores Michael Richter e Dieter Rombach da Universidade de Kaiserslautern da Alemanha e pelo professor Frank Maurer da Universidade de Calgary do Canadá. Este modelo foi utilizado como referência para o desenvolvimento de uma ferramenta com atuação nas áreas de planejamento, gerenciamento de dependências entre atividades e gestão do conhecimento. O projeto "Urban Land-Use Planning" conduzido na Volkswagen Foundation da Alemanha foi o primeiro projeto que serviu de motivação ao modelo MILOS. O trabalho de pesquisa, focado no desenvolvimento de uma ferramenta de modelagem para gestão de workflow na forma de cronograma, foi patrocinado também pelas instituições NSERC (Natural Sciences and Engineering Research 
Council of Canada), NORTEL (empresa da área de telecomunicações dos EUA) e DFG (Fundação de Pesquisa da Alemanha).

O modelo proposto por Goldmann et al. (1999a, 1999b, 1999c, 1999d, 2002) foca em processos que ocorrem no nível tático de um projeto. $\mathrm{O}$ objetivo deste modelo é promover o planejamento distribuído de forma estruturada e permitir que as decisões de planejamento possam ser registradas, conhecidas e rastreadas. Conforme necessidade de alteração de decisões tomadas, as atividades impactadas são identificadas, avaliadas, replanejadas e comunicadas.

O modelo MILOS é composto por um processo para planejamento e reavaliação do planejamento do projeto. Este processo é utilizado no início do projeto e também ao longo de sua execução. O planejamento consiste de quatro etapas:

1. Adição de atividades ao plano.

2. Especificação dos métodos a serem utilizados em cada atividade.

3. Alocação dos recursos responsáveis por cada atividade.

4. Alocação de prazo e esforço para cada atividade.

A ontologia MILOS está baseada na definição de um meta-plano. Um meta-plano consiste nas atividades necessárias para a criação de um plano. O meta-plano possui metaatividades que podem ser atividades de planejamento (etapas um e dois) ou de alocação (etapas três e quatro).

O processo inicia-se com a execução de meta-atividades antes do início do projeto, isto é, o planejamento do projeto. O planejamento ocorre de forma iterativa na medida em que cada atividade do projeto é planejada com base nas restrições de custo, prazo e método de execução da atividade indicadas no planejamento da atividade hierarquicamente superior.

Cada atividade pode ser subdividida em outras atividades e alocada a outros membros do projeto. Cada nova atividade pode ser subdividida novamente ou ter o planejamento definido anteriormente mantido. Caso um membro do projeto perceba que o planejamento de 
sua atividade não pode ser cumprido, ele avisa o nível hierárquico anterior. Este tenta realocar as outras atividades de forma a atender as restrições impostas pela atividade anterior. Caso também não seja possível, ele também avisa o nível anterior e assim sucessivamente.

Segundo Goldmann, Münch e Holz. (1999b), em projetos complexos como o desenvolvimento de software, geralmente, informações necessárias para o planejamento serão conhecidas apenas durante a execução do projeto. Desta forma, durante a execução do projeto o plano pode ser reavaliado e alterado conforme necessidade. O replanejamento ocorre de forma parecida com o proposto durante a fase de planejamento. Caso ocorra a alteração de um plano, todas as atividades e membros do projeto afetados são notificados.

A Figura 8 apresenta um exemplo de árvore de planejamento de uma atividade de criação de um componente de software em um projeto.

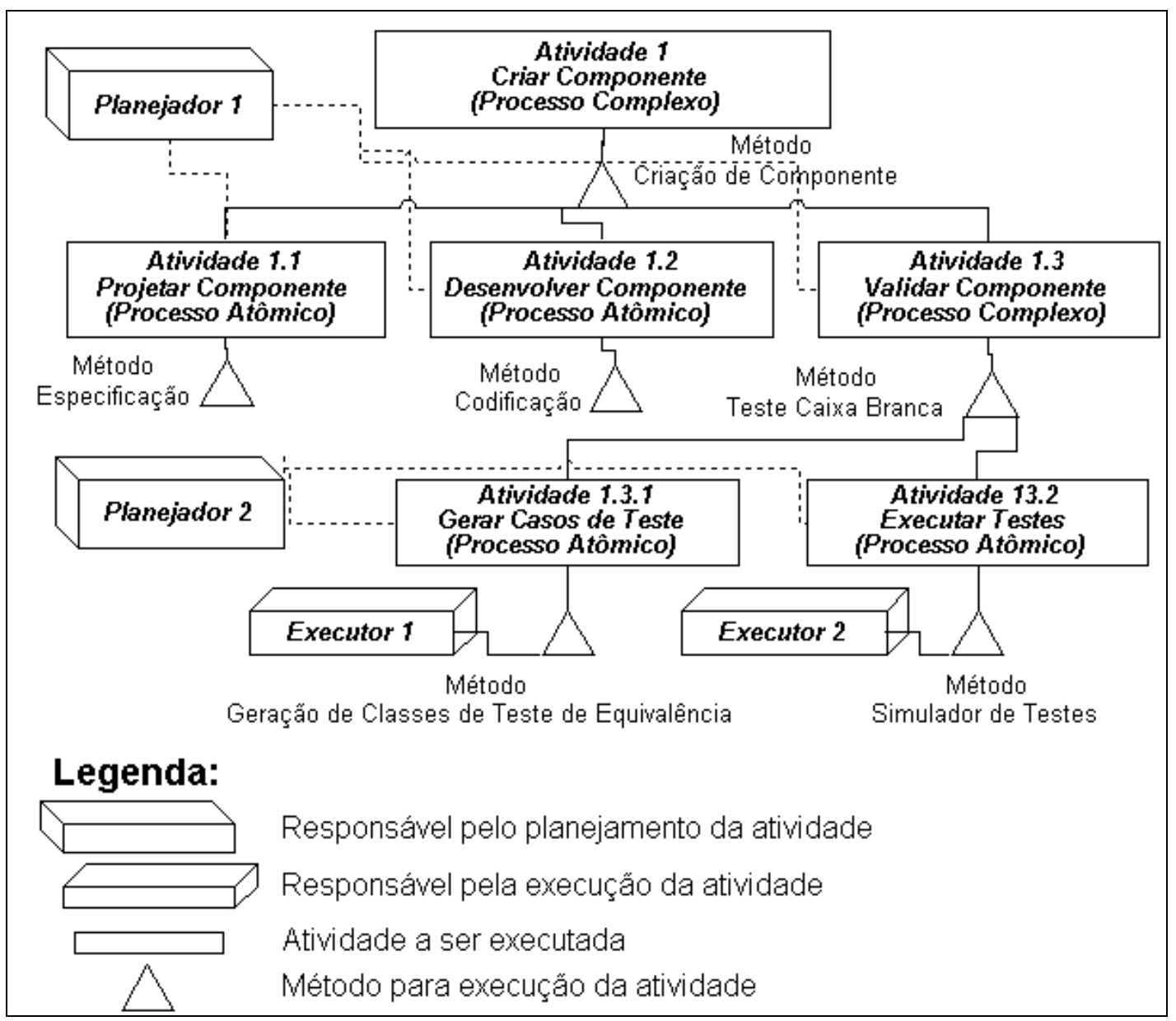

Figura 8. MILOS. Goldmann, Münch e Holz. (1999b). 
A atividade "Criar Componente" foi atribuída para o Planejador 1. Este percebe que esta atividade só pode ser concluída através de mais do que um método (método complexo). Desta forma, ele divide a atividade em outras três atividades e faz o planejamento (custo, prazo, esforço e alocação de agente responsável) destas.

As atividades "Projetar Componente" e "Desenvolver Componente" são do tipo atômica, pois são resolvidas com apenas um método. A atividade "Validar Componente", alocada ao Planejador 2, é do tipo complexa e é desdobrada da mesma forma que a atividade inicial ("Criar Componente").

Caso o Executor 1 perceba (durante o planejamento ou a execução do projeto) que o planejamento não pode ser cumprido, ele entra em contato com o nível hierárquico superior (Planejador 2) e negocia um novo planejamento. Neste exemplo, o Planejador 2 tenta replanejar a atividade "Gerar Casos de Teste" sem interferir no planejamento da atividade complexa "Validar Componente". Caso isto não seja possível, ele também negocia com o Planejador 1 um replanejamento.

Durante a execução do projeto, quando é necessário replanejar o projeto, os responsáveis pelo planejamento executam meta-atividades de replanejamento. Como todas as meta-atividades também são controladas como um projeto, cria-se um histórico das atividades de planejamento e replanemento. Cada meta-atividade de planejamento e replanejamento também é associada a decisões de projeto. No exemplo da Figura 8, a atividade "Executar Testes" foi planejada com base em uma decisão de utilizar uma ferramenta para automatização dos testes. Caso durante a execução do projeto, a ferramenta de testes não estivesse disponível, esta decisão deveria ser revista e as meta-atividades de planejamento impactadas precisariam ser replanejadas. Desta forma, durante o replanejamento é possível identificar as dependências entre as decisões e os planejamentos com objetivo de identificar quais meta-atividades impactadas devem ser replanejadas. 


\subsection{Metodologia para Descrição de Processos}

A metodologia escolhida para descrição de processos neste trabalho é a definida por Burlton (2001). Esta metodologia está baseada na notação IDEF0 que foi desenvolvida pelo Departamento de Defesa dos Estados Unidos e foi escolhida por estar baseada em um padrão bastante utilizada pela comunidade científica e pelo mercado de trabalho. Além disso, a notação IDEF0 possui características que permitem modelar características adicionais de processos (mecanismos e controles) que não são encontradas em outras notações de modelagem de processos de negócio.

Segundo Burlton (2001), os processos são patrimônios de uma organização. Eles são a estrutura que organiza todos os componentes da empresa. Um processo de negócio inicia-se por um evento externo envolvendo um participante do processo e é composto de todas as ações necessárias para prover as saídas de negócio esperadas, associadas aos eventos de negócio.

Além disso, ele transforma as entradas em saídas de acordo com regras e políticas e com o suporte de recursos e possui passos lógicos que percorrem horizontalmente áreas funcionais e unidades de uma organização. Outra característica importante de um processo é que ele entrega produtos e serviços a envolvidos externos ou a outro processo interno. Por fim, um processo também possui indicadores de desempenho que permitem acompanhar o processo para verificar se ele está sendo realizado de acordo com o esperado.

A Figura 9 apresenta o hexágono de gerenciamento de processos. 


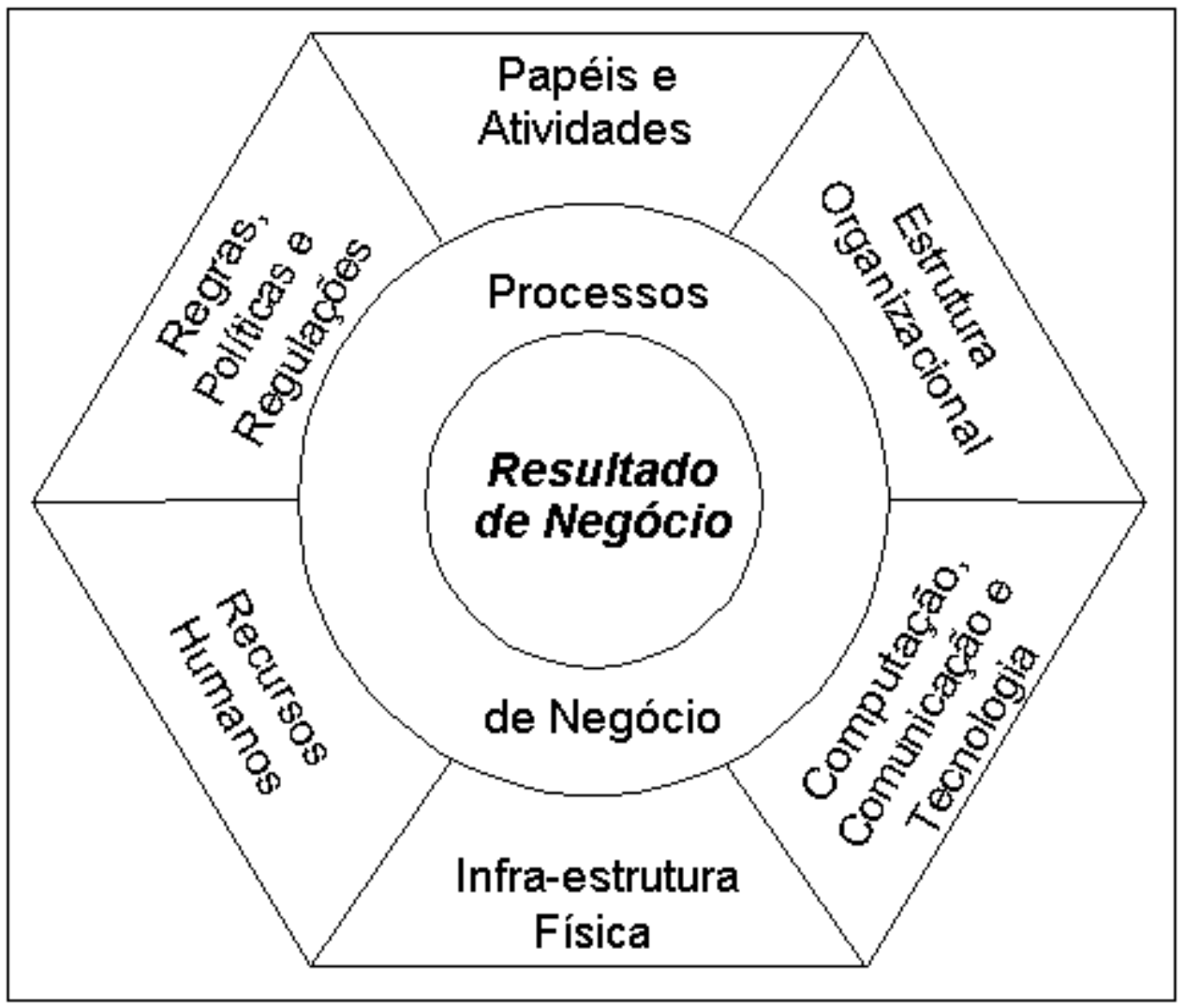

Figura 9. Hexágono de gerenciamento de processos. Burlton (2001).

As componentes superiores são chamadas de controles e são responsáveis por limitar e restringir a forma de execução de uma atividade. Os controles podem ser de três tipos:

- $\quad$ Políticas, regras e regulações.

- $\quad$ Papéis e atividades.

- $\quad$ Estrutura organizacional.

As componentes inferiores do hexágono são chamadas de mecanismos de suporte. Os mecanismos de suporte se constituem em infra-estruturas que servem de apoio à execução das atividades do processo. Os mecanismos de suporte podem ser de três tipos:

- Recursos humanos.

- Infra-estrutura física (mobílias, equipamentos, etc...).

- Computação, comunicação e tecnologia. 
Um processo possui alguns atributos que permitem entender claramente o escopo e a finalidade de um processo. Os atributos de um processo são:

- $\quad$ Objetivo do Processo. O objetivo do processo descreve qual a finalidade de um processo e quais são os resultados esperados.

- $\quad$ KPI (Key Performance Indicator). Os KPI são métricas utilizadas para medir o desempenho de um processo e devem ser acompanhados para verificar se o processo está evoluindo de acordo com as expectativas dos interessados do processo.

- Limites de um processo. Os limites de um processo permitem identificar o escopo de um processo. A clara identificação de um processo permite delimitar onde começa e termina um processo. É importante entender os limites de um processo do ponto de vista dos clientes e interessados do processo.

A notação básica do IDEF0 é ilustrada na Figura 10.

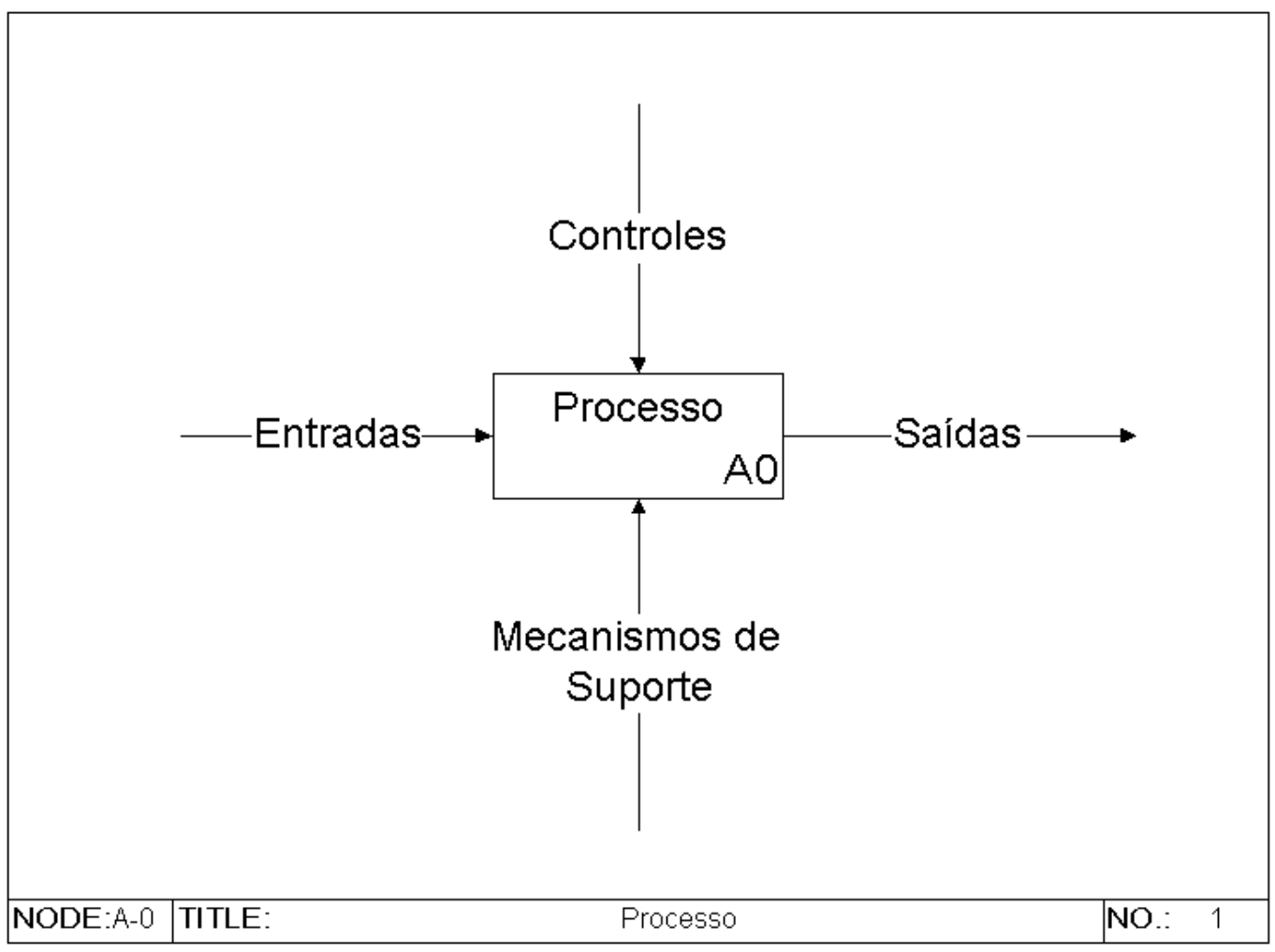

Figura 10. IDEF0. Diagrama de contexto. Burlton (2001). 
O retângulo representa processos ou subprocessos, as setas que entram na lateral esquerda representam as entradas do processo. As setas que entram pela lateral superior representam os controles e as setas inferiores representam os mecanismos de suporte. As setas que saem pela direita representam saídas de um processo.

A notação IDEF0 permite que um determinado processo seja detalhado em um conjunto de subprocessos como apresentado na Figura 11. Neste subnível, as entradas, saídas, controles e mecanismos de suporte de um subprocesso podem estar conectados a outro subprocesso.

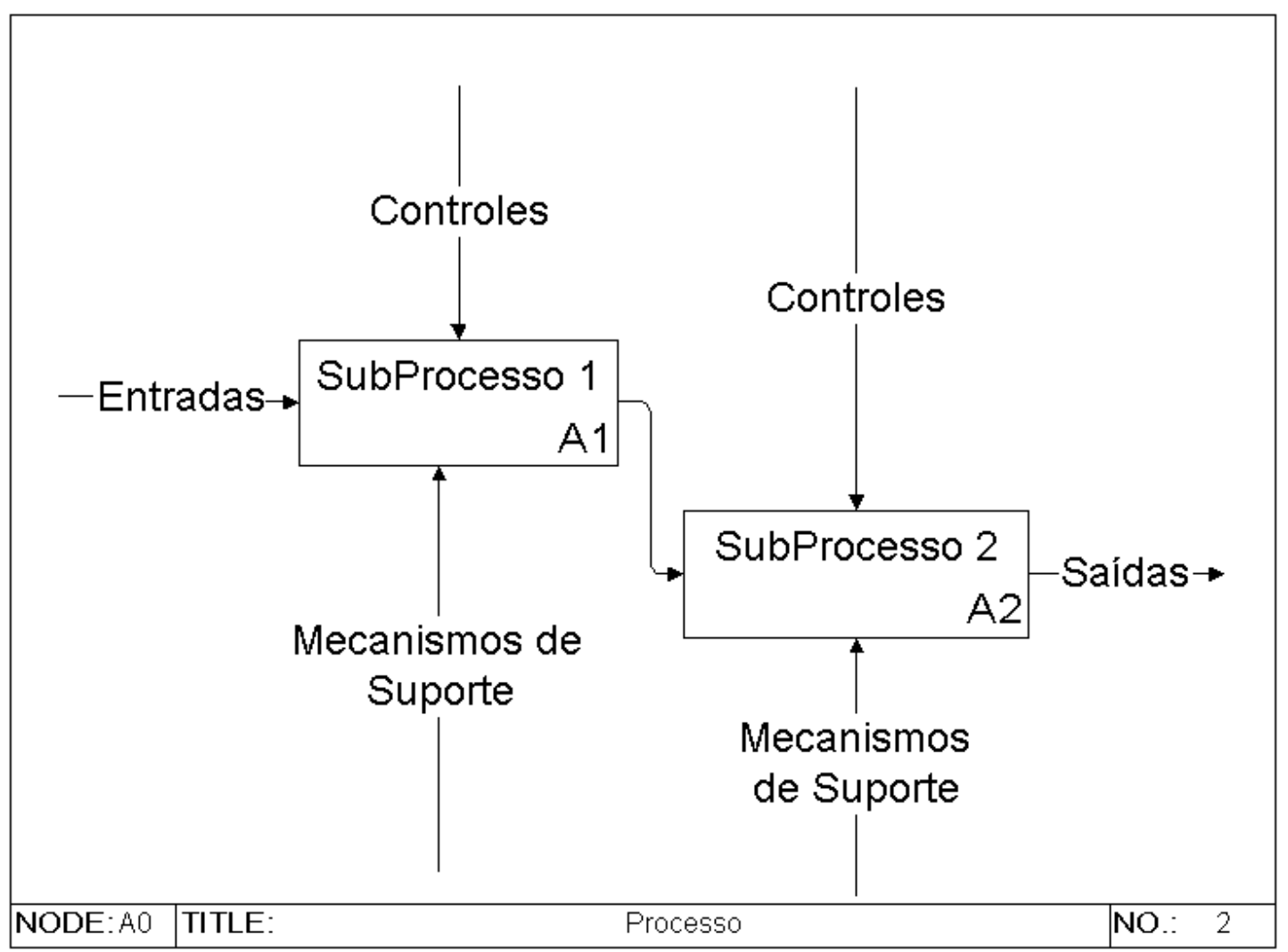

Figura 11. IDEF0. Representação de subprocessos. Burlton (2001). 


\section{Análise das bases conceituais}

Este capítulo apresenta uma análise a respeito das bases conceituais apresentadas no capítulo de revisão da literatura. Inicialmente são descritos os principais problemas e dificuldades encontradas na gestão de projetos distribuídos de software. A partir disto, os problemas identificados são relacionados com modelos de gestão de projetos utilizados pela indústria de software e com modelos específicos para projetos de Desenvolvimento Distribuído de Software (GSD). As principais carências em relação a este tipo de desenvolvimento são identificadas. Por fim, o último item apresenta uma coleção de boas práticas identificadas nos modelos apresentados no capítulo de revisão da literatura.

\subsection{Dificuldades do GSD}

Este item apresenta um conjunto de experiências coletadas na literatura em relação aos problemas enfrentados em projetos GSD. O objetivo é identificar os principais problemas para compará-los aos modelos de gestão de projetos. Os problemas identificados foram agrupados conforme categorias relacionadas às áreas de conhecimento do modelo PMBoK (2000), às áreas de processo do CMMI (2002) e também com base no agrupamento dos problemas discutidos por Carmel (1999), Haywood (1998), Oppenheimer (2002) e Karolak (1998). A categoria "Empobrecimento da Comunicação" foi relacionada à "Gerência das Comunicações do Projeto", a categoria "Aumento das Barreiras para Coordenação e Controle" foi relacionada à "Gerência da Integração do Projeto" e a categoria "Dificuldade de Avaliação dos Riscos da Distribuição de Projetos" foi relacionada à "Gerência de Riscos do Projeto" do Modelo PMBoK. A categoria "Dificuldades Relacionadas à Gestão do Ambiente Físico de 
Desenvolvimento" foi relacionada à área de processo "Ambiente Organizacional para Integração" do modelo CMMI.

\section{Empobrecimento da Comunicação:}

- $\quad$ Segundo Carmel (1999), projetos distribuídos sofrem com o empobrecimento da comunicação. Em um projeto tradicional, muitas questões são resolvidas através de comunicação informal. Este tipo de comunicação é considerado rico já que permite uma maior liberdade e criatividade entre as partes (comunicação de caminho duplo). Nestes casos, membros da equipe conseguem resolver pequenos problemas e realizar inspeções de código informais. De forma geral, as pessoas preferem uma comunicação informal, o que auxilia na construção de relacionamentos e no aumento de confiança entre os membros de uma equipe. A dispersão facilita mal entendidos e torna as realimentações mais lentas.

- Segundo Haywood (1998), membros de uma Equipe Virtual têm medo de ser excluídos da comunicação de um projeto pelos membros da Organização Responsável pelo Contrato. Além disso, também existe uma preocupação que independente da dedicação e esforço de um membro de uma Equipe Virtual, este nunca será reconhecido pelo gerente do projeto devido à dificuldade de comunicação imposta pela distribuição.

\section{Aumento das Barreiras para Coordenação e Controle:}

- $\quad$ Segundo Carmel (1999), o desenvolvimento de software implica em um conjunto de atividades que são interdependentes. Desta forma, a gestão de projetos requer coordenação entre as tarefas desenvolvidas pelas Equipes Virtuais para se atingir os objetivos globais do projeto. Além disso, é muito importante que os produtos desenvolvidos estejam de acordo com os padrões especificados. Assim, o 
controle da qualidade dos produtos desenvolvidos também é uma atividade de gestão importante. Quando projetos de software são conduzidos de forma distribuída, torna-se mais difícil estabelecer mecanismos de coordenação e controle. A dispersão aumenta as barreiras para a integração das atividades e controle dos produtos. Em um único ambiente de desenvolvimento, mecanismos informais de coordenação e controle são utilizados que não são aplicados em ambientes distribuídos. No GSD, não é possível resolver dúvidas de maneira informal, nem acompanhar o projeto através da técnica MBWA (Management By Walking Around) na qual o gerente do projeto pode entrar em contato fisicamente com seus funcionários para verificar o andamento do projeto e resolver problemas de coordenação e controle.

\section{Diferenças Culturais:}

- $\quad$ Um exemplo de diferenças culturais descrito por Karolak (1998), consiste na existência de formas de planejamento e gerenciamento diferentes entre empresas. No exemplo descrito, a Empresa A aloca todos os seus recursos até a conclusão de um projeto, enquanto a Empresa B, um pouco antes da conclusão do projeto, realoca seus recursos para poder alavancar outros projetos. Em uma Organização Virtual, estas diferenças culturais podem prejudicar o encerramento do projeto.

- $\quad$ O segundo estudo de caso analisado por Karolak (1998) apresenta claramente problemas decorrentes de diferenças culturais. A Empresa A possuía uma estrutura gerencial com poder de decisão em níveis mais altos enquanto a Empresa B uma estrutura com poder de decisão em níveis baixos da hierarquia. Este tipo de diferença pode tornar uma empresa mais ágil, porém pode também levar a descobrir decisões erradas tardiamente. Estas diferenças culturais, como não foram bem trabalhadas, acabaram levando à desconfiança entre as equipes, o que resultou no 
desenvolvimento de dois sistemas com a mesma funcionalidade e com problemas de desempenho.

- Segundo Oppenheimer (2002), fatores culturais dificultam a construção de relacionamento entre membros de Equipes Virtuais e o estabelecimento de confiança entre eles. Nestes casos, mesmo quando as decisões de projeto são tomadas e comunicadas corretamente, as equipes não agem de acordo com o estabelecido.

\section{Dificuldades na Gestão e Distribuição de Informações:}

- Segundo Oppenheimer (2002), apesar de muitos projetos possuírem uma grande quantidade de informações relativas ao andamento do projeto, em muitos casos, estas informações não estão acessíveis às equipes que precisam da informação, não são claramente entendidas e não estão atualizadas. Isto ocorre, pois muitas vezes, Equipes Virtuais distintas reportam progresso de forma paralela ou então porque o responsável pela informação esquece ou comunica os destinatários errados. Este tipo de problema dificulta o entendimento das estratégias, prioridades e decisões de uma organização. Além disso, riscos críticos não são percebidos e o estado atual do projeto é desconhecido pelos membros da Organização Virtual.

\section{Dificuldades Relacionadas à Gestão do Ambiente Físico de Desenvolvimento:}

- $\quad$ O terceiro estudo de caso apresentado por Karolak (1998) ressalta problemas de integração de sistemas devido à falta de planejamento do ambiente de desenvolvimento distribuído. No momento de planejamento do projeto não foram especificadas as ferramentas CASE a serem utilizadas. Desta forma, cada Equipe Virtual desenvolveu seus produtos em ferramentas diferentes o que dificultou e atrasou a integração do software e da documentação do projeto. 
- $\quad$ Segundo Haywood (1998), Equipes Virtuais precisam de suporte técnico para obter acesso a recursos e ferramentas que as habilitem a trabalhar em um ambiente de uma Organização Virtual. Problemas de acesso a estes recursos podem diminuir consideravelmente o desempenho de um membro de uma Equipe Virtual.

\section{Falta de Padronização de Métodos e Técnicas de Desenvolvimento:}

- $\quad$ Oppenheimer (2002) relata um problema na utilização de técnicas diferentes para estimativa de esforço das atividades de um projeto. Esta situação pode levar a um planejamento incoerente e a dificuldades no acompanhamento e monitoração do projeto. Mesmo quando os cronogramas das Equipes Virtuais parecem sincronizados, acabam ocorrendo desvios. Desta forma, deve haver uma padronização das técnicas e métodos a serem utilizados em projetos GSD para minimizar impactos decorrentes de modos diferentes de trabalho.

\section{Dificuldade de Avaliação dos Riscos da Distribuição de Projetos:}

- $\quad$ O terceiro estudo de caso apresentado por Karolak (1998) discute dificuldades decorrentes da falta de avaliação de riscos no momento da decisão de utilização de um projeto GSD. A Organização Responsável pelo Contrato decidiu subcontratar uma parte do desenvolvimento de software devido à baixa produtividade e projeção de lucros correntes comparados às estimativas iniciais do projeto. A opção pelo GSD com objetivo de atender metas de prazo e custo, pode gerar perdas financeiras se não forem avaliados os riscos e benefícios da decisão. Muitas empresas não identificam os riscos associados a este modelo de desenvolvimento e só percebem os problemas quando já é tarde demais. 


\subsection{Análise dos Modelos Apresentados}

Neste tópico são apresentados comentários a respeito dos modelos detalhados anteriormente e também uma comparação entre os modelos de gestão em relação a problemas identificados na literatura a respeito de projetos GSD.

Tabela 1. Relação entre problemas identificados e modelos de gestão.

\begin{tabular}{|l|c|c|c|c|c|}
\hline \multirow{2}{*}{ Categorias de Problema } & \multicolumn{3}{|l|}{ Gestão de Projetos GSD } & \multicolumn{2}{l|}{ Referências } \\
\cline { 2 - 6 } & CPMA & MuNDDoS & MILOS & PMBoK & CMMI \\
\hline $\begin{array}{l}\text { Empobrecimento da } \\
\text { Comunicação. }\end{array}$ & $\mathrm{X}$ & & & $\mathrm{X}$ & $\mathrm{X}$ \\
\hline $\begin{array}{l}\text { Aumento das Barreiras para } \\
\text { Coordenação e Controle. }\end{array}$ & $\mathrm{X}$ & & $\mathrm{X}$ & $\mathrm{X}$ & $\mathrm{X}$ \\
\hline Diferenças Culturais & & $\mathrm{X}$ & & $\mathrm{X}$ & $\mathrm{X}$ \\
\hline $\begin{array}{l}\text { Dificuldades na Gestão e } \\
\text { Distribuição de Informações. }\end{array}$ & $\mathrm{X}$ & & & & $\mathrm{X}$ \\
\hline $\begin{array}{l}\text { Dificuldades Relacionadas à } \\
\text { Gestão do Ambiente Físico de } \\
\text { Desenvolvimento. }\end{array}$ & & & $\mathrm{X}$ & & \\
\hline $\begin{array}{l}\text { Falta de Padronização de } \\
\text { Métodos e Técnicas de } \\
\text { Desenvolvimento }\end{array}$ & & $\mathrm{X}$ & & $\mathrm{X}$ & $\mathrm{X}$ \\
\hline $\begin{array}{l}\text { Dificuldade de Avaliação dos } \\
\text { Riscos da Distribuição de } \\
\text { Projetos. }\end{array}$ & & & & & \\
\hline
\end{tabular}

Legenda:

- $\quad \mathbf{X}$ - Modelo possui processos e práticas que diminuem os problemas identificados.

A Tabela 1 apresenta uma comparação entre os modelos para gestão de projetos GSD e os modelos de gestão de projetos mais utilizados atualmente a respeito do grau de atendimento destes modelos em relação aos principais problemas encontrados neste tipo de projeto.

O modelo CPMA, proposto por Chen, Romano e Nunamaker (2002, 2003a, 2003b), minimiza o empobrecimento da comunicação através do processo de processo de suporte a presença e gestão do conhecimento. O processo de suporte a níveis de colaboração aumenta a 
integração e coordenação entre as Equipes Virtuais. As dificuldades no gerenciamento e distribuição de informações podem ser diminuídas através do processo de gestão de conhecimento.

O modelo MuNDDoS proposto por Zanoni e Audy (2003) e Prikadnicki e Audy (2002, 2003), possui práticas para a análise de viabilidade de utilização do GSD em um novo projeto. O modelo cobre os problemas de avaliação de riscos de distribuição e dificuldades de gestão de informações com um processo de avaliação de riscos da distribuição apoiado em uma Base de Conhecimento formada com experiências obtidas em projetos GSD.

O modelo MILOS, proposto por Goldmann et al. (1999a, 1999b, 1999c, 1999d, 2002), está focado em apoiar o processo de planejamento e replanejamento de projetos. Ele pressupõe que o planejamento e replanejamento são realizados também de forma distribuída e que alterações nos prazos e em decisões tomadas por uma Equipe Virtual podem influenciar no planejamento de outras equipes do projeto. O modelo MILOS apresenta práticas que permitem aumentar a integração entre as equipes e que padronizam o processo de planejamento de uma Organização Virtual.

O modelo PMBoK (2000), é composto por nove áreas de conhecimento. A área de conhecimento de "Gerência das Comunicações do Projeto" estabelece atividades que minimizam o empobrecimento da comunicação e também auxiliam na gestão e distribuição de informações do projeto. A área de conhecimento "Gerência da Integração do Projeto" também apóia a falta de coordenação e integração decorrentes da distância física. O PMBoK também possui uma área de conhecimento chamada de "Gerência dos Riscos do Projeto" que tem como objetivo identificar, avaliar, priorizar e mitigar riscos do projeto.

O CMMI (2002) cobre grande parte dos problemas identificados na Tabela 1. Os problemas de integração, coordenação e controle existentes podem ser minimizados pelas práticas descritas nas áreas de processo de "Gestão Integrada de Projeto" e "Gestão Integrada 
de Equipes". A área de processo de “Ambiente Organizacional para Integração" possui práticas que têm como objetivo estabelecer uma infra-estrutura de trabalho para a organização. Esta área de processo possui uma prática que é a de estabelecer e manter a Visão Compartilhada da organização. Esta prática contribui para diminuir os problemas de comunicação e apóia na gestão e distribuição das informações do projeto.

Além disso, a prática "Estabelecer um Ambiente Integrado de Trabalho", também desta área de processo, tem como objetivo prover e manter o ambiente físico de trabalho da Organização Virtual a fim de habilitar a colaboração e o desenvolvimento concorrente entre as Equipes Virtuais. Esta prática minimiza os problemas relacionados ao ambiente físico de desenvolvimento. A área de processo de "Gestão de Riscos" apresenta práticas para identificação, avaliação, priorização e mitigação de riscos.

A Tabela 1 permite identificar as principais carências em termos de processos em relação ao GSD que não estão cobertas pelos modelos atuais de gestão de projetos. Os problemas associados às diferenças culturais existentes entre as equipes não são tratados especificamente por nenhum modelo. Apenas o CMMI trata da gestão do ambiente físico de desenvolvimento e apenas o MILOS considera práticas para a padronização das técnicas de desenvolvimento. A comunicação e a colaboração em projetos GSD também representam grandes dificuldades. Apesar de modelos como o PMBoK (2000) e o CMMI (2002) tratarem explicitamente da questão da comunicação, a distância física imposta em projetos GSD aumenta a complexidade destes processos. Desta forma, o GesProDS, modelo proposto neste trabalho, é baseado em práticas e processos identificados nos modelos da Tabela 1, porém é detalhado e refinado considerando os problemas identificados para projetos GSD. 


\subsection{Boas Práticas para Gestão de Projetos Distribuídos}

Este item apresenta uma relação de boas práticas coletadas a partir dos modelos descritos e também da literatura sobre GSD e gestão de projetos distribuídos. As boas práticas são:

Avaliação dos riscos de utilização de um modelo GSD em um projeto. Segundo Zanoni e Audy (2003) e Prikladnicki e Audy (2002), a opção pela utilização do GSD em um projeto deve ser analisada no nível estratégico de uma organização. A partir das características de um projeto (tamanho, tecnologias envolvidas, prazo, criticidade do projeto, etc...) e das condições existentes em uma organização (Equipes Virtuais disponíveis, disponibilidade de recursos, tecnologias conhecidas, etc...), deve ser feito um levantamento dos riscos potenciais, benefícios, impactos e probabilidades considerando os dois modelos de desenvolvimento (tradicional e GSD). A decisão deve ser baseada na análise descrita.

- $\quad$ Atividades de planejamento e replanejamento devem ser associadas às decisões tomadas para que seja possível avaliar os impactos de alterações de decisões. O modelo MILOS, proposto por Goldmann et al. (1999a, 1999b, 1999c, 1999d, 2002), está baseado no fato de que as atividades de planejamento e replanejamento também fazem parte das atividades a serem executadas em um projeto. O resultado da execução destas atividades é a identificação de esforço, prazo e custo de atividades a serem realizadas no projeto. Alterações em decisões de projeto (tecnologias, arquiteturas, padrões de qualidade, etc...) podem impactar no planejamento de outras atividades e devem ser analisadas e avaliadas.

- Aumento do entendimento dos conceitos do projeto por todas as equipes envolvidas. Segundo Chen, Romanto e Nunamaker (2002, 2003a, 2003b), em um 
ambiente de projetos GSD, deve-se aumentar o entendimento dos conceitos do projeto através do processo de "Suporte à Presença". Este processo tem como objetivo dar visibilidade e tornar presente para as Equipes Virtuais, os conceitos importantes do projeto. Isto é obtido através dos seguintes mecanismos: descrição e divulgação de regras e políticas de negócio, prazos, orçamentos, custos, recursos, glossário de definições do projeto, etc. Entende-se que um membro de uma equipe pode ter uma produtividade maior se existirem mecanismos que permitam visualizar ou presenciar estes conceitos. O CMMI (2002) também indica como uma boa prática a adoção de uma Visão Compartilhada da organização. O objetivo da Visão Compartilhada é promover um entendimento comum a respeito dos princípios diretivos de uma organização: missão, objetivos, comportamentos esperados, valores, resultados esperados. A partir da Visão Compartilhada da organização é derivada a Visão Compartilhada do Projeto.

Apoio à colaboração entre as equipes distribuídas. Segundo Chen, Romano e Nunamaker (2002, 2003a, 2003b), em um projeto todos os tipos de colaboração (esforço individual, coordenado e sincronizado) entre os membros das Equipes Virtuais são necessários. A Organização Virtual deve possuir mecanismos para promover cada tipo de colaboração adequado a cada atividade do projeto, de forma a maximizar a produtividade dos membros do projeto.

- $\quad$ Apoio ao conhecimento colaborativo do projeto. Esta boa prática é indicada em vários modelos. Chen, Romano e Nunamaker (2002, 2003a, 2003b) identificam o armazenamento de experiências e conhecimentos de projetos GSD como uma importante prática para obtenção de informações para apoio à decisão em projetos futuros. O modelo proposto por Zanoni e Audy (2003) e Prikladnicki e Audy (2003) também propõe a utilização de uma Base de Conhecimento para acúmulo de 
experiências a respeito dos riscos e problemas ocorridos em projetos GSD com a finalidade de apoiar em decisões estratégicas na adoção desta forma de desenvolvimento em outros projetos.

- $\quad$ Gestão do ambiente físico distribuído. O ambiente físico de uma Organização Virtual é composto por uma infra-estrutura distribuída e mantida por diversas empresas ou departamentos de uma empresa. Desta forma, pode estar sujeita a diferenças nas configurações de hardware, software e telecomunicações que podem impactar a integração, coordenação e controle do projeto. O modelo CMMI (2002) possui uma prática "Estabelecer Ambiente de Trabalho Integrado" da área de processo "Ambiente Organizacional para Integração" que tem como objetivo planejar e controlar o ambiente organizacional. Para isso, deve-se elaborar um documento com os requisitos e o projeto do ambiente distribuído. Estes requisitos devem ser implementados e gerenciados para garantir a efetiva colaboração entre as Equipes Virtuais e a integração dos produtos elaborados. 


\section{GesProDS - Modelo de Gestão de Projetos Distribuídos de Software}

Este capítulo apresenta o GesProDS, modelo proposto para gerenciamento de projetos de Desenvolvimento Distribuído de Software (GSD). Primeiramente, é apresentada uma lista dos processos que compõem o modelo proposto e a classificação deles quanto ao ciclo de vida de projetos do modelo PMBoK (2000). Posteriormente, a estrutura organizacional e funcional de uma Organização Virtual que suporta projetos distribuídos de software é discutida. Para cada processo descrito no modelo, as principais características, o fluxo das atividades, as estradas, saídas, recursos e controles são detalhados. Por fim, o modelo GesProDS é avaliado e discutido.

\subsection{Classificação dos Processos do Modelo GesProDS}

Os processos do GesProDS foram organizados com base nos processos do ciclo de vida de gestão de projetos do modelo PMBoK (2000), descrito na Figura 5 do capítulo de revisão da literatura.

O GesProDS é composto por processos identificados nos modelos de gestão de apresentados no capítulo 3, por processos desenvolvidos com base na análise dos problemas do item 3.2 e com base nas boas práticas descritas no item 3.3. Outros processos básicos foram selecionados dos modelos PMBoK (2000) e CMMI (2002) para permitir um fluxo de gerenciamento consistente.

Vale ressaltar que não é objetivo deste trabalho discutir todas as áreas de conhecimento do PMBoK no modelo proposto. Desta forma, o modelo proposto foca nos 
problemas identificados no capítulo 3 e deve ser utilizado como um complemento a outros modelos para a gestão de projetos GSD.

A classificação de cada processo selecionado com relação ao ciclo de vida de projetos do modelo PMBoK (2000) é descrita a seguir:

- Iniciação do Projeto

O processo de Iniciação do Projeto é muito importante para formalização do início do projeto, pois é o momento em que ocorre a caracterização do projeto e a divulgação para a organização do início do projeto. Neste processo, o escopo macro, premissas, restrições e o gerente do projeto são definidos. Este processo é inspirado no PMBoK (2000) e é classificado como um processo de Iniciação do ciclo de vida de projetos (mesma definição do modelo PMBoK).

- $\quad$ Avaliação de Riscos de Distribuição de Projetos e de Equipes Virtuais

O processo de Avaliação de Riscos de Distribuição de Projetos e de Equipes Virtuais tem como objetivo identificar se o GSD é a melhor forma de desenvolvimento para um projeto e quais são as Equipes Virtuais mais indicadas para um determinado projeto. Este processo é inspirado no modelo MuNDDoS, proposto por Zanoni e Audy (2003) e Prikladnicki e Audy (2002, 2003). Este processo caracteriza-se por um planejamento estratégico do tipo de desenvolvimento a ser utilizado no projeto e da seleção de equipes para o projeto. Desta forma, enquadra-se no processo de Planejamento do ciclo de vida de projetos.

- $\quad$ Meta-Planejamento do Tempo do Projeto

O Meta-Planejamento do Tempo do Projeto caracteriza-se por um processo de planejamento e replanejamento do tempo de um projeto. Ele é inspirado no modelo MILOS, proposto por Goldmann et al. (1999a, 1999b, 1999c, 1999d, 2002). Este processo permite desenvolver um plano integrado de tempo do projeto para todas as Equipes Virtuais e, desta forma, permite avaliar impactos de alterações de decisões e prazos de atividades no prazo 
final do projeto. Ele é classificado como processo de Planejamento do ciclo de vida de projetos.

- $\quad$ Gestão da Colaboração entre as Equipes Virtuais

O processo de Gestão da Colaboração entre as Equipes Virtuais é inspirado no modelo CPMA, proposto por Chen, Romano e Nunamaker (2002, 2003a, 2003b). O objetivo é gerenciar as atividades do projeto de forma a identificar o melhor tipo de colaboração necessário e disponibilizar ferramentas, processos e conhecimentos necessários para uma efetiva colaboração entre as equipes. Este processo é conduzido durante o planejamento do projeto e deve ser revisado e replanejado durante a execução do projeto. Ele é classificado como um processo de Execução no ciclo de vida de projetos.

- Gestão do Conhecimento Colaborativo

A Gestão do Conhecimento Colaborativo é uma das práticas mais recomendadas na literatura. O objetivo é armazenar o conhecimento para que ele possa ser utilizado em projetos futuros evitando a perda de conhecimentos já adquiridos. Segundo Chen, Romano e Nunamaker (2002, 2003a, 2003b), Zanoni e Audy (2003) e Prikladnicki e Audy (2003) esta é uma importante prática para a gestão de projetos GSD. O conhecimento colaborativo é armazenado durante todo o ciclo de vida do projeto, porém ocorre em maior quantidade durante a execução do projeto. Desta forma, o processo Gestão do Conhecimento Colaborativo é classificado como um processo de Execução do ciclo de vida de projetos.

- $\quad$ Gestão do Ambiente Físico de Desenvolvimento Distribuído

A Gestão do Ambiente Físico de Desenvolvimento Distribuído envolve a definição de um ambiente padrão de hardware, software, telecomunicações, ferramentas, processos e forma de trabalho. A partir desta definição, é necessário monitorar e prestar suporte às Equipes Virtuais para garantir a adequação ao padrão especificado. Os problemas decorrentes da falta de gestão do ambiente físico de distribuição são discutidos por Karolak (1998) e 
Haywood (1998). O modelo CMMI (2002) também descreve uma área de processo com foco na gestão do ambiente físico. Este processo suporta a execução do projeto e é classificado como um processo de Execução no ciclo de vida de projetos.

- $\quad$ Suporte ao Entendimento de Conceitos do Projeto

O processo de Suporte ao Entendimento de Conceitos do Projeto foi identificado com base nas boas práticas descritas no modelo CPMA, proposto por Chen, Romano e Nunamaker (2002, 2003a, 2003b) e também com base no conceito de Visão Compartilhada proposto no modelo CMMI (2002). Este processo permite construir um entendimento comum dos principais conceitos para que todos os integrantes das Equipes Virtuais conheçam de forma clara os objetivos, metas e conceitos importantes do projeto. Este processo também minimiza o problema de diferenças culturais identificado no item 3.1 e relatados por Karolak (1998) e Oppenheimer (2002). A criação de uma Visão Compartilhada do Projeto envolve a criação de uma cultura do projeto que deve estar clara a todos os envolvidos. Esta Visão Compartilhada é construída no início do projeto e também ao longo de sua execução e desta forma, o subprocesso é classificado como um processo de Execução no ciclo de vida de projetos.

- $\quad$ Gestão da Distribuição de Informações do Projeto.

Este processo é inspirado na identificação de problemas na distribuição de informações para envolvidos em projetos GSD. Este problema é relatado em Oppenheimer (2002) e em Haywood (1998). O modelo PMBoK (2000) também possui um processo para distribuição de informações do projeto. Este processo apóia a execução das atividades do projeto, desta forma, é classificado como um processo de Execução no ciclo de vida de projetos.

- $\quad$ Controle de Mudança de Escopo

O processo de Controle de Mudança de Escopo também é essencial para um projeto. Este processo tem como objetivo analisar o impacto e gerenciar alterações de Escopo do 
Projeto. Em um contexto de projetos GSD, o escopo de trabalho de cada Equipe Virtual deve estar definido de forma clara, e alterações no Escopo do Projeto, se aceitas, devem ser comunicadas e distribuídas para as Equipes Virtuais e interessados do projeto. Este processo, inspirado no PMBoK (2000), ocorre durante a execução do projeto apoiando na identificação e controle de mudanças no Escopo do Projeto. Desta forma, é classificado como um processo de Acompanhamento.

- $\quad$ Controle do Cronograma

O processo de Controle do Cronograma é essencial para um projeto. Ele permite acompanhar o progresso do projeto em termos de prazo e esforço. Apesar de não ter sido identificado como um problema nas bases conceituais consultadas, em projetos GSD, o controle e acompanhamento de cronograma torna-se mais complexo já que as informações de progresso estão distribuídas pelas Equipes Virtuais. Este processo é inspirado no PMBoK (2000) e é classificado como um processo de Acompanhamento no ciclo de vida de projetos.

- $\quad$ Encerramento do Projeto

O processo de Encerramento do Projeto é muito importante para formalização da conclusão do projeto. Neste processo, obtém-se a aceitação formal da entrega dos produtos do projeto e registram-se lições aprendidas e boas práticas para utilização em novos projetos. Este processo é inspirado no PMBoK (2000) e é classificado como um processo de Encerramento no ciclo de vida de projetos.

O GesProDS é detalhado nos próximos itens. Primeiramente foi definida uma estrutura da Organização Virtual para entendimento das organizações envolvidas em um contexto de projeto GSD. Também foram identificados os principais papéis envolvidos. Por fim, cada processo identificado no modelo proposto é detalhado com base nas boas práticas coletadas nos modelos de gestão de projetos do capítulo 3. 


\subsection{Estrutura Organizacional de Projetos GSD}

Uma Organização Virtual é composta com o objetivo de desenvolver um sistema de software com base nos requisitos do cliente. Esta organização pode ser formada por uma ou um conjunto de empresas que coexistem enquanto durar o projeto. Normalmente, existe uma área ou empresa que é responsável pelo contato com o cliente. Esta é chamada de "Organização Responsável pelo Contrato" A Figura 12 apresenta a estrutura proposta. A Organização Responsável pelo Contrato é a responsável pelo projeto. Também é responsável por selecionar um conjunto de organizações ou departamentos de uma mesma organização que irão formar as Equipes Virtuais do projeto.

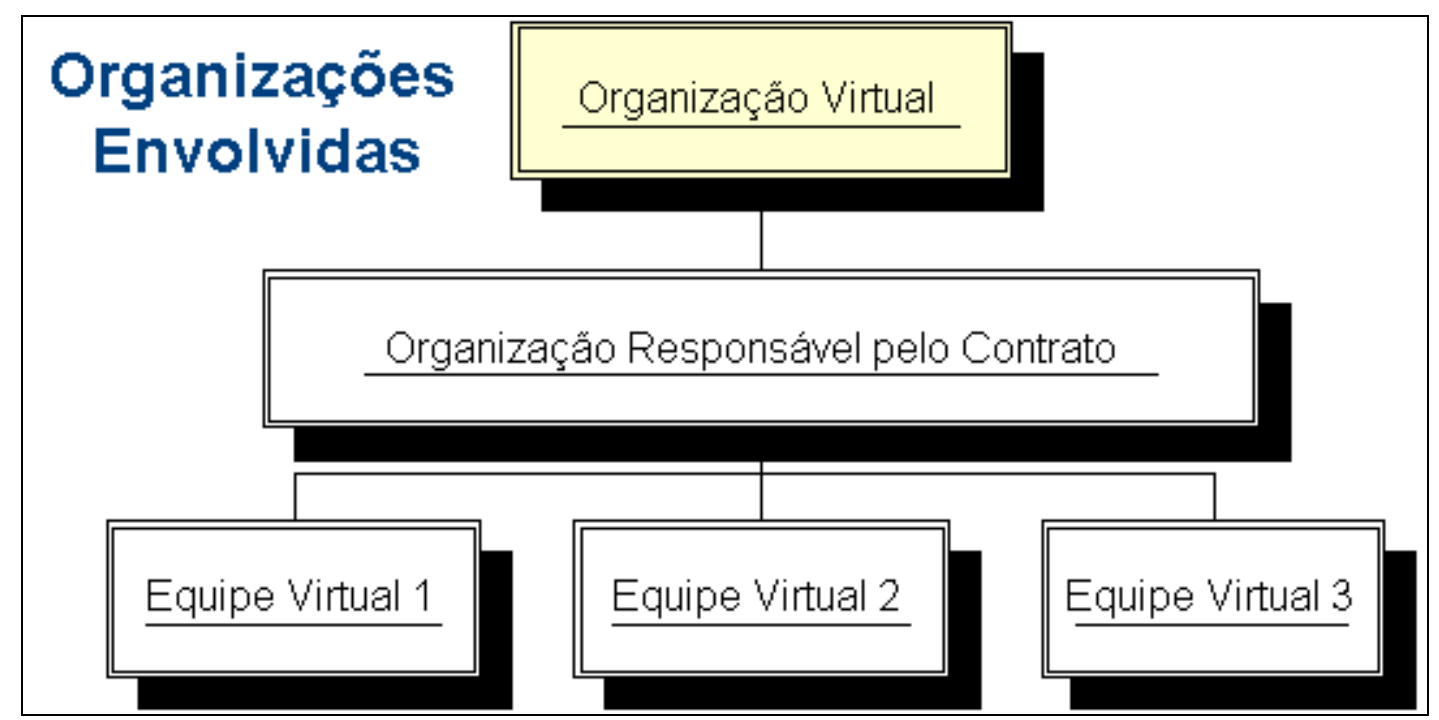

Figura 12. Estrutura organizacional de projetos GSD.

A Organização Responsável pelo Contrato, com objetivo de distribuir o trabalho pelas Equipes Virtuais, pode realizar seções verticais, horizontais ou as duas juntas. As seções verticais são identificadas quando o projeto é dividido em fases e cada Equipe Virtual é responsável por uma ou mais fases do projeto (Figura 13). 


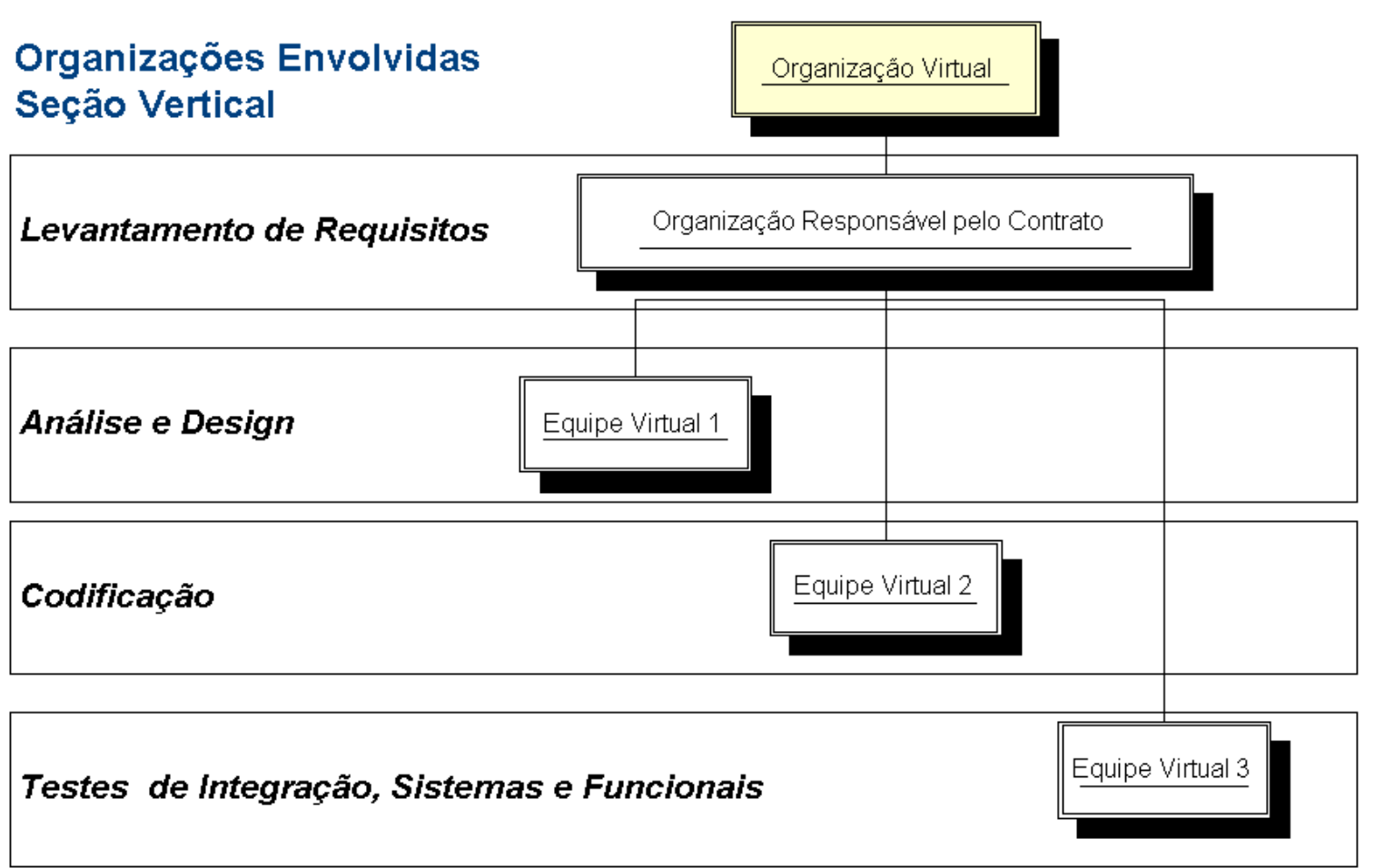

Figura 13. Seção vertical.

A seção horizontal consiste na divisão funcional de um projeto. Equipes virtuais diferentes trabalham em subsistemas ou componentes de software de um mesmo sistema. Este tipo de seção demanda um esforço adicional de integração de sistemas (Figura 14).

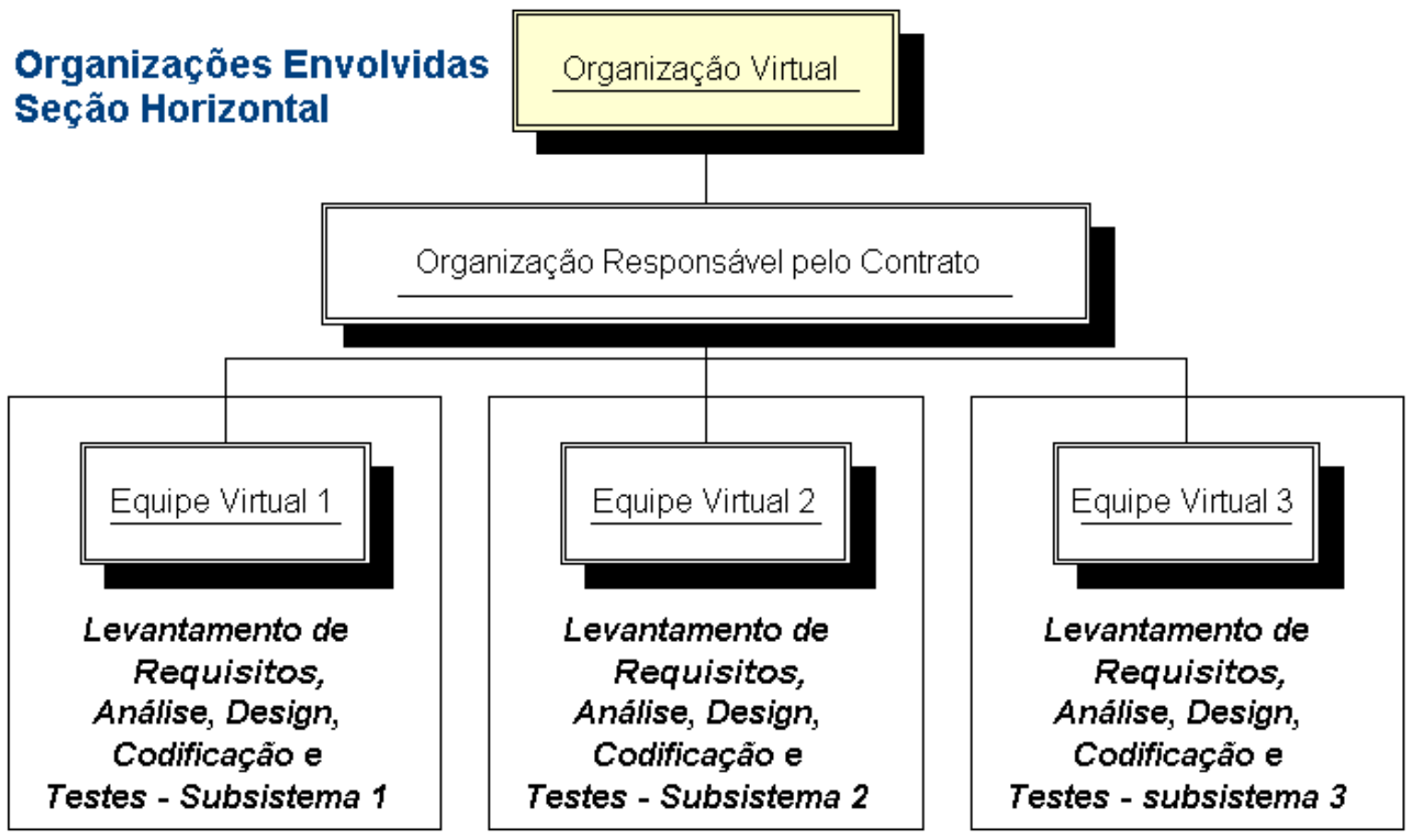

Figura 14. Seção horizontal. 
Em um contexto de projetos GSD, a utilização de seções verticais associadas com seções horizontais representa maior ganho de produtividade e um menor custo, entretanto agrega uma maior complexidade de gestão. A Figura 15 apresenta uma possível organização das fases e subsistemas considerando uma seção mista.

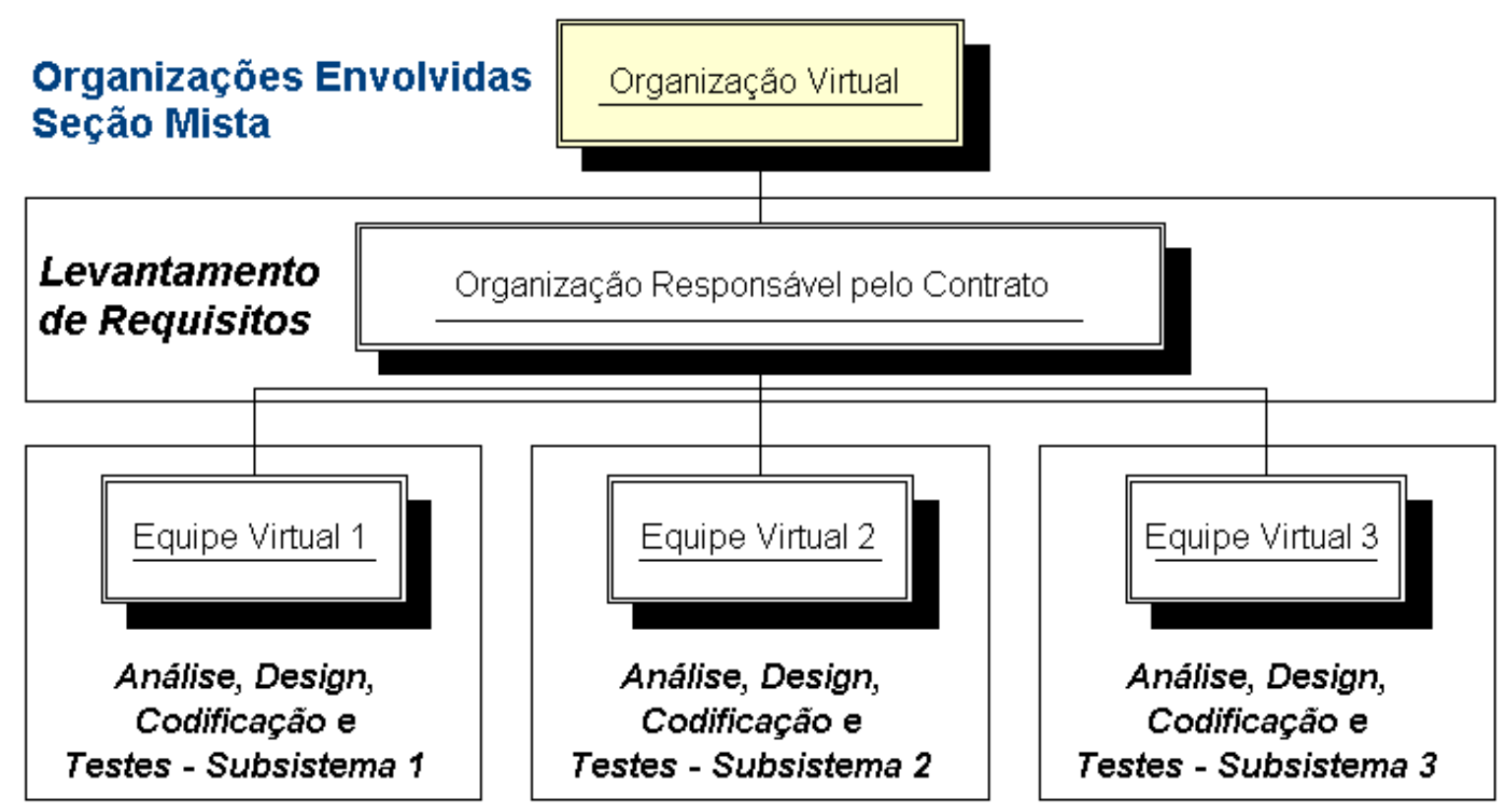

Figura 15. Seção mista.

\subsection{Estrutura Funcional}

Este item apresenta os principais papéis e grupos envolvidos no modelo de Gestão para projetos GSD proposto neste trabalho. Estes papéis e grupos são referenciados nos próximos itens de detalhamento dos processos do modelo GesProDS. A Figura 16 apresenta uma definição da estrutura funcional proposta para uma Organização Virtual baseada nas responsabilidades identificadas em um projeto GSD. 


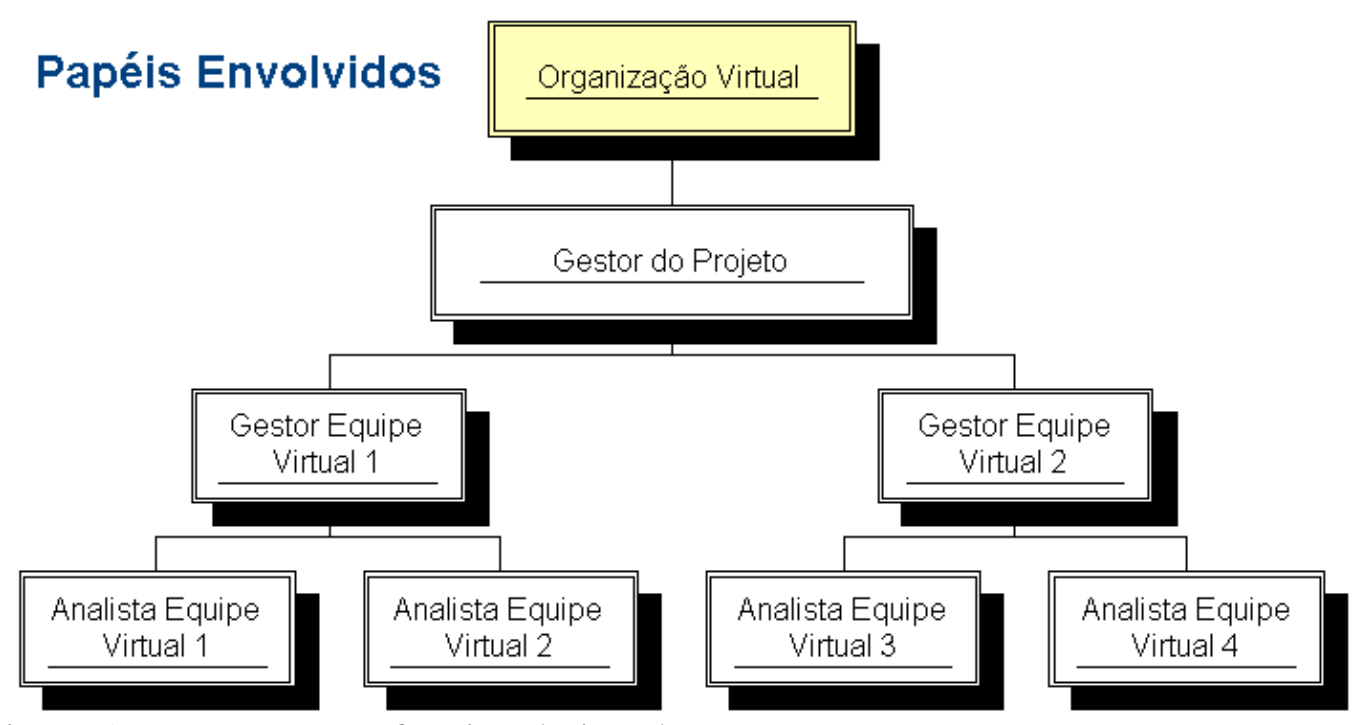

Figura 16. Estrutura funcional virtual.

O Gestor do Projeto é escolhido pela Organização Responsável pelo Contrato e é o responsável pela gestão do projeto GSD. Todas as Equipes Virtuais respondem ao Gestor do Projeto que é o responsável pela coordenação das Equipes Virtuais e do progresso global do projeto. Cada equipe possui um Gestor de Equipe Virtual que é o principal canal de comunicação entre a sua equipe e a Organização Responsável pelo Contrato. Ele também é o responsável pela gestão das atividades de sua equipe. Cada Equipe Virtual também possui Analistas de Equipe Virtual que são responsáveis pela execução das atividades determinadas pelo Gestor de Equipe Virtual. Todos os recursos descritos anteriormente podem desempenhar vários papéis e participar de vários grupos ao longo da execução do projeto conforme estratégia definida pelos membros da Organização Virtual.

Alguns dos papéis desempenhados por estes recursos são:

- $\quad$ Analista de Negócios. Responsável pela identificação e captura dos requisitos do projeto.

- Analista de Arquitetura de Software. Responsável pela elaboração da arquitetura do sistema a ser desenvolvido. 
- $\quad$ Analista de Sistemas. Responsável pela análise dos requisitos e elaboração do projeto da solução.

Programador de Software. Responsável pelo desenvolvimento de produtos de software de acordo com o projeto da solução.

- $\quad$ Analista de Testes de Software. Responsável pelos diversos tipos de testes dos produtos de software desenvolvidos.

- Analista de Riscos. Responsável pela identificação, análise, priorização, quantificação e mitigação dos riscos.

- $\quad$ Analista de Garantia da Qualidade. Responsável pela monitoração e controle da qualidade dos produtos e processos de acordo com os padrões estabelecidos.

- Analista de Gestão de Configuração. Responsável pelo armazenamento e garantia da integridade dos produtos de software desenvolvidos no projeto.

Os grupos formados por estes recursos são:

- Grupo de Gestão de Colaboração. Grupo responsável por atuar no subprocesso de "Gestão da Colaboração entre as Equipes Virtuais" com objetivo de analisar os tipos de atividades existentes no projeto para determinar os tipos de colaboração existentes e identificar processos e ferramentas que facilitem a colaboração e aumentem a produtividade das Equipes Virtuais.

- Grupo de Gestão do Conhecimento. Grupo responsável por atuar no subprocesso de "Gestão do Conhecimento Colaborativo" com objetivo de identificar conhecimentos gerados no projeto e analisar se eles devem compor a Base de Conhecimento Colaborativo da Organização Virtual.

- Grupo de Validação do Ambiente Físico de Desenvolvimento Distribuído. É formado por membros das Equipes Virtuais com objetivo de definir o Plano de Especificação do Ambiente Físico de Desenvolvimento Distribuído e monitorar a 
infra-estrutura da Organização Virtual para garantir que está de acordo com o plano definido.

Grupo de Avaliação de Regras e Conceitos. Grupo que atua no subprocesso "Suporte ao Entendimento de Conceitos do Projeto" e tem como objetivo analisar conceitos e regras de diferentes fontes do projeto e definir se devem fazer parte da Visão Compartilhada do Projeto.

- Grupo de Comunicação da Organização Virtual. Este grupo atua no subprocesso de "Gestão da Distribuição de Informações do Projeto". O objetivo deste grupo é gerenciar e garantir a integridade das comunicações do projeto. Para isso, eles avaliam informações recebidas dos membros do projeto e monitoram informações que deveriam ser comunicadas.

- Grupo de Garantia da Qualidade. O Grupo de Garantia da Qualidade atua no subprocesso de "Controle de Cronograma". O objetivo deste grupo é auditar produtos e processos para auxiliar na geração de informações de progresso do projeto.

- Grupo de Gestão de Escopo do Projeto. Grupo que atua no subprocesso de “Controle de Mudança de Escopo" e que tem como objetivo analisar solicitações de alteração de Escopo do Projeto e os respectivos impactos para definir a viabilidade de alteração do Escopo do Projeto.

\subsection{Diagrama de Contexto}

Este item apresenta o diagrama de contexto do GesProDS.

Este processo tem como objetivo monitorar e controlar diversos aspectos de gestão de um projeto GSD. Este processo possui duas saídas. A primeira saída que ocorre ao longo da 
execução do projeto é o "Projeto Gerenciado". Esta saída é identificada pela correta evolução do projeto em relação às metas estabelecidas. A segunda saída é o "Projeto Encerrado" que representa a entrega do projeto ao cliente respeitando os requisitos solicitados e as restrições de prazo, custo e qualidade definidas.

Os controles deste processo são as "Regras e Políticas das Empresas do Projeto" que vão compor a Organização Virtual e também as regras e condições impostas, definidas no "Contrato com Cliente".

Os mecanismos de suporte deste processo são: a Organização Virtual que irá executar o projeto, as Ferramentas para Colaboração e Gestão que viabilizam a colaboração entre as Equipes Virtuais e a Infra-Estrutura de Hardware, Software e Telecomunicações necessária para viabilizar a execução do projeto. A Figura 17 apresenta o diagrama IDEF0 de contexto do modelo.

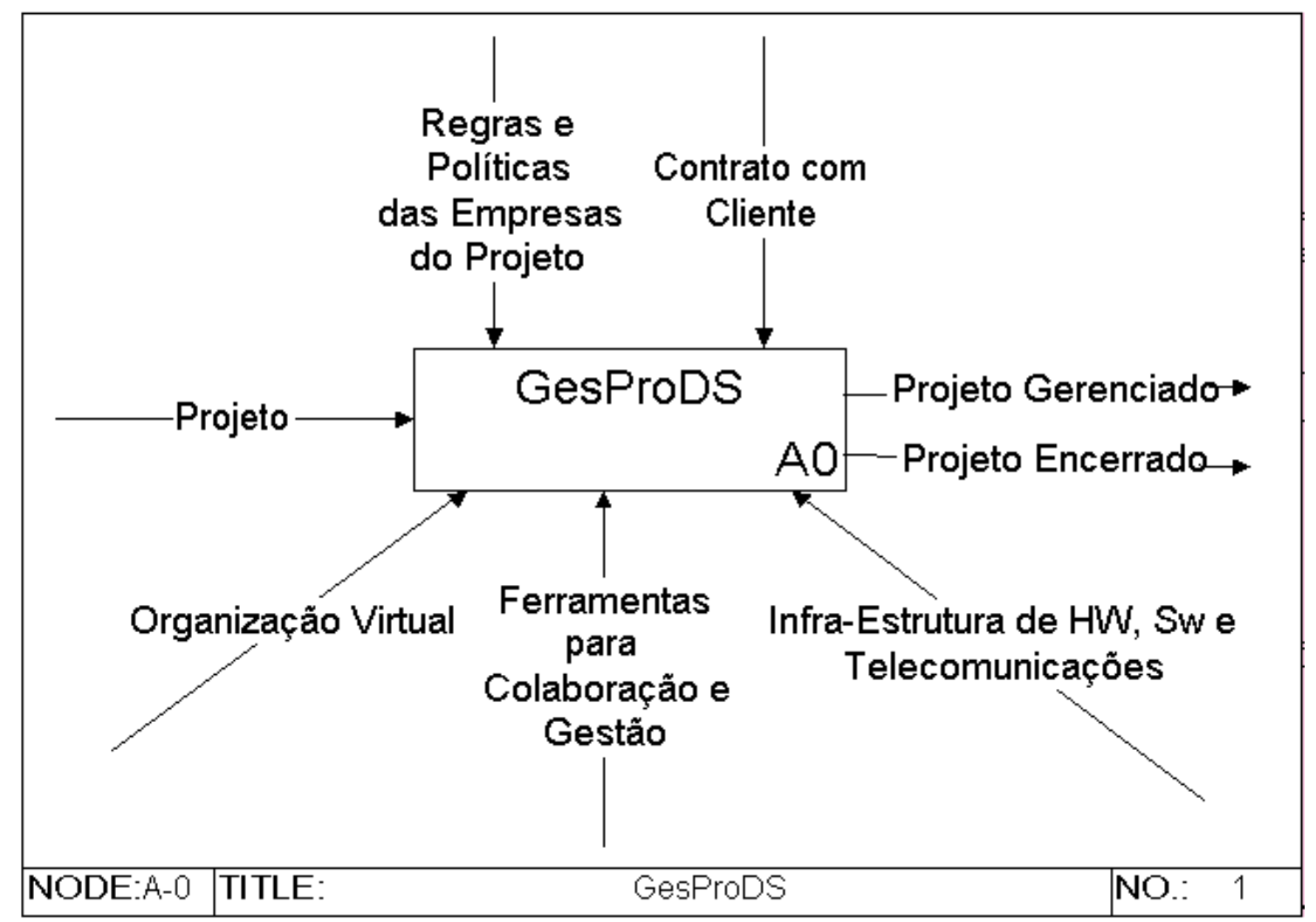

Figura 17. Diagrama de Contexto do modelo GesProDS. 


\subsection{Processos do Modelo GesProDS}

Este item apresenta o diagrama IDEF0 de primeiro nível do modelo proposto GesProDS. A Figura 18 apresenta os processos que compõe o modelo.

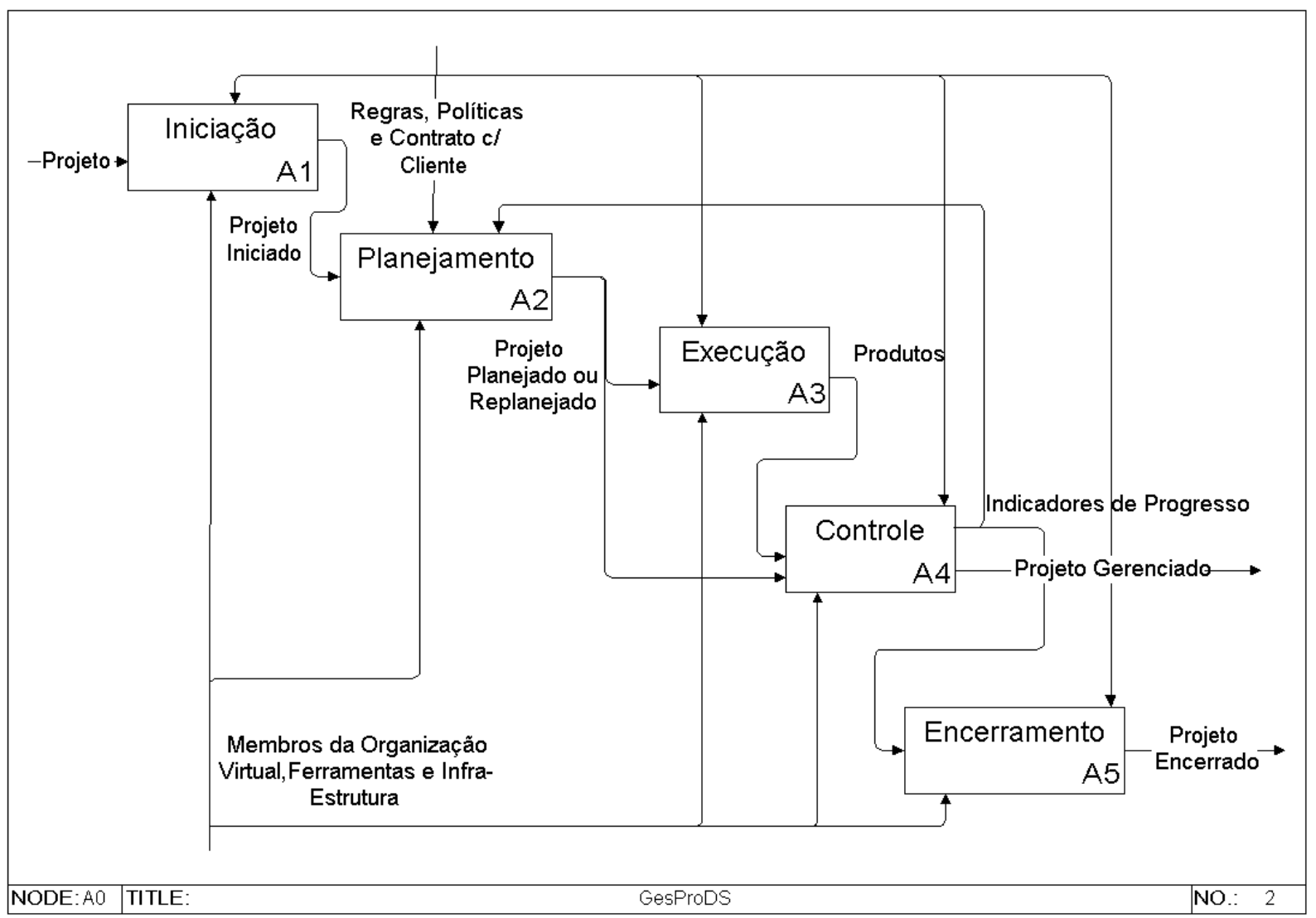

Figura 18. A0 - GesProDS.

O processo de Iniciação tem como objetivo identificar, formalizar e comunicar o início do projeto. A saída deste processo é o Projeto Iniciado.

O processo de Planejamento tem como objetivo apoiar na geração e manutenção dos planos de risco e tempo do projeto. A manutenção destes planos ocorre quando é necessário replanejar o projeto. A saída deste processo é o Projeto Planejado ou Replanejado.

O processo de Execução tem como objetivo apoiar na execução das fases e dos produtos do projeto. O resultado deste processo é o conjunto de produtos gerados nas fases do 
projeto com o apoio de subprocessos que facilitam a comunicação, colaboração e a integração entre as Equipes Virtuais.

O processo de Controle tem como objetivo monitorar a execução do projeto para identificar desvios em relação ao planejamento e fornecer subsídios para tomada de ações corretivas e alterações no planejamento no projeto. A saída deste processo é um conjunto de informações que dá visibilidade do progresso do projeto e que demonstra se o projeto está ou não gerenciado de acordo com o planejado.

O processo de Encerramento tem como objetivo identificar, formalizar e comunicar o encerramento do projeto. A saída deste projeto é o Projeto Encerrado.

Os próximos itens deste capítulo descrevem de forma detalhada os subprocessos do modelo proposto GesProDS.

\subsection{Processos de Iniciação}

Este item apresenta o subprocesso relacionado ao processo de Iniciação descrito no item 4.5. O seguinte subprocesso é descrito neste item:

- Iniciação do Projeto.

A Figura 19 apresenta o detalhamento do processo de Iniciação que é composto por apenas um subprocesso. 


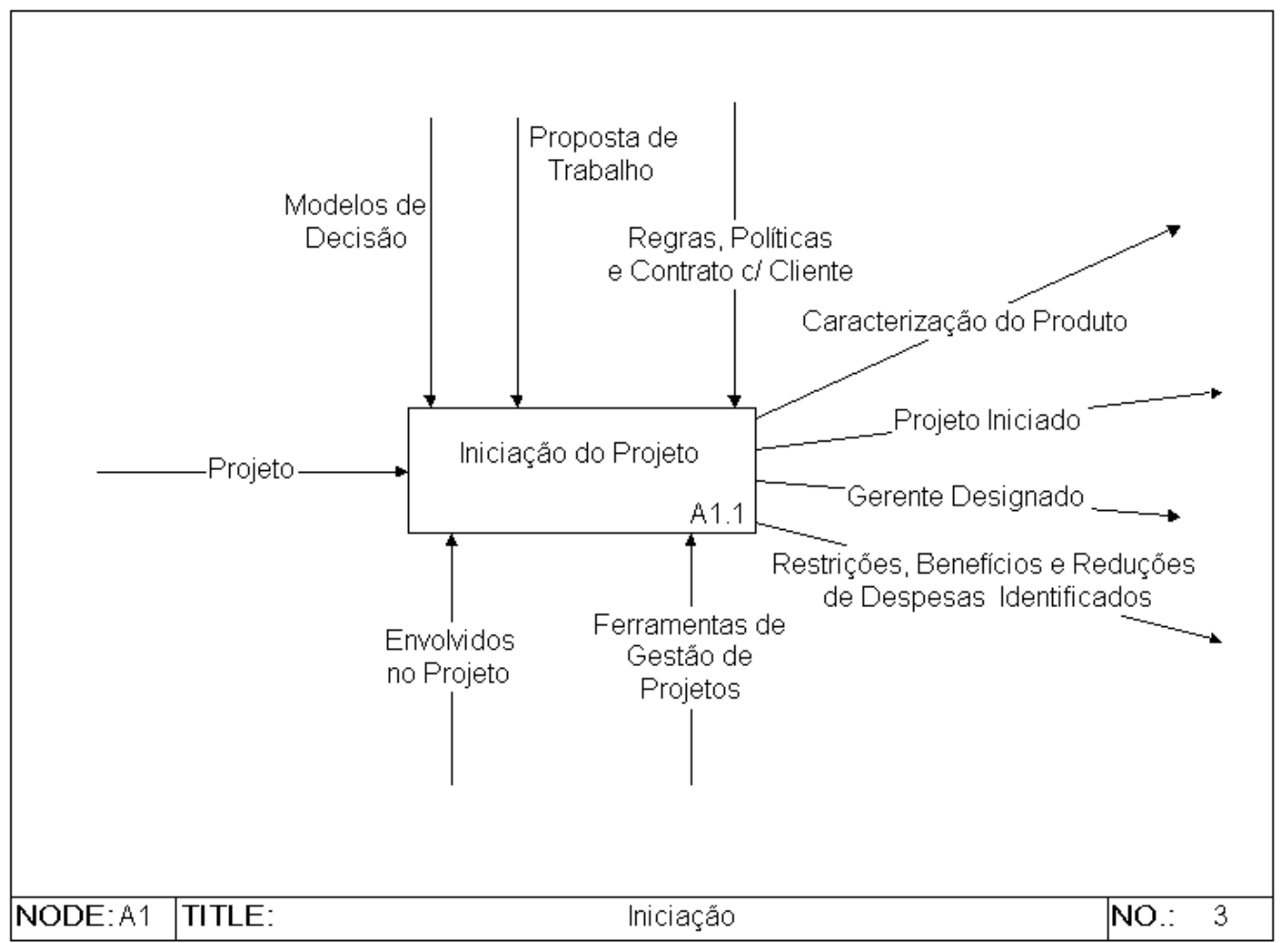

Figura 19. A1 - Iniciação.

\subsubsection{Iniciação do Projeto}

O subprocesso de Iniciação do Projeto é muito importante, pois permite identificar e formalizar o momento de início de um projeto. Este subprocesso não apresenta diferenciações para projetos convencionais ou projetos GSD. A Tabela 2 apresenta os atributos deste subprocesso.

Tabela 2. Atributos da Iniciação do Projeto.

\begin{tabular}{|l|l|}
\hline Objetivos do subprocesso: & Identificar e formalizar o início do projeto. \\
\hline Limites do processo: & $\begin{array}{l}\text { Início: Após a aprovação da proposta de trabalho. } \\
\text { Fim: Documento formal de início do projeto aprovado } \\
\text { com gerente do projeto designado, restrições do projeto e } \\
\text { características do produto definidas. }\end{array}$ \\
\hline Indicadores de Desempenho: & - Esforço dispendido para iniciação do projeto. \\
\hline
\end{tabular}

O subprocesso de Iniciação do Projeto é iniciado quando uma proposta de projeto é aprovada por um cliente. A própria proposta é insumo (Controle) para direcionamento das 
principais características do produto a ser entregue. As principais saídas deste processo são: a caracterização do produto a ser entregue no final do projeto, a formalização do início do projeto, a designação de um gerente do projeto e a definição de restrições e objetivo financeiro do projeto. O processo de Iniciação do Projeto deve ser feito de acordo com as regras e políticas da empresa, com o contrato estabelecido com o cliente e também com base em modelos para determinação do objetivo financeiro do projeto. Para isso, este processo é executado por interessados no projeto (StakeHolders) e pelo Gestor do Projeto com o suporte de ferramentas para o registro da abertura e formalização de projetos.

A Figura 20 apresenta a explosão do subprocesso de Iniciação do Projeto.

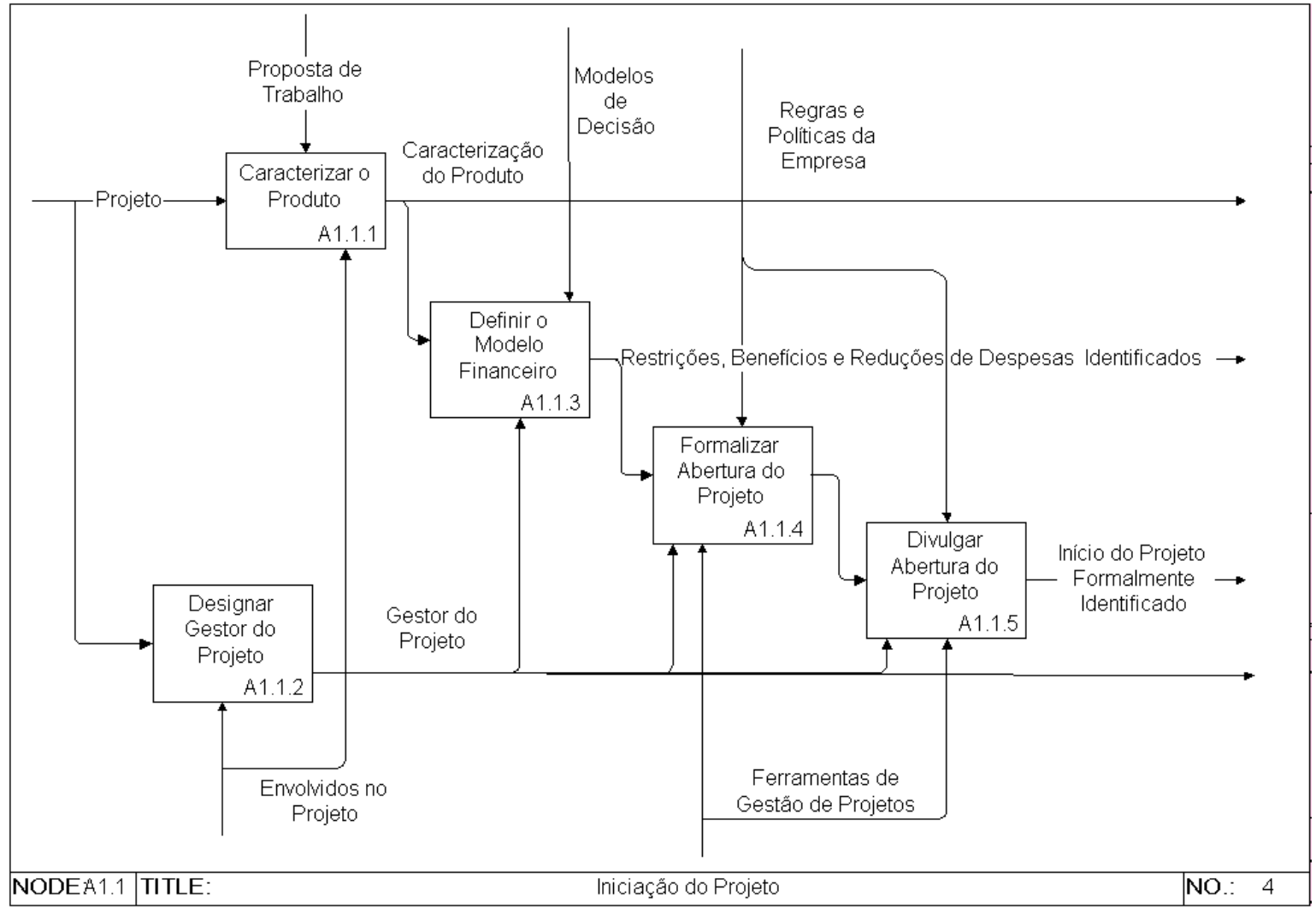

Figura 20. A1.1 - Iniciação do Projeto.

Considerando o momento de início de um projeto, a primeira atividade a ser conduzida é a caracterização do produto a ser entregue ao final do projeto. Esta atividade tem como objetivo identificar as principais características de forma a orientar a definição do Escopo do 
Projeto. Com base nos dados da proposta e na caracterização do produto, deve ser feito um estudo financeiro para identificação das restrições, benefícios e reduções de despesas do projeto. Em paralelo, o Gestor do Projeto deve ser selecionado e designado. A partir destas informações é possível registrar um termo de abertura do projeto e divulgar para os envolvidos no projeto. O Início do Projeto Formalmente Identificado é entrada para o subprocesso de “Gestão da Distribuição de Informações do Projeto" descrito no item 4.8.5.

\subsection{Processos de Planejamento}

Este item apresenta os subprocessos relacionados ao processo de Planejamento. Os seguintes subprocessos são descritos neste item:

- $\quad$ Avaliação de Riscos de Distribuição de Projetos e de Equipes Virtuais.

- $\quad$ Meta-Planejamento do Tempo do Projeto.

A Figura 21 apresenta os subprocessos do processo de Planejamento. O subprocesso de “Avaliação de Riscos de Distribuição de Projetos e Equipes Virtuais" é executado para verificar e avaliar a relação custo e benefício da utilização do GSD em um projeto. Após esta definição, as Equipes Virtuais disponíveis devem ser avaliadas e selecionadas. Estas definições são entradas para o subprocesso de "Meta-Planejamento do Tempo do Projeto" que tem como objetivo elaborar e manter o plano de tempo do projeto. 


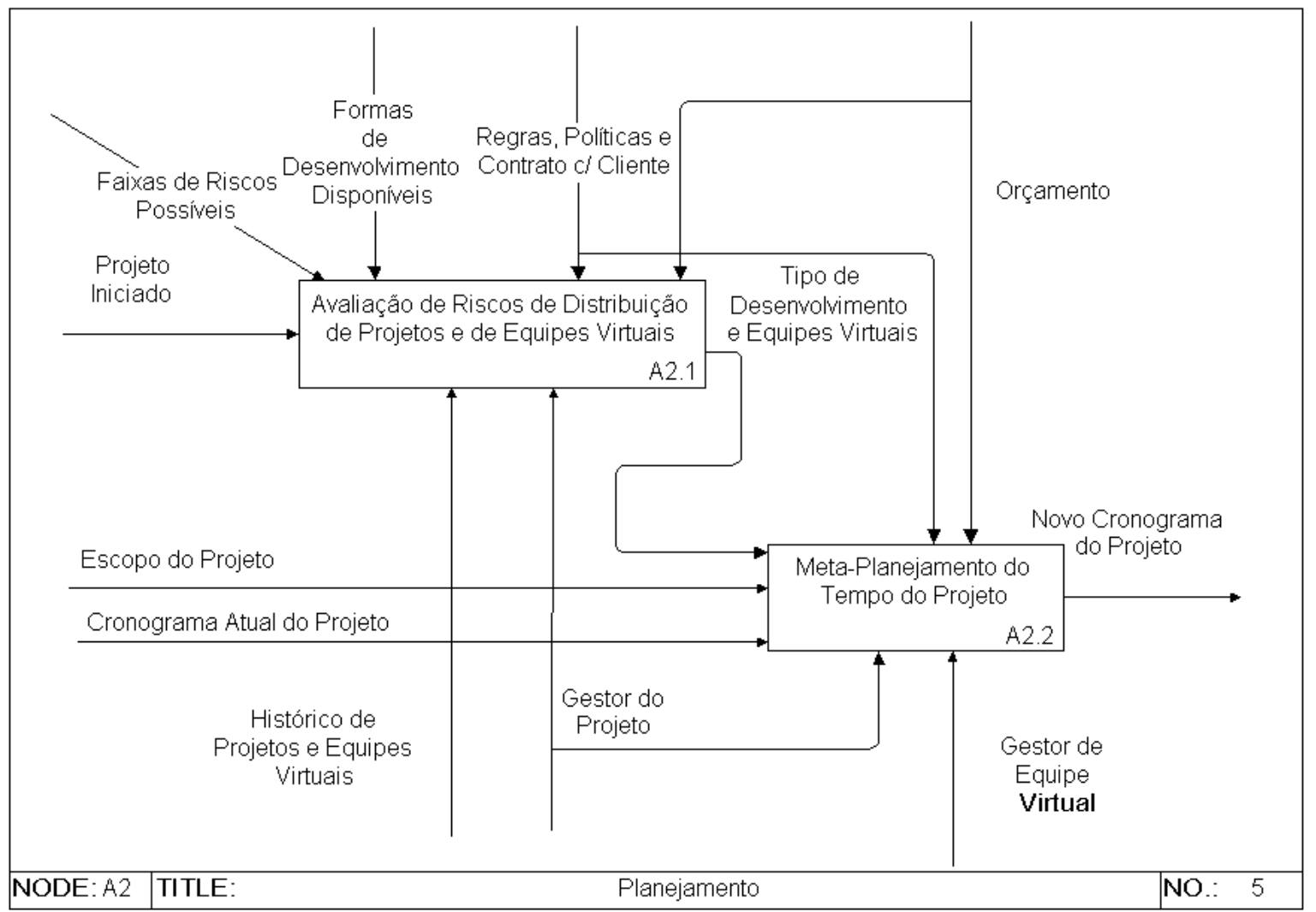

Figura 21. A2 - Planejamento.

\subsubsection{Avaliação de Riscos de Distribuição de Projetos e Equipes Virtuais}

O subprocesso de "Avaliação de Riscos de Distribuição de Projetos e Equipes Virtuais" é baseado no modelo MuNDDoS, proposto por Zanoni e Audy (2003) e Prikladnicki e Audy $(2002,2003)$. A estratégia de utilização do Desenvolvimento Distribuído de Software, apesar de prover muitos benefícios, envolve muitos riscos. Desta forma, é necessário avaliar os riscos envolvidos no projeto para as duas formas de desenvolvimento: GSD e desenvolvimento tradicional. Se a opção for pelo GSD ainda é necessário selecionar as Equipes Virtuais que envolvem menos riscos para o projeto. A Tabela 3 apresenta os atributos desse subprocesso. 
Tabela 3. Atributos da Avaliação de Riscos de Distribuição.

\begin{tabular}{|l|l|}
\hline Objetivos do subprocesso: & $\begin{array}{l}\text { Optar pela forma de desenvolvimento e equipes } \\
\text { envolvidas mais adequadas e que envolvem menos } \\
\text { riscos. }\end{array}$ \\
\hline Limites do processo: & $\begin{array}{l}\text { Início: Após a formalização de início do projeto. } \\
\text { Fim: Após a definição da forma de desenvolvimento e da } \\
\text { seleção das Equipes Virtuais. }\end{array}$ \\
\hline Indicadores de Desempenho: & $\begin{array}{l}\text { - Quantidade de riscos identificados. } \\
\text { - Esforço para levantamento de riscos. }\end{array}$ \\
\hline
\end{tabular}

A Figura 22 apresenta o detalhamento do subprocesso "Avaliação de Riscos de Distribuição de Projetos e Equipes Virtuais”.

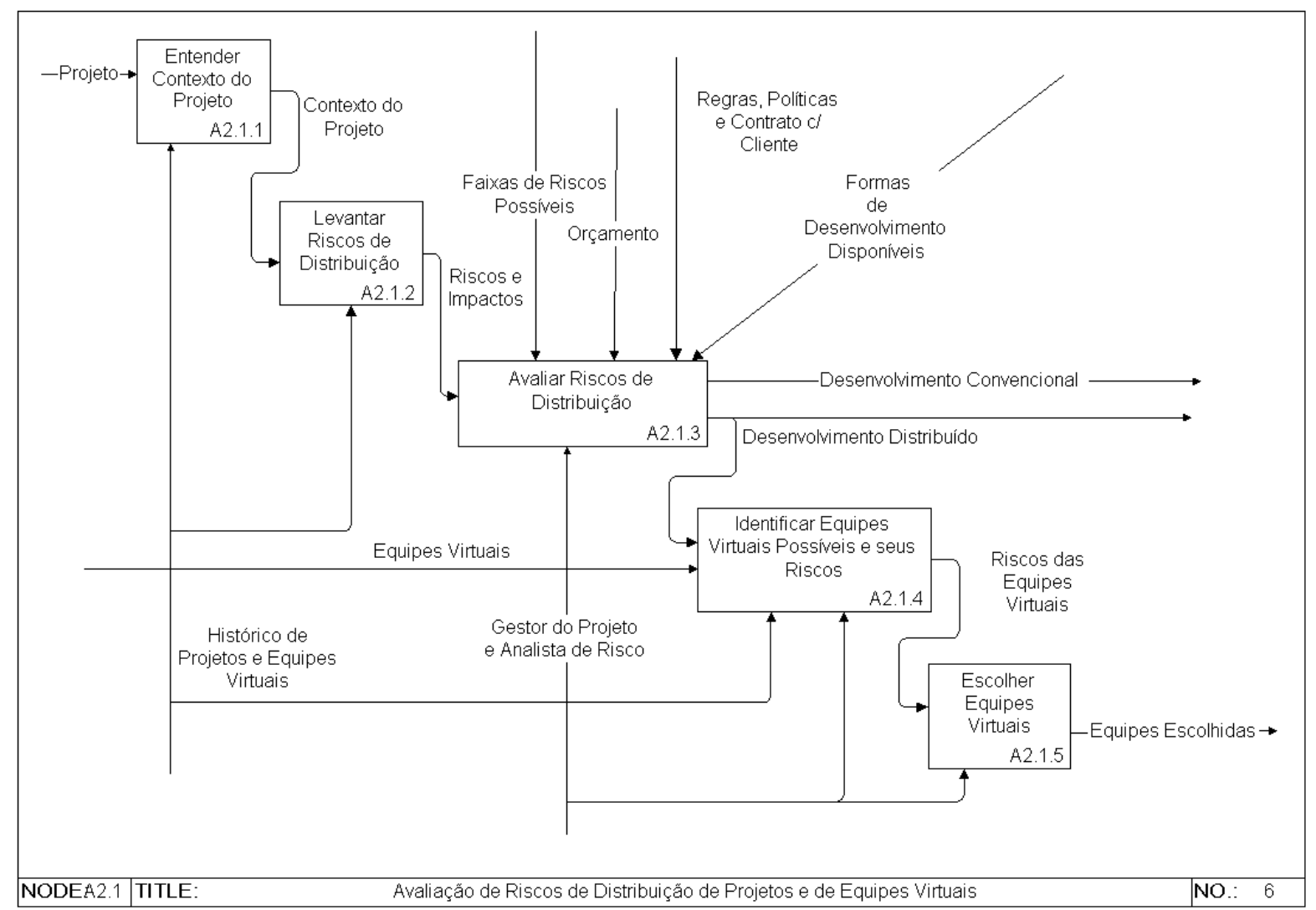

Figura 22. A2.1 - Avaliação de Riscos de Distribuição.

A primeira atividade a ser realizada é o entendimento do contexto do projeto. Esta atividade é realizada em conjunto pelo Gestor do Projeto e o Analista de Risco. Depois disto, eles buscam identificar os riscos de utilizar o GSD para o projeto. Para isso, acessam a Base de Conhecimento Colaborativo da Organização Virtual para identificação de histórico de 
outros projetos que foram desenvolvidos de forma distribuída e de Equipes Virtuais que participaram destes projetos.

Os seguintes tipos de riscos podem ser identificados, segundo Karolak (1998):

- Riscos organizacionais. Os riscos organizacionais envolvem a falta de atendimento dos membros dos projetos às regras e responsabilidades definidas pela Organização Virtual.

- Riscos técnicos. Os riscos técnicos envolvem possíveis problemas causados pelo não atendimento às metodologias, ferramentas e decisões de arquitetura e projeto tomadas pela Organização Virtual.

- $\quad$ Riscos de comunicação. Ocorrem devido a distância entre as equipes e por problemas de infra-estrutura de hardware, software e telecomunicações que causam mal entendidos e geram fluxo de informação incorreta.

Depois da identificação dos riscos e possíveis impactos, o Gestor do Projeto e o Analista de Riscos realizam uma avaliação dos riscos de utilização do GSD em relação às faixas de riscos aceitáveis definidas pelos interessados no projeto e com base no orçamento do projeto. Estas são algumas características de projetos e de Equipes Virtuais, segundo Karolak (1998) e Carmel (1999), que devem ser avaliadas:

- $\quad$ Segurança da informação.

- $\quad$ Prazo estipulado em contrato frente às estimativas de desenvolvimento.

- $\quad$ Conhecimento das Equipes Virtuais em relação às tecnologias do projeto.

- $\quad$ Conhecimento das equipes em relação ao assunto do projeto.

- $\quad$ Nível de acoplamento e integração entre os módulos funcionais do sistema.

- $\quad$ Perfil e custo das Equipes Virtuais envolvidas.

- $\quad$ Nível de complexidade do sistema. 
Caso o Gestor do Projeto e o Analista de Riscos optem pelo GSD, eles realizam a seleção das Equipes Virtuais que vão participar do projeto. Para isso, também acessam a Base de Conhecimento Colaborativo para identificação do histórico de Equipes Virtuais que participaram de outros projetos GSD.

Os riscos das Equipes Virtuais são identificados e avaliados para posteriormente fundamentar a seleção das Equipes Virtuais do projeto.

\subsubsection{Meta-Planejamento do Tempo do Projeto}

O subprocesso de Meta-Planejamento do Tempo do Projeto é inspirado no modelo MILOS proposto por Goldmann (1999a, 1999b, 1999c, 1999d, 2002). O objetivo deste subprocesso é permitir o planejamento e o replanejamento de tempo de um projeto de forma distribuída. Este se inicia depois da definição do Escopo do Projeto ou na necessidade de replanejamento ao longo do projeto e termina apenas quando o cronograma é aprovado pelo Gestor do Projeto e pelos Gestores de Equipes Virtuais. A Tabela 4 apresenta os atributos do subprocesso.

Tabela 4. Atributos do Meta Planejamento do Tempo do Projeto.

\begin{tabular}{|l|l|}
\hline Objetivos do subprocesso: & Planejar e replanejar prazo e cronograma do projeto. \\
\hline Limites do processo: & Início: Após a definição do Escopo do Projeto ou \\
& necessidade de replanejamento do projeto. \\
& $\begin{array}{l}\text { Fim: Após a aprovação do cronograma de planejamento } \\
\text { ou replanejamento pelo Gestor do Projeto e pelos } \\
\text { Gestores de Equipes Virtuais envolvidos. }\end{array}$ \\
\hline Indicadores de Desempenho: & $\begin{array}{l}\text { - Esforço dispendido em planejamento } \\
\text { - Esforço dispendido em replanejamento }\end{array}$ \\
\hline
\end{tabular}

O cronograma do projeto é desenvolvido de forma hierárquica. O Gestor do Projeto é o responsável pelo planejamento de primeiro nível onde, a partir da análise do Escopo do 
Projeto, os produtos a serem entregues são identificados e desmembrados. Para cada produto identificado, são identificadas as técnicas a serem utilizadas para o seu desenvolvimento. A partir disto, o Gestor do Projeto baseado em técnicas de planejamento, estima o esforço dos produtos a serem entregues, identifica o Gestor de Equipe Virtual responsável pelo desenvolvimento do produto e estima prazo e custo da atividade de elaboração do produto definido.

O Gestor de Equipe Virtual alocado para a atividade, realiza a verificação do planejamento da atividade. Caso concorde, ele aloca um analista da Equipe Virtual que desenvolverá o produto. Caso identifique que o "Prazo e o Esforço são Insuficientes", ele renegocia com o Gestor do Projeto novo replanejamento. Além disso, caso perceba que o produto a ser desenvolvido é um "Produto Composto", o processo de planejamento é reiniciado para o "Produto Composto" identificado. Ele desmembra o produto, seleciona técnicas de desenvolvimento, estima esforço, aloca recursos para a atividade de elaboração dos subprodutos e estima o esforço e prazo. Novamente, os recursos alocados devem revisar o planejamento.

Ao longo da execução do projeto, pode ser necessário alterar o planejamento de tempo do projeto. Neste caso, o processo de planejamento de tempo, descrito anteriormente, é executado novamente para as atividades que precisam ser revisadas. Os produtos são identificados, as técnicas de desenvolvimento revisadas e o esforço, os recursos, o prazo e o custo replanejados. Caso o planejamento deste subproduto impacte o cronograma do produto composto, o Gestor de Equipe Virtual deve renegociar o planejamento com o Gestor do Projeto.

A Figura 23 apresenta as atividades do subprocesso de Meta-Planejamento de Tempo do Projeto. 


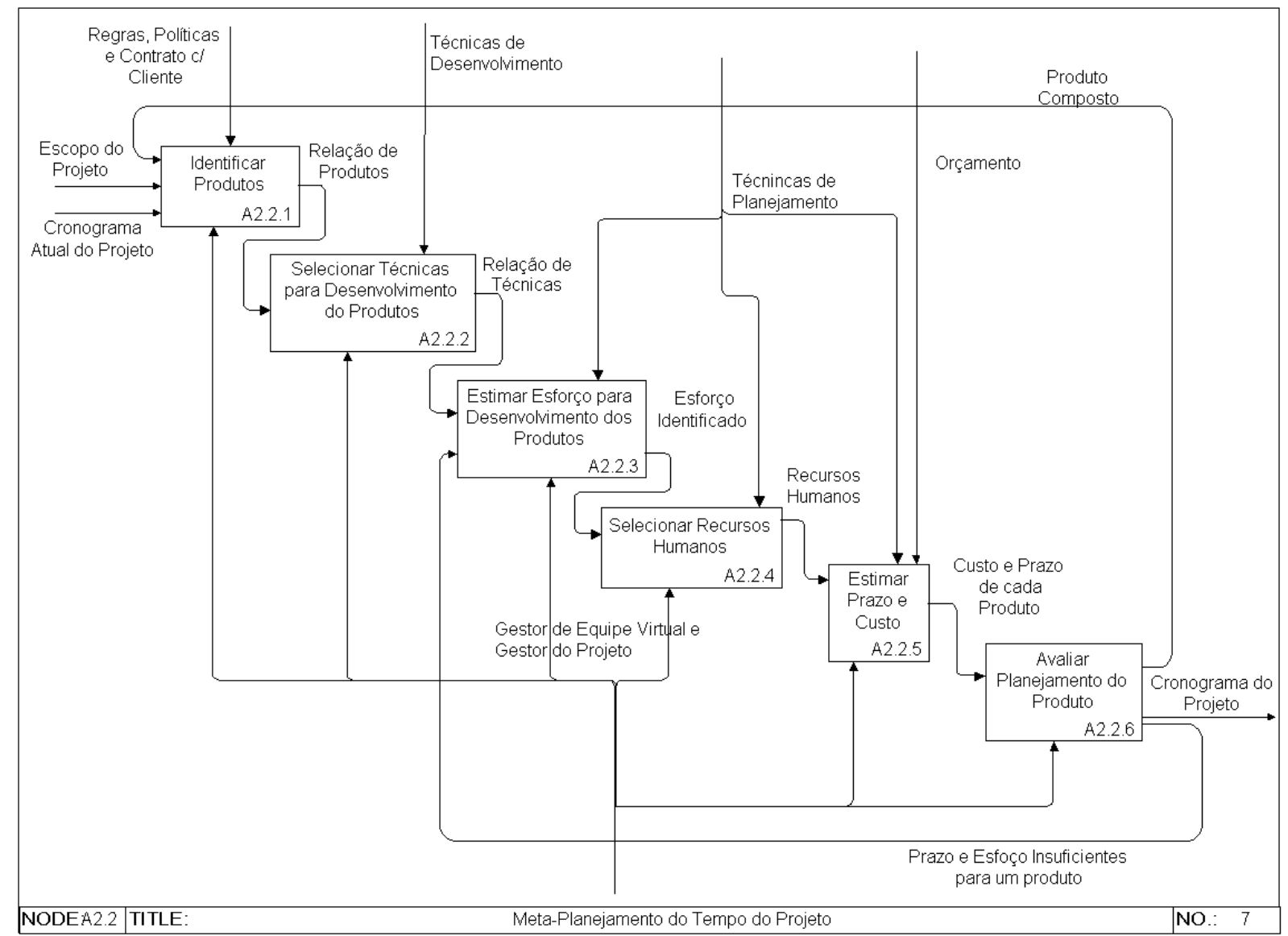

Figura 23. A2.2 - Meta-Planejamento do Tempo do Projeto.

\subsection{Processos de Execução}

Este item apresenta os subprocessos relacionados ao processo de Execução do ciclo de vida de projetos. Os seguintes subprocessos são descritos neste item:

- $\quad$ Gestão da Colaboração entre as Equipes Virtuais.

- $\quad$ Gestão do Conhecimento Colaborativo.

- $\quad$ Gestão do Ambiente Físico de Desenvolvimento Distribuído.

- $\quad$ Suporte ao Entendimento de Conceitos do Projeto.

- $\quad$ Gestão da Distribuição de Informações do Projeto.

Os subprocessos do processo de Execução ocorrem desde o início da execução do projeto até a sua conclusão. Estes são subprocessos de apoio e desta forma não tem uma sequiência de execução definida. A Figura 24 apresenta estes subprocessos e permite verificar 
que existe um grande relacionamento entre eles. A Visão Compartilhada do Projeto (descrita no item 4.8.4) é utilizada como controle dos outros subprocessos. O subprocesso de "Gestão da Distribuição de Informações do Projeto" é utilizado para a comunicação de qualquer informação gerada nos outros subprocessos que tenham importância para a Organização Virtual. O subprocesso de "Gestão da Colaboração entre as Equipes Virtuais" fornece requisitos de ferramentas para o subprocesso de "Gestão do Ambiente Físico de Desenvolvimento Distribuído". Por fim, o subprocesso de "Gestão do Conhecimento Colaborativo" fornece informações para composição da Visão Compartilhada do Projeto. Os subprocessos apresentados na Figura 24 são detalhados nos próximos itens.

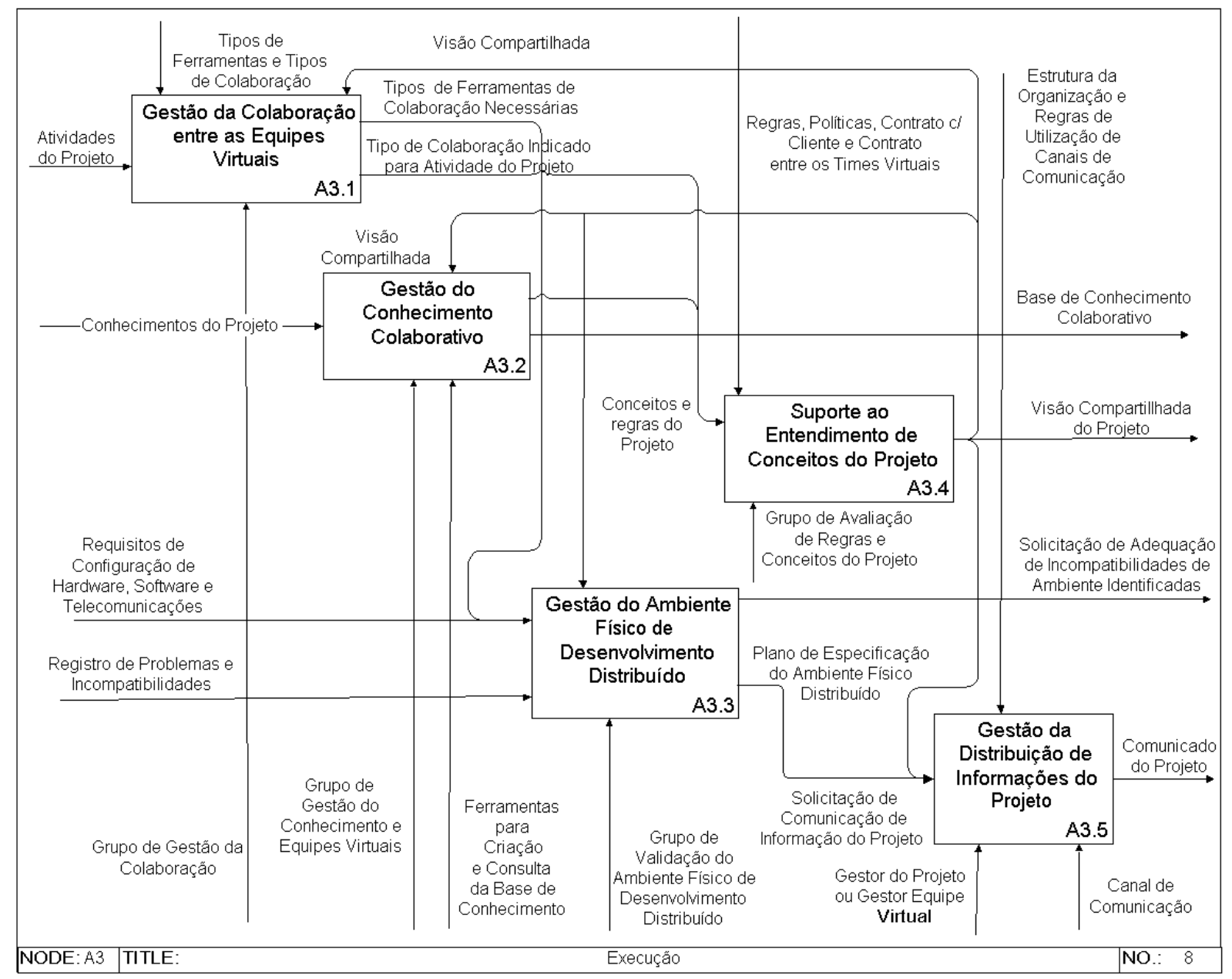

Figura 24. A3 - Execução. 


\subsubsection{Gestão da Colaboração entre as Equipes Virtuais}

O subprocesso de Gestão da Colaboração entre as Equipes Virtuais tem como objetivo gerenciar a colaboração necessária para as atividades de um projeto de modo a obter melhor produtividade e qualidade em sua execução. Este processo também é inspirado no modelo CPMA, proposto por Chen, Romano e Nunamaker (2002, 2003a, 2003b).

Em um projeto GSD as atividades demandam tipos de colaboração diferenciados. Uma atividade de elaboração da arquitetura de um sistema pode envolver especialistas de diferentes tipos de tecnologia interagindo com muita colaboração para a criação de uma arquitetura adequada às necessidades do projeto (colaboração sincronizada e conjunta). Enquanto que a codificação de um programa pode ser feita por apenas um programador, o que caracteriza um esforço individual. Desta forma, este subprocesso apresenta atividades para apoiar a identificação e definição dos tipos de colaboração necessários para cada atividade do projeto e também os tipos de ferramentas mais adequados a cada uma.

Além disso, ele também apóia na monitoração da colaboração das atividades do projeto de modo a melhorar a produtividade e qualidade das atividades através da alteração dos métodos e ferramentas de colaboração.

A Tabela 5 apresenta os atributos do subprocesso.

Tabela 5. Atributos da Gestão da Colaboração entre as Equipes Virtuais.

\begin{tabular}{|l|l|}
\hline Objetivos do subprocesso: & $\begin{array}{l}\text { Identificar e selecionar os tipos de colaboração e } \\
\text { ferramentas necessários para cada atividade do projeto e } \\
\text { monitorar a colaboração entre as equipes. }\end{array}$ \\
\hline Limites do processo: & $\begin{array}{l}\text { Início: Após o início do projeto. } \\
\text { Fim: Até o encerramento do projeto. }\end{array}$ \\
\hline Indicadores de Desempenho: & $\begin{array}{l}\text { - Esforço dispendido para análise, identificação e seleção } \\
\text { de ferramentas e métodos. } \\
\text { - Esforço dispendido para monitoração das atividades. }\end{array}$ \\
\hline
\end{tabular}


Esse subprocesso tem duas entradas: as atividades do projeto oriundas do plano detalhado do projeto e a produtividade e qualidade corrente das atividades do projeto. $\mathrm{O}$ subprocesso tem como objetivo analisar as atividades do plano de trabalho para identificar o melhor tipo de colaboração e tipos de ferramenta necessários para cada atividade. Além disso, também apóia na monitoração da produtividade e qualidade da execução das atividades de modo a identificar problemas e propor alterações na forma de colaboração e tipos de ferramenta para melhoria das atividades.

Esse subprocesso é apoiado pelo Grupo de Gestão de Colaboração que faz análises de acordo com os tipos de colaboração (esforço individual, coordenado e sincronizado e conjunto) e tipos de ferramentas existentes.

A Figura 25 apresenta o detalhamento do subprocesso "Gestão da Colaboração entre as Equipes Virtuais".

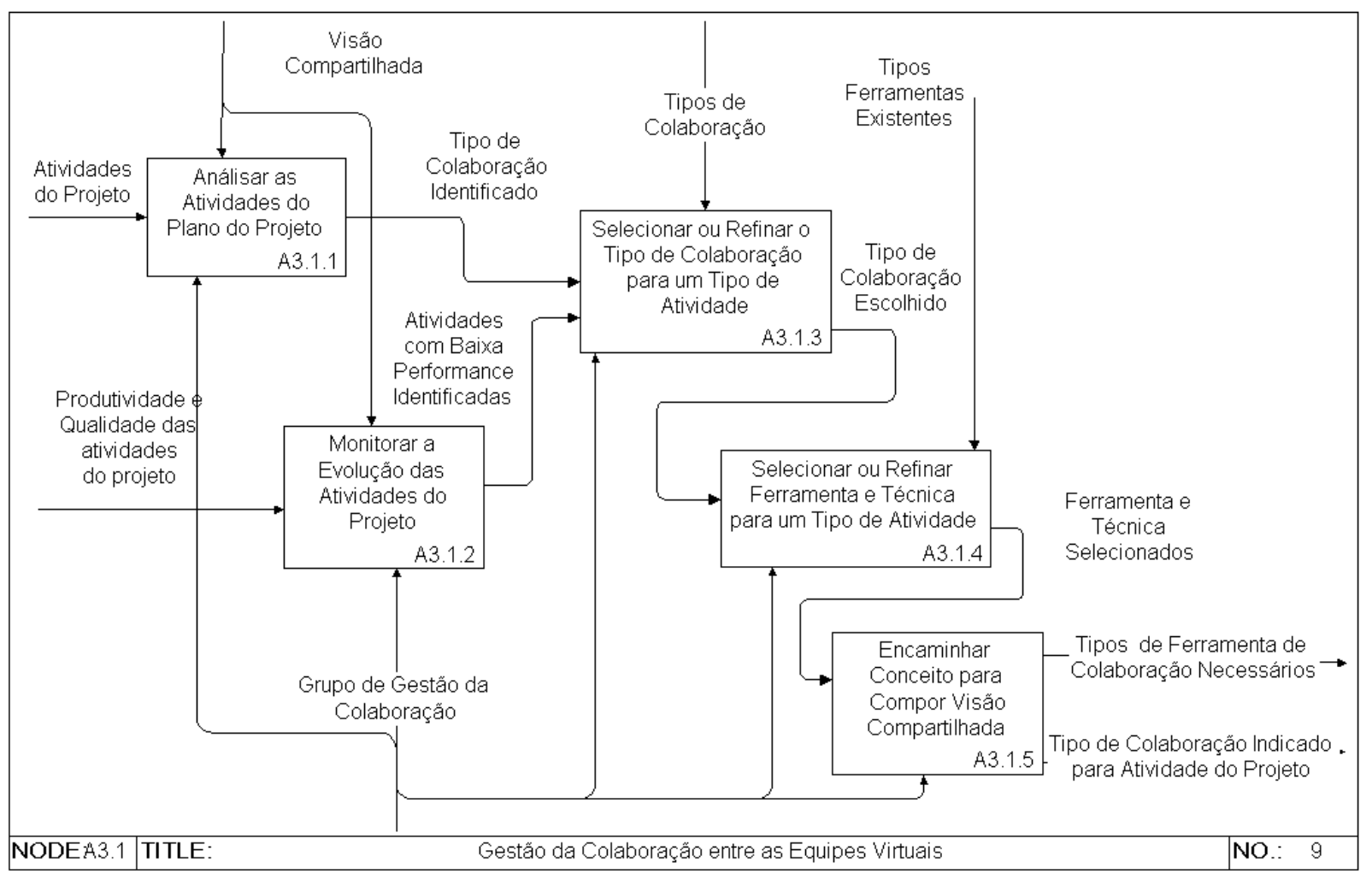

Figura 25. A3.1 - Gestão da Colaboração entre as Equipes Virtuais. 
Esse subprocesso possui dois principais objetivos. O primeiro é analisar as atividades do plano do projeto para identificar o tipo de colaboração necessário a cada uma e quais as ferramentas mais adequadas para essas atividades. Em projetos GSD existem alguns tipos de atividade que demandam uma maior colaboração entre os membros de uma Organização Virtual enquanto outras atividades demandam pouca ou nenhuma colaboração.

Em geral, atividades de elaboração de arquitetura, especificação de contrato de serviços e revisões de produtos do projeto demandam grande colaboração e desta forma apresentam melhor desempenho se apoiadas por ferramentas de colaboração (Exemplos: edição colaborativa de documentos, ferramentas para revisão colaborativa de produtos, sistemas para tele e áudio conferências, etc...). Por outro lado, atividades como levantamento de requisitos, codificação de programas e testes de sistemas demandam menor colaboração.

O segundo objetivo deste subprocesso é monitorar a produtividade, qualidade e progresso das atividades do projeto para identificar problemas provenientes de falta de colaboração. Desvios nos indicadores de produtividade, qualidade e progresso podem ter como causa problemas de colaboração em um projeto GSD. Desta forma, a monitoração dessas atividades tem como objetivo identificar quais precisam sofrer alteração do regime de colaboração (técnica e ferramenta).

Depois das atividades "Analisar as Atividades do Plano do Projeto" e "Monitorar a Evolução das atividades do Projeto", ocorre a atividade de seleção ou refinamento do tipo de colaboração necessário para a atividade do projeto. Em seguida, as ferramentas e técnicas mais adequadas são identificadas e então encaminhadas para compor a Visão Compartilhada do Projeto através do subprocesso de "Suporte ao Entendimento de Conceitos do Projeto" descrito no item 4.8.4. 


\subsubsection{Gestão do Conhecimento Colaborativo}

O subprocesso de "Gestão do Conhecimento Colaborativo" tem como objetivo armazenar experiências e conhecimentos a respeito de projetos GSD para reutilização de conhecimento em momentos futuros do próprio projeto ou em outros projetos. Este processo é indicado por vários autores em projetos tradicionais ou projetos GSD. Este processo é inspirado nos trabalhos de Chen, Romano e Nunamaker (2002, 2003a, 2003b), Zanoni e Audy (2003) e Prikladnicki e Audy (2002 2003).

O subprocesso de Gestão do Conhecimento Colaborativo ocorre durante todo o projeto, entretanto é mais utilizado durante a fase de Execução do projeto. Na Iniciação e Planejamento, a Base de Conhecimento Colaborativo é bastante consultada para identificação de informações e para simulação de cenários com objetivo de apoiar no planejamento do projeto. A Base de Conhecimento Colaborativo também é utilizada no subprocesso “Avaliação de Riscos de Distribuição de Projetos e Equipes Virtuais”, descrito no item 4.7.1.

O subprocesso de Gestão do Conhecimento Colaborativo também ocorre na fase de Encerramento do projeto, onde as lições aprendidas com o projeto são registradas. Durante a fase de Execução, entende-se que o processo de Gestão do Conhecimento Colaborativo é mais utilizado em virtude da grande quantidade de conhecimento acumulado.

O esforço dispendido para registro e armazenamento do conhecimento e a quantidade de conhecimentos armazenados ao longo do tempo são os indicadores de desempenho definidos para esse subprocesso. A Tabela 6 apresenta os atributos do subprocesso.

Tabela 6. Atributos da Gestão do Conhecimento Colaborativo.

\begin{tabular}{|l|l|}
\hline Objetivos do subprocesso: & $\begin{array}{l}\text { Armazenar experiências e conhecimentos a respeito de } \\
\text { projetos GSD para reutilização do conhecimento. }\end{array}$ \\
\hline Limites do processo: & Do início ao fim do projeto. \\
\hline Indicadores de Desempenho: & $\begin{array}{l}\text { - Esforço dispendido para gestão do conhecimento } \\
\text { - Quantidade de conhecimentos registrados ou revisados. }\end{array}$ \\
\hline
\end{tabular}


O subprocesso de Gestão do Conhecimento Colaborativo tem como entrada Conhecimentos do Projeto identificados pelas Equipes Virtuais. Estes conhecimentos ajudam a formar a Base de Conhecimento Colaborativo que é uma das saídas do subprocesso. Outra saída é o conjunto de conceitos identificados a partir da Base de Conhecimento que deve fazer parte também da Visão Compartilhada do Projeto. A Visão Compartilhada do Projeto é formada através do subprocesso de "Suporte ao Entendimento de Conceitos do Projeto" que é descrito no item 4.8.4.

Este subprocesso tem como controle a Visão Compartilhada do Projeto e como mecanismo de suporte o Grupo de Gestão do Conhecimento, os membros e envolvidos no projeto e ferramentas para criação, manutenção e consulta da Base de Conhecimento Colaborativo.

O subprocesso de Gestão do Conhecimento Colaborativo é composto por quatro atividades. A primeira atividade consiste em identificar conhecimentos do projeto. Esta pode ser feita através de pesquisas ou entrevistas com membros do projeto ou auditorias de produtos, ferramentas e processos de trabalho. O subprocesso também pode receber conhecimentos através de membros do projeto que registram conhecimentos em alguma ferramenta de captura.

Após isto, inicia-se uma atividade, pelo Grupo de Gestão do Conhecimento, de análise dos conhecimentos recebidos. Esta atividade tem como objetivo identificar se um determinado conhecimento é importante e se pode vir a ser utilizado em outros momentos ou em outros projetos. Além disso, esta atividade também permite identificar conceitos que podem fazer parte da Visão Compartilhada do Projeto. Os conhecimentos selecionados são registrados através de uma ferramenta de apoio à manutenção da Base de Conhecimento Colaborativo e desta forma podem ser consultados e utilizados por membros do próprio projeto ou de projetos futuros. 
A Figura 26 apresenta o detalhamento do subprocesso "Gestão do Conhecimento Colaborativo".

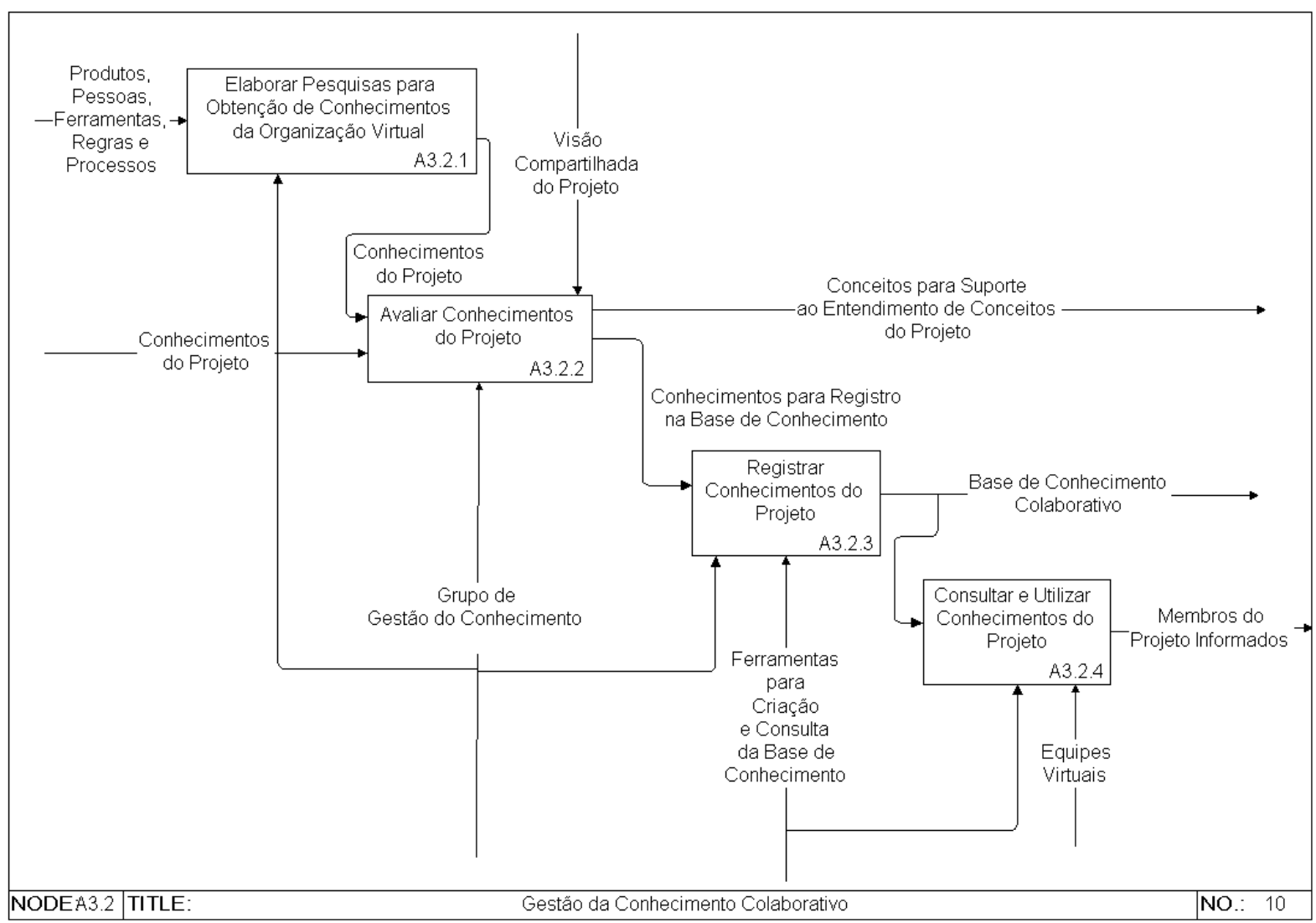

Figura 26. A3.2 - Gestão do Conhecimento Colaborativo.

\subsubsection{Gestão do Ambiente Físico de Desenvolvimento Distribuído}

O subprocesso de "Gestão do Ambiente Físico de Desenvolvimento Distribuído" tem como objetivo prover e manter uma infra-estrutura de software, hardware e telecomunicações de forma a garantir boa produtividade e colaboração entre as Equipes Virtuais da Organização Virtual.

Esse subprocesso é crítico em um ambiente GSD, pois se os ambientes distribuídos das Equipes Virtuais possuírem diferentes configurações e incompatibilidades de software e hardware, os problemas de comunicação são agravados e a atividade de integração pode ser 
inviabilizada. Esse processo é inspirado no modelo CMMI (2002) na área de processo de "Ambiente Organizacional para Integração".

Ele inicia-se durante o processo de Planejamento do ciclo de vida de projetos e ocorre durante todo o processo de Execução, suportando as atividades de desenvolvimento das Equipes Virtuais. Um possível indicador de desempenho deste subprocesso é o esforço dispendido na atividade de suporte e gestão ao ambiente físico distribuído. Outro indicador indireto é a quantidade de problemas ao longo do tempo, relacionada ao ambiente físico de desenvolvimento distribuído. Os seguintes problemas podem ser identificados: problemas de lentidão de comunicação entre as Equipes Virtuais, problemas de incompatibilidade de ferramenta ou versão de ferramenta de apoio ao desenvolvimento, incompatibilidades relacionadas a dispositivos de hardware, problemas de integração de componentes de software, etc. A Tabela 7 apresenta os atributos do subprocesso de Gestão do Ambiente Físico de Desenvolvimento Distribuído.

Tabela 7. Atributos da Gestão do Ambiente Físico de Desenv. Distribuído.

\begin{tabular}{|l|l|}
\hline Objetivos do subprocesso: & $\begin{array}{l}\text { Prover e manter uma infra-estrutura de software, } \\
\text { hardware e telecomunicações de forma a garantir uma } \\
\text { boa produtividade e colaboração entre as Equipes } \\
\text { Virtuais do projeto. }\end{array}$ \\
\hline Limites do processo: & $\begin{array}{l}\text { Início: No processo de Planejamento do ciclo de vida de } \\
\text { projetos. } \\
\text { Final: Até o encerramento do projeto. }\end{array}$ \\
\hline Indicadores de Desempenho: & $\begin{array}{l}\text { - Esforço dispendido na gestão do ambiente físico de } \\
\text { desenvolvimento distribuído. } \\
\text { - Problemas identificados, por unidade de tempo, } \\
\text { relacionados à incompatibilidade de ambientes físicos de } \\
\text { desenvolvimento distribuídos. }\end{array}$ \\
\hline
\end{tabular}

O principal objetivo deste subprocesso é elaborar um plano de especificação da infraestrutura física da Organização Virtual e monitorar essa infra-estrutura para verificação de sua adequação ao plano proposto. Este subprocesso tem duas entradas. A primeira entrada é um conjunto de requisitos de hardware, software e telecomunicações definidos em outros 
subprocessos, tais como, os tipos de ferramenta de colaboração necessários definidos no subprocesso de Gestão da Colaboração entre as Equipes Virtuais.

A segunda entrada é o conjunto de problemas e incompatibilidades identificados durante a execução do projeto e reportadas pelos membros das Equipes Virtuais. Este subprocesso tem como saída, um Plano de Especificação do Ambiente Físico de Desenvolvimento Distribuído que deve ser adotado por todas as Equipes Virtuais.

Esse subprocesso tem como principal direcionador a Visão Compartilhada do Projeto elaborada pelos membros da Organização Virtual.

O "Grupo de Validação do Ambiente Físico de Desenvolvimento Distribuído" atua como facilitador do subprocesso e a infra-estrutura existente na Organização Virtual também é um mecanismo de suporte para o subprocesso. A Figura 27 apresenta o detalhamento do subprocesso "Gestão do Ambiente Físico de Desenvolvimento Distribuído”.

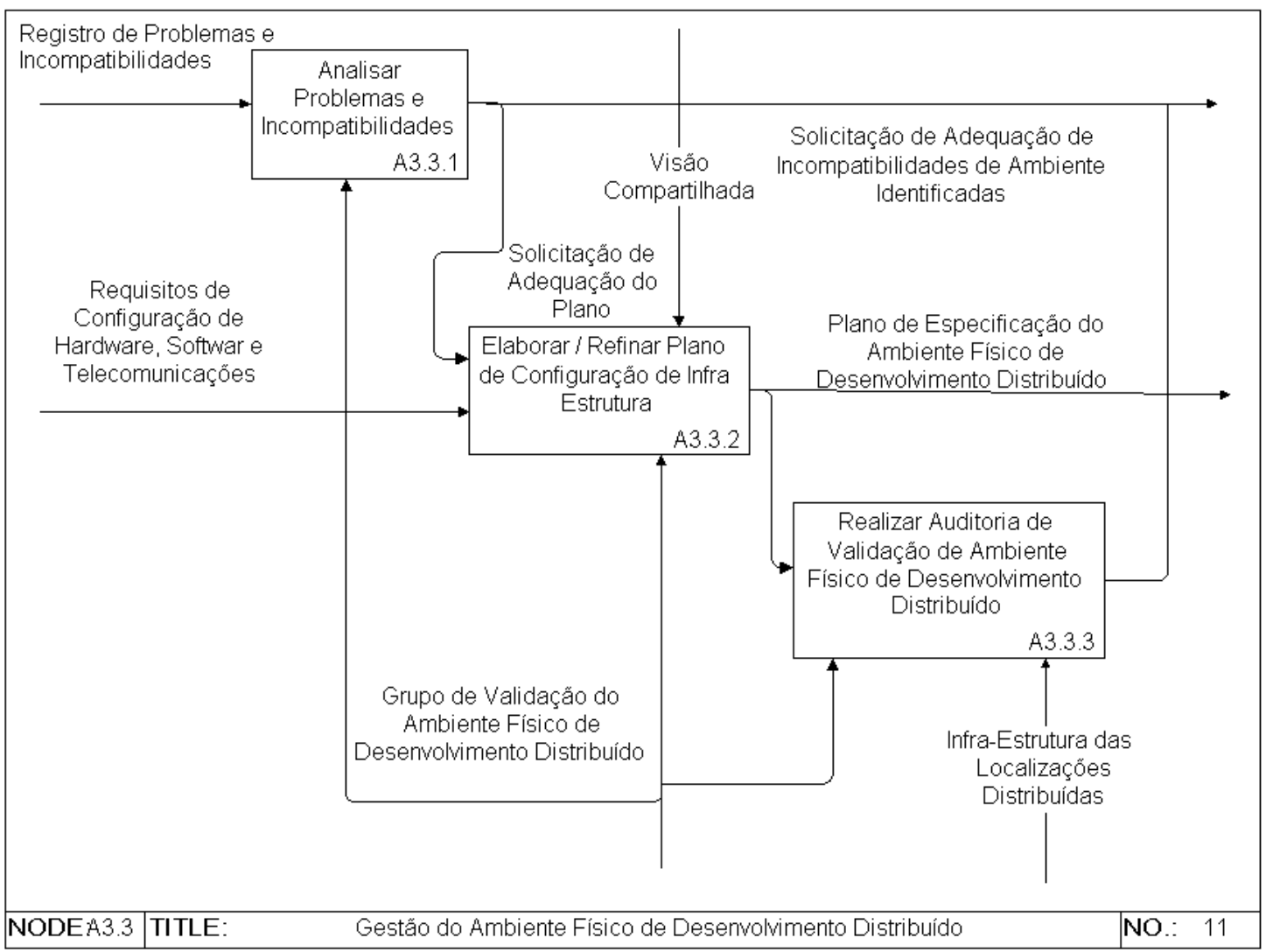

Figura 27. A3.3 - Gestão do Ambiente Físico de Desenvolvimento Distribuído. 
A primeira atividade tem como objetivo analisar problemas e incompatibilidades registrados por membros das Equipes Virtuais. Um problema ou incompatibilidade pode ser diagnosticado como uma configuração fora do padrão estabelecido. Desta forma, é gerada uma solicitação de adequação de um componente de um ou mais ambientes físicos distribuídos. Esta saída é entrada para o processo de "Gestão da Distribuição de Informações do Projeto" descrito no item 4.8.5. Caso o problema de incompatibilidade permita identificar um componente ou versão de componente mais adequado para a infra-estrutura da Organização Virtual, este pode ser incorporado ao Plano de Especificação do Ambiente Físico de Desenvolvimento Distribuído após uma análise de custo e benefício de adequação da infraestrutura. Em caso positivo, é gerada uma solicitação de adequação do Plano de Especificação do Ambiente Físico de Desenvolvimento Distribuído.

A segunda atividade consiste na elaboração ou refinamento do Plano de Especificação do Ambiente Físico de Desenvolvimento Distribuído. Este plano deve conter uma lista de todos os hardwares, aplicativos e ferramentas de suporte (CASE) e especificações de rede necessários para o ambiente físico distribuído. É possível coexistirem Equipes Virtuais com ferramentas ou versões diferentes de ferramentas, contanto que esteja descrito no plano as regras de conversão e mapeamento necessários para a integração dos produtos gerados.

Esse plano também deve conter um diagrama de topologia de rede no qual estão identificadas as Equipes Virtuais e os canais físicos de comunicação. Alterações no Plano de Especificação do Ambiente Físico de Desenvolvimento Distribuído devem ser comunicadas aos membros da Organização Virtual através do subprocesso Gestão da Distribuição de Informações do Projeto.

A última atividade do plano está associada à monitoração dos ambientes físicos de desenvolvimento distribuído para verificação de sua conformidade com as especificações do plano. Esta monitoração pode ser feita de forma centralizada através de ferramentas de 
monitoração e controle de componentes de rede. Além disso, membros do Grupo de Validação do Ambiente Físico de Desenvolvimento Distribuído também podem realizar localmente testes e validação da compatibilidade dos componentes dos ambientes físicos distribuídos. A forma de condução destas auditorias depende de cada Organização Virtual que pode ter um grupo centralizado ou então grupos distribuídos. Esses grupos devem consolidar relatórios de problemas e incompatibilidades identificados e solicitar a adequação através do processo de Gestão da Distribuição de Informações do Projeto.

\subsubsection{Suporte ao Entendimento de Conceitos do Projeto}

O subprocesso de Suporte ao Entendimento de Conceitos do Projeto é inspirado no conceito de Visão Compartilhada do CMMI (2002) e no processo de Suporte à Presença do modelo CPMA proposto por Chen, Romano e Nunamaker (2002, 2003a, 2003b). O objetivo desse subprocesso é criar uma visão comum de regras e conceitos importantes a serem seguidos e utilizados no projeto que é chamada neste trabalho de Visão Compartilhada do Projeto.

A Visão Compartilhada do Projeto é composta pela missão, políticas, metas e objetivos da Organização Virtual. Além disso, também descreve regras de conduta, convivência e interação entre os membros das Equipes Virtuais. Ela também é alimentada ao longo do projeto pelos membros do projeto com conceitos e definições importantes a respeito de características do projeto e do produto a ser entregue no final do projeto.

A Visão Compartilhada do Projeto é um artifício importante para o comum entendimento dos objetivos da Organização Virtual e do projeto e permite que os membros das Equipes Virtuais possam ter uma maior sinergia na execução do projeto, diminuindo os atritos e mal entendidos entre as equipes. Ela deve refletir primeiramente as regras e restrições 
impostas pelo contrato com o cliente e também as regras e políticas acordadas entre as Equipes Virtuais e a Organização Responsável pelo Contrato. A Tabela 8 apresenta os atributos do subprocesso "Suporte ao Entendimento de Conceitos do Projeto".

Tabela 8. Atributos do Suporte ao Entendimento de Conceitos do Projeto.

\begin{tabular}{|l|l|}
\hline Objetivos do subprocesso: & $\begin{array}{l}\text { Suportar o entendimento das principais regras e conceitos } \\
\text { do projeto através da elaboração, refinamento e } \\
\text { divulgação da Visão Compartilhada do Projeto. }\end{array}$ \\
\hline Limites do processo: & $\begin{array}{l}\text { Início: Após o início do projeto. } \\
\text { Fim: Até o encerramento do projeto. }\end{array}$ \\
\hline Indicadores de Desempenho: & $\begin{array}{l}\text { - Esforço dispendido para elaboração e manutenção da } \\
\text { Visão Compartilhada do Projeto. } \\
\text { - Quantidade de conceitos e regras definidos. }\end{array}$ \\
\hline
\end{tabular}

O subprocesso tem como entrada conceitos e regras do projeto descritos por membros do projeto e por interessados no projeto (cliente e patrocinador). As Equipes Virtuais e membros do projeto também são considerados entrada para o subprocesso, pois são transformados pelo processo. Espera-se que eles tenham um maior entendimento das regras e conceitos ao longo do projeto.

A Visão Compartilhada do Projeto é saída do subprocesso de Suporte ao Entendimento de Conceitos do Projeto. Os mecanismos de suporte do subprocesso são: ferramenta para gestão e divulgação dos conceitos; membros do projeto e Grupo de Avaliação de Regras e Conceitos. Os controles do subprocesso são: Contrato com o Cliente e Contrato com as Equipes Virtuais.

A Figura 28 apresenta o detalhamento do subprocesso "Suporte ao Entendimento dos Conceitos do Projeto". 


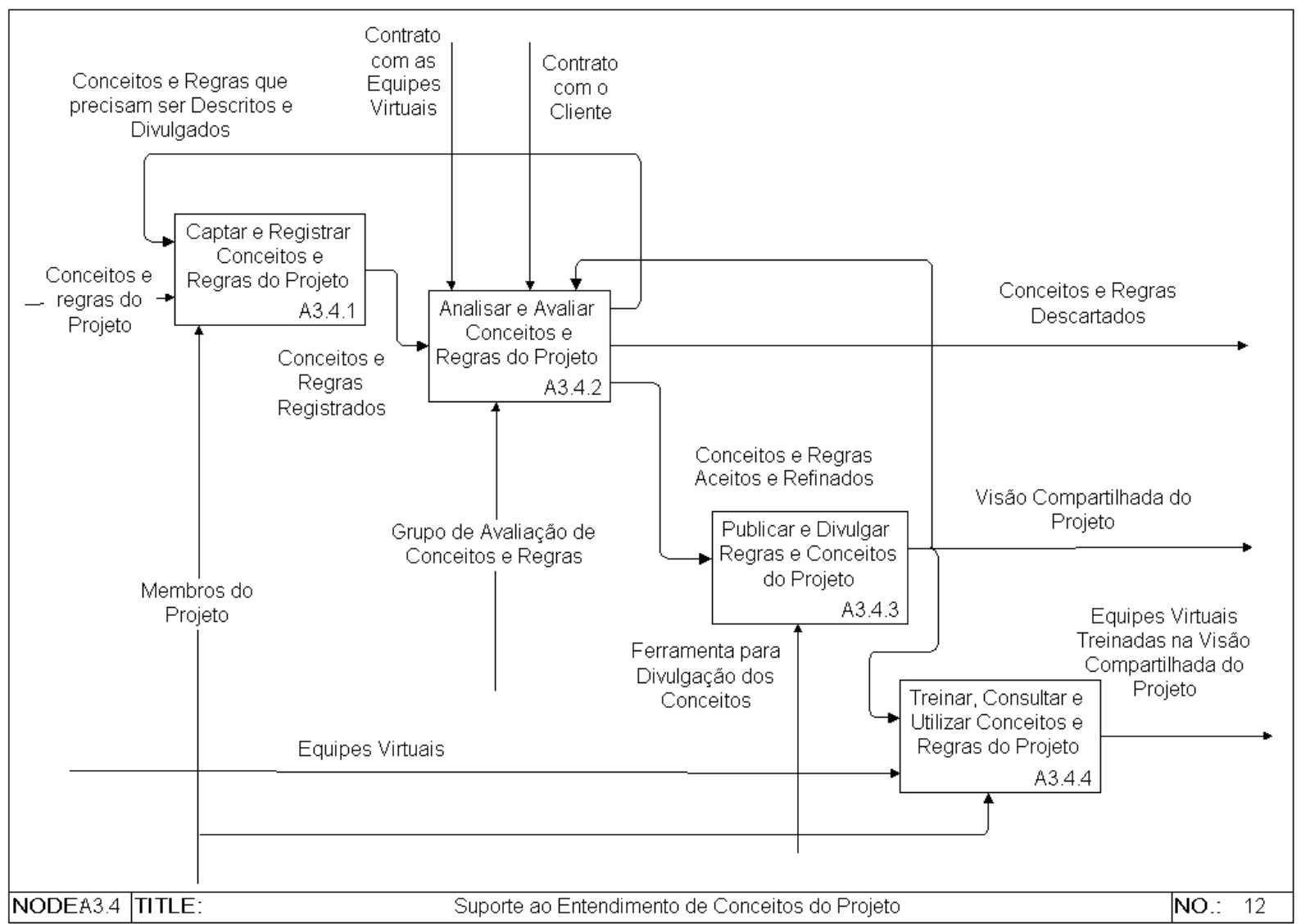

Figura 28. A3.4 - Suporte ao Entendimento de Conceitos do Projeto.

Esse subprocesso possui dois principais objetivos. O primeiro objetivo é analisar e validar conceitos e regras definidos e captados pela equipe de projeto de modo a respeitar as condições impostas pelos contratos existentes e também as definições já existentes na Visão Compartilhada do Projeto.

O segundo objetivo é identificar conceitos e regras que precisam ser definidos para melhorar o entendimento comum dos membros da Organização Virtual.

A primeira atividade é utilizada para registro de regras e definições pelos membros do projeto. A princípio, qualquer membro do projeto pode registrar um Conceito do Projeto.

Conceitos registrados são submetidos a um Grupo de Avaliação de Conceitos e Regras que analisa os conceitos contra os contratos existentes e também com relação à própria Visão Compartilhada do Projeto. Esse grupo pode elaborar fóruns para discussão de conceitos e regras submetidos se necessário. Além de analisar conceitos submetidos, esse grupo também 
pode propor a definição de conceitos e regras com base em discussões a respeito de temas entre membros do projeto. Após a validação de um conceito, esse é publicado e divulgado através de ferramentas de colaboração e divulgação através do subprocesso de "Gestão da Distribuição de Informações do Projeto", descrito no item 4.8.5.

A partir da divulgação e publicação, membros do projeto podem ser treinados com base na Visão Compartilhada do Projeto, além de consultar e utilizar as regras e conceitos definidos quando necessário.

\subsubsection{Gestão da Distribuição de Informações do Projeto}

O subprocesso de Gestão da Distribuição de Informações do Projeto é baseado nos seguintes modelos de gestão de projetos: CPMA, proposto por Chen, Romano e Nunamaker (2002, 2003a, 2003b), MuNDDoS, proposto por Zanoni e Audy (2003) e Prikladnicki e Audy (2002, 2003), MILOS, proposto por Goldmann (1999a, 1999b, 1999c, 1999d, 2002) e PMBoK (2000). O subprocesso garante uma comunicação eficaz de informações do projeto e também a integridade da comunicação auxiliando a colaboração, integração e coordenação. Esse subprocesso, além de centralizar a análise e distribuição das informações, também auxilia na identificação de informações necessárias ainda não comunicadas e divulgadas.

A Tabela 9 apresenta os atributos do subprocesso.

Tabela 9. Atributos da Gestão da Distribuição de Informações do Projeto.

\begin{tabular}{|l|l|}
\hline Objetivos do subprocesso: & $\begin{array}{l}\text { Analisar e distribuir as informações do projeto. } \\
\text { Monitorar a comunicação e identificar informações } \\
\text { carentes. }\end{array}$ \\
\hline Limites do processo: & $\begin{array}{l}\text { Início: Necessidade de comunicação. } \\
\text { Fim: No encerramento do projeto.Monitoração contínua } \\
\text { durante o projeto. }\end{array}$ \\
\hline Indicadores de Desempenho: & $\begin{array}{l}\text { - Quantidade de comunicações por período. } \\
\text { - Tempo para comunicação de informação. }\end{array}$ \\
\hline
\end{tabular}


O principal objetivo deste subprocesso é suportar a comunicação do projeto de tal forma que as informações que são comunicadas sejam confiáveis e que todas as comunicações necessárias sejam realizadas. A Figura 29 apresenta o detalhamento do subprocesso.

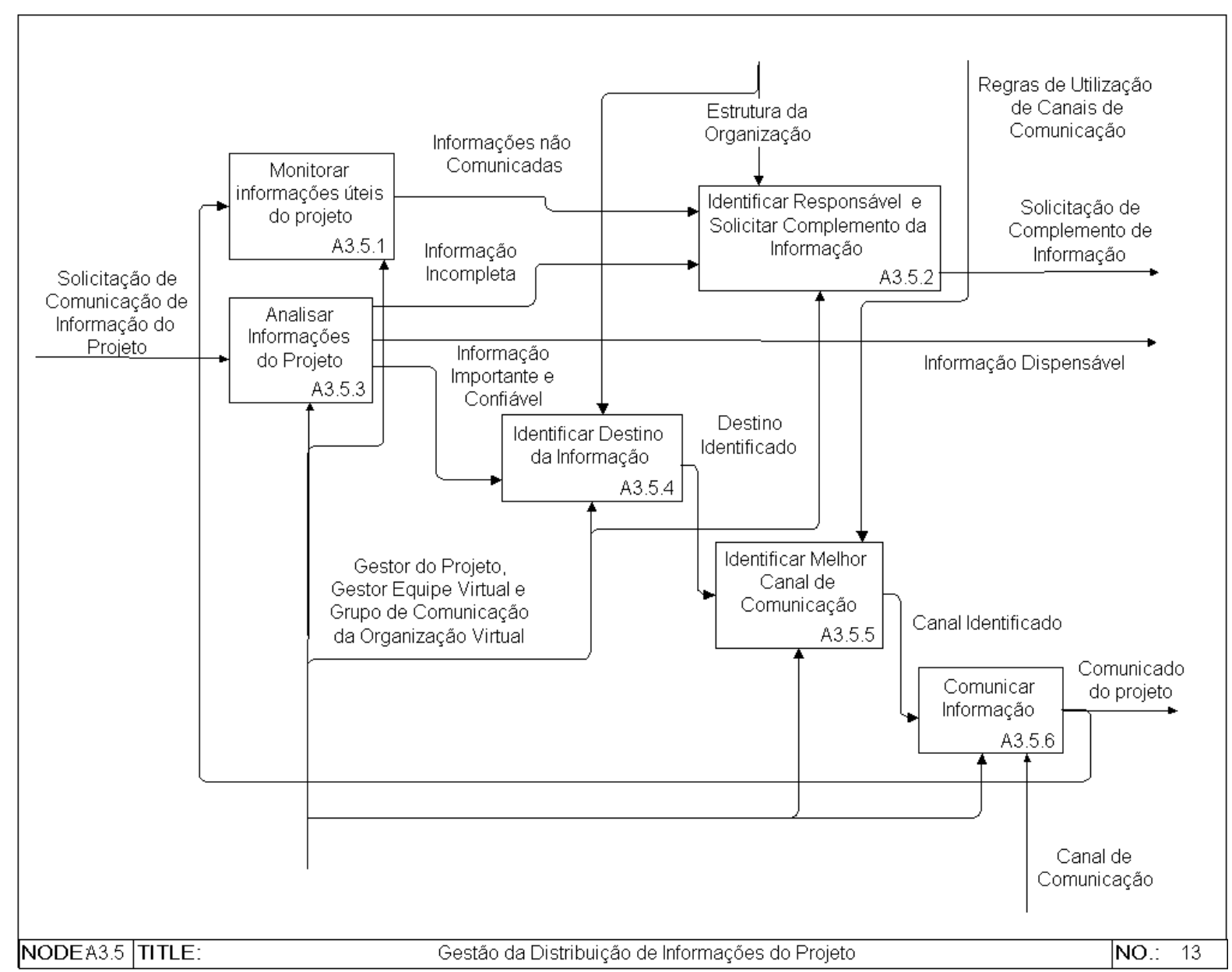

Figura 29. A3.5 - Gestão da Distribuição de Informações do Projeto.

A estratégia utilizada para garantir os objetivos descritos anteriormente é composta de duas atividades principais. A validação das informações recebidas e a monitoração de informações não divulgadas para as Equipes Virtuais da Organização Virtual.

Após o recebimento de uma informação do projeto, o Gestor do Projeto, o Gestor da Equipe Virtual e o Grupo de Comunicação da Organização Virtual devem analisar e checar a informação recebida de forma a garantir a confiabilidade da informação. Após essa validação, os destinatários das informações e o canal de informação a ser utilizado (este depende das 
regras de utilização de canais de comunicação que variam com tipo de informação e prioridade) são identificados. Por fim executa-se a comunicação.

Paralelamente, deve-se realizar um acompanhamento das comunicações que estão sendo executadas. Informações importantes do projeto que não são comunicadas devem ser identificadas e então requisitadas.

\subsection{Processos de Acompanhamento}

Este item apresenta os subprocessos relacionados ao processo de Acompanhamento do ciclo de vida de projetos. Os seguintes subprocessos são descritos nos próximos itens:

- $\quad$ Controle de Mudança de Escopo.

- $\quad$ Controle de Cronograma do Projeto.

A Figura 30 apresenta os subprocessos do processo de Acompanhamento.

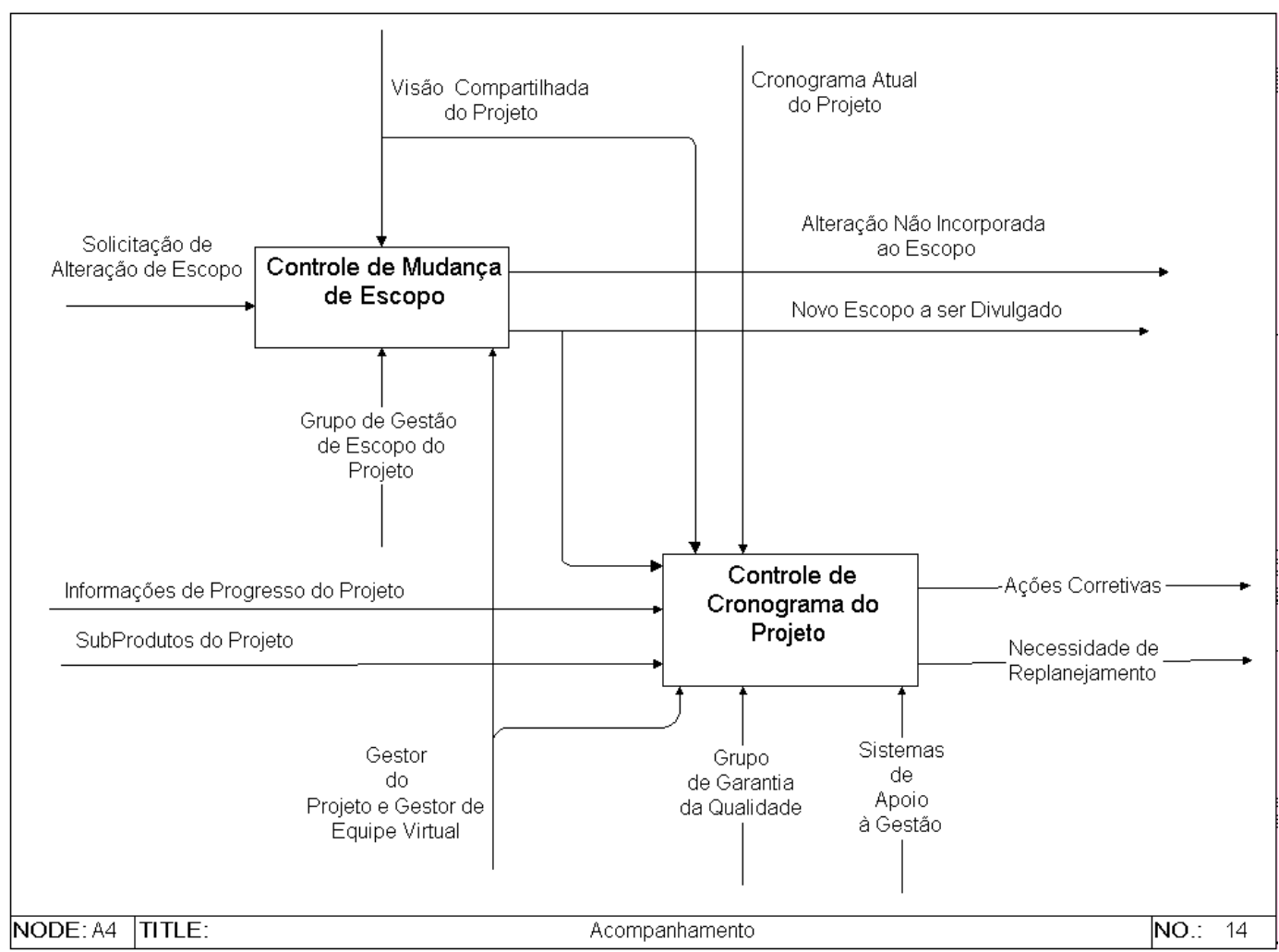

Figura 30. A4 - Acompanhamento. 
O processo de Acompanhamento é composto por dois subprocessos que são realizados em paralelo conforme necessidade do projeto. O subprocesso de "Controle de Mudança de Escopo" tem como objetivo identificar e gerenciar mudanças de Escopo do Projeto. O Novo Escopo a ser Divulgado é uma saída desse processo e também é entrada para o subprocesso de "Controle de Cronograma do Projeto".

O objetivo do "Controle de Cronograma do Projeto" é acompanhar e monitorar o progresso do projeto para dar visibilidade aos envolvidos no projeto e também fornecer subsídios para tomada de ações corretivas e replanejamento do projeto. Os próximos itens descrevem detalhadamente estes subprocessos.

\subsubsection{Controle de Mudança de Escopo}

O subprocesso de "Controle de Mudança de Escopo" tem como objetivo analisar solicitações de alteração de escopo de forma a garantir uma evolução adequada do Escopo do Projeto. A importância desse subprocesso, em um ambiente GSD, é o fato de que existem Equipes Virtuais trabalhando em paralelo e uma mudança de escopo pode significar grande retrabalho.

Além disso, alterações de escopo aprovadas devem ser divulgadas de forma rápida para todas as Equipes Virtuais evitando problemas de comunicação. Este subprocesso é inspirado na atividade de controle de alteração de escopo da área de conhecimento de Gerenciamento de Escopo do modelo PMBoK (2000).

Este subprocesso inicia-se após a definição inicial do Escopo do Projeto durante o processo de planejamento do ciclo de vida de projetos e ocorre durante o processo de monitoração da execução do projeto até o seu encerramento. $\mathrm{O}$ primeiro indicador de desempenho proposto é o esforço dispendido na atividade de controle de alteração de escopo. 
Outro indicador proposto é a quantidade de alterações incorporadas e não incorporadas ao escopo, o que denota o nível de estabilização dos requisitos do projeto.

A Tabela 10 apresenta os atributos do subprocesso de Controle de Mudança de Escopo.

Tabela 10. Atributos do Controle de Mudança de Escopo.

\begin{tabular}{|l|l|}
\hline Objetivos do subprocesso: & $\begin{array}{l}\text { Analisar solicitações de alteração de escopo de forma a } \\
\text { garantir uma evolução adequada do Escopo do Projeto. }\end{array}$ \\
\hline Limites do processo: & $\begin{array}{l}\text { Início: Após o processo de Planejamento do ciclo de vida } \\
\text { de projetos. }\end{array}$ \\
& Fim: Até o encerramento do projeto. \\
\hline Indicadores de Desempenho: & $\begin{array}{l}\text { - Esforço dispendido na gestão de mudança de escopo } \\
\text { - Quantidade alterações incorporadas e não incorporadas } \\
\text { por unidade de tempo. }\end{array}$ \\
\hline
\end{tabular}

A entrada para execução deste subprocesso é uma Solicitação de Alteração de Escopo. Uma Solicitação de Alteração de Escopo pode ser feita por um cliente do projeto ou então por algum membro de uma Equipe Virtual que perceba que a implementação de uma determinada regra de negócio não foi detalhada o suficiente e que apresenta impactos em outras funcionalidades do projeto.

As solicitações de alteração de escopo podem ou não ser incorporadas ao Escopo do Projeto. Caso sejam incorporadas, um novo Escopo do Projeto é elaborado e constitui uma saída deste subprocesso. Este subprocesso ainda tem como controle a Visão Compartilhada do Projeto e como mecanismo de suporte o cliente, os envolvidos no projeto, o Gestor do Projeto e Gestores de Equipe Virtual.

A Figura 31 apresenta o detalhamento do subprocesso. 


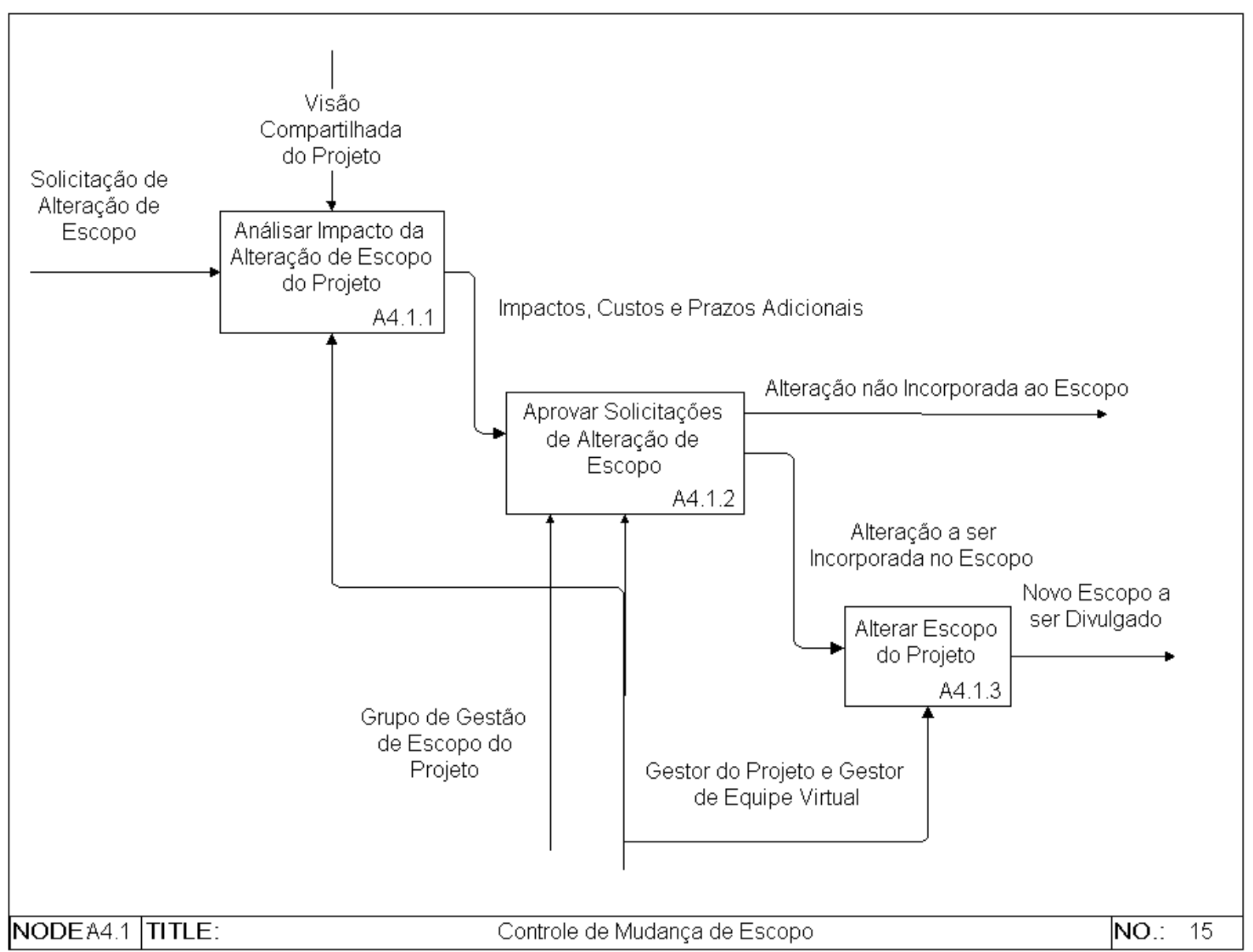

Figura 31. A4.1 - Controle de Mudança de Escopo.

O subprocesso de Controle de Mudança de Escopo possui três atividades. A atividade inicial consiste em analisar o impacto das solicitações de alteração de escopo. Dependendo do estágio de desenvolvimento do projeto, uma alteração de escopo pode ter impactos bastante significativos. De modo geral quanto mais evoluído, maiores são as conseqüências.

Qualquer alteração precisa passar por uma análise de impacto que tem como objetivo identificar a dificuldade de adequação dos produtos, subsistemas e funcionalidades impactados pela alteração. As Equipes Virtuais do projeto, responsáveis pelos componentes, devem ser envolvidas para avaliação destas questões. Os impactos nos custos e prazos do projeto devem ser identificados. 
Posteriormente, devem-se aprovar as solicitações de alteração do Escopo do Projeto. A aprovação será feita por um conjunto de envolvidos e membros do projeto que compõe o Grupo de Gestão de Escopo do Projeto.

Por fim, a última atividade envolve a revisão do Escopo do Projeto. Este novo Escopo do Projeto demanda alterações nos planos do projeto e deve ser divulgado e comunicado aos interessados no projeto conforme subprocesso de "Gestão da Distribuição de Informações do Projeto", descrito no item 4.8.5. As alterações no Escopo do Projeto também constituem uma entrada para o subprocesso de "Meta-Planejamento do Tempo do Projeto", descrito no item 4.7.2.

\subsubsection{Controle de Cronograma}

O subprocesso "Controle de Cronograma" tem como objetivo controlar e acompanhar o progresso de um projeto de forma a garantir o cumprimento do cronograma acordado. Em um contexto GSD, a distância imposta aumenta a dificuldade de obtenção de informações precisas a respeito do progresso do projeto. Desta forma, atividades de auditoria para validação de progresso apontado para uma atividade do projeto devem ser conduzidas. O subprocesso de "Controle de Cronograma" é baseado na atividade de controle de cronograma do PMBoK (2000) e também no modelo MILOS proposto por Goldmann et al. (1999a, 1999b, 1999c, 1999d, 2002).

Este subprocesso inicia-se após a elaboração do cronograma do projeto na fase de Planejamento do ciclo de vida de projetos e ocorre durante o processo de monitoração da execução do projeto até o seu encerramento. Normalmente, o controle de cronograma ocorre periodicamente em um projeto, conforme o prazo e criticidade do projeto. 
O primeiro indicador de desempenho proposto é o esforço dispendido na atividade de controle de cronograma. Outro indicador proposto é a quantidade de ações corretivas e a quantidade de alterações do cronograma (prazo ou esforço).

A Tabela 11 apresenta os atributos do subprocesso Controle de Cronograma.

Tabela 11. Atributos do Controle de Cronograma.

\begin{tabular}{|l|l|}
\hline Objetivos do subprocesso: & $\begin{array}{l}\text { Controlar e acompanhar o progresso de um projeto de } \\
\text { forma a garantir o cumprimento do cronograma } \\
\text { acordado. }\end{array}$ \\
\hline Limites do processo: & $\begin{array}{l}\text { Início: Após o processo de Planejamento do ciclo de vida } \\
\text { de projetos. } \\
\text { Fim: Até o encerramento do projeto. }\end{array}$ \\
\hline Indicadores de Desempenho: & $\begin{array}{l}\text { - Esforço dispendido no controle de cronograma. } \\
\text { - Quantidade ações corretivas geradas. } \\
\text { - Quantidade de alterações no cronograma. }\end{array}$ \\
\hline
\end{tabular}

O Controle de Cronograma do projeto tem como entrada informações de progresso, subprodutos e atividades concluídas do projeto. As informações de progresso do projeto podem ser obtidas através de sistemas de gestão de projetos ou de reportes feitos pelas Equipes Virtuais.

As saídas do processo são ações corretivas a serem tomadas para adequação ao cronograma e necessidade de replanejamento do cronograma do projeto identificada.

Este subprocesso tem como controle a Visão Compartilhada do Projeto e como mecanismo de suporte o Grupo de Garantia da Qualidade, o Gestor do Projeto, o Gestor de Equipe Virtual, sistemas e ferramentas de apoio à gestão de projetos.

A Figura 32 apresenta o detalhamento do subprocesso de Controle de Cronograma. 


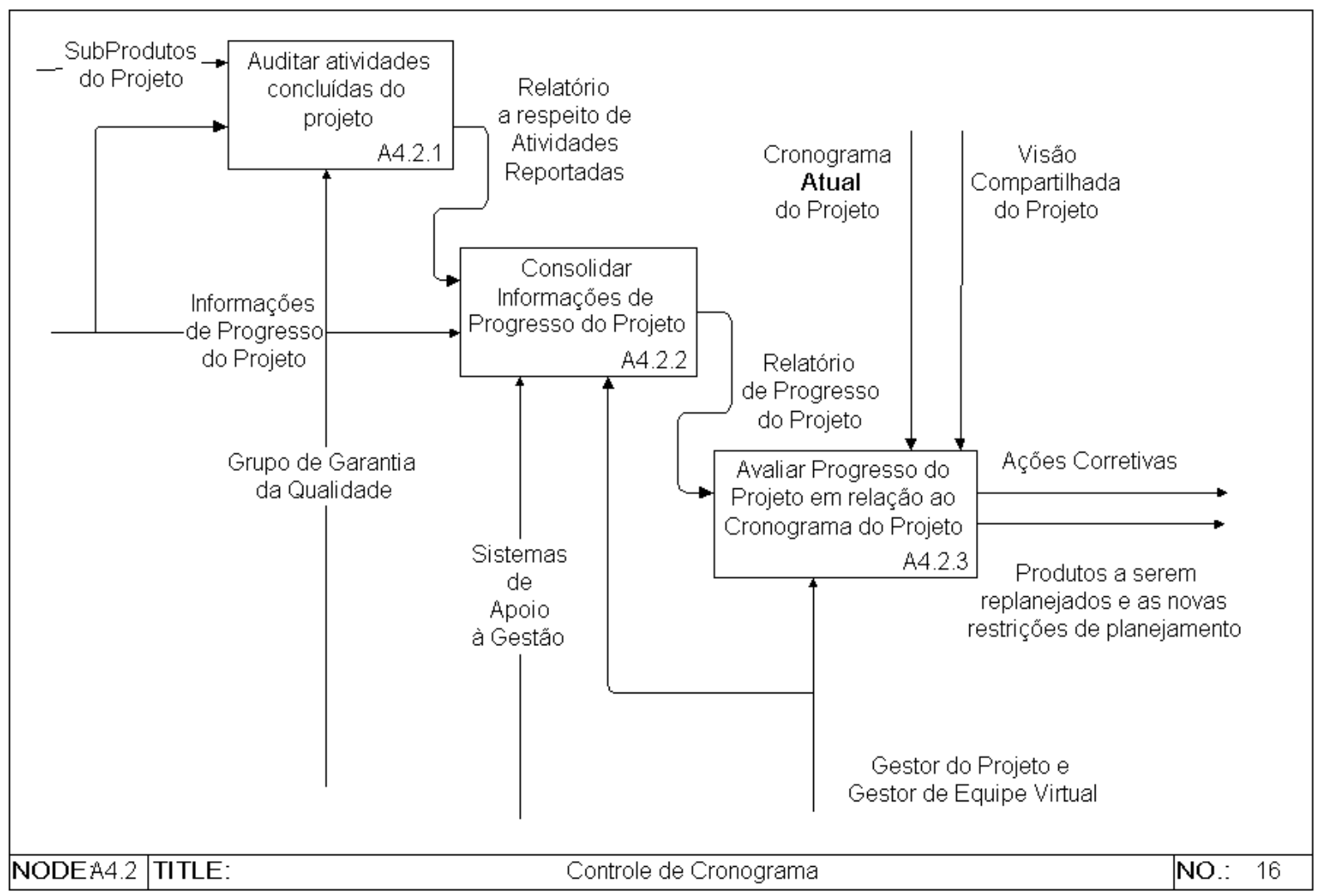

Figura 32. A4.2 - Controle de Cronograma.

O subprocesso de Controle de Cronograma do projeto é composto por três atividades. A atividade de auditoria de atividades concluídas do projeto tem como objetivo verificar e validar se uma atividade foi realmente concluída ou se foi reportada de forma errada. Esta atividade não é executada para todas as atividades concluídas do projeto, mas de forma eventual e por amostragem conforme necessidades do projeto.

O relatório de auditoria a respeito de atividades do projeto e informações de progresso obtidas de sistemas ou reporte de equipes virtuais são consolidadas para geração de um relatório de progresso do projeto.

Depois disso, a atividade seguinte tem como objetivo avaliar o resultado esperado do projeto (cronograma atual) em relação ao progresso aferido. Nesta, os desvios são identificados, os problemas ocorridos são discutidos e as medidas necessárias para adequação do progresso do projeto são identificadas. 
As ações podem ser de dois tipos: ações corretivas e replanejamentos. As ações corretivas pressupõem que o planejamento é mantido (prazo e escopo) e que se deve alterar o esforço ou a produtividade para atingir o planejamento atual. Exemplos: contratar mais recursos, automatizar partes da atividade, melhorar processos de apoio para aumento da produtividade, etc.

As atividades de replanejamento pressupõem alterar o escopo (diminuir funcionalidades) ou aumentar o prazo de uma atividade. Esta ação envolve o replanejamento do cronograma do projeto. Esta saída do subprocesso de Controle de Cronograma é entrada para o subprocesso de Meta-Planejamento do Tempo do Projeto, descrito no item 4.7.2, que irá gerar o novo cronograma do projeto.

\subsection{Processos de Encerramento}

Este item apresenta o subprocesso relacionado ao processo de Encerramento do ciclo de vida de projetos. O seguinte subprocesso é descrito neste item:

- $\quad$ Encerramento do Projeto.

A Figura 33 apresenta o detalhamento do processo de Encerramento que é composto por apenas um subprocesso. 


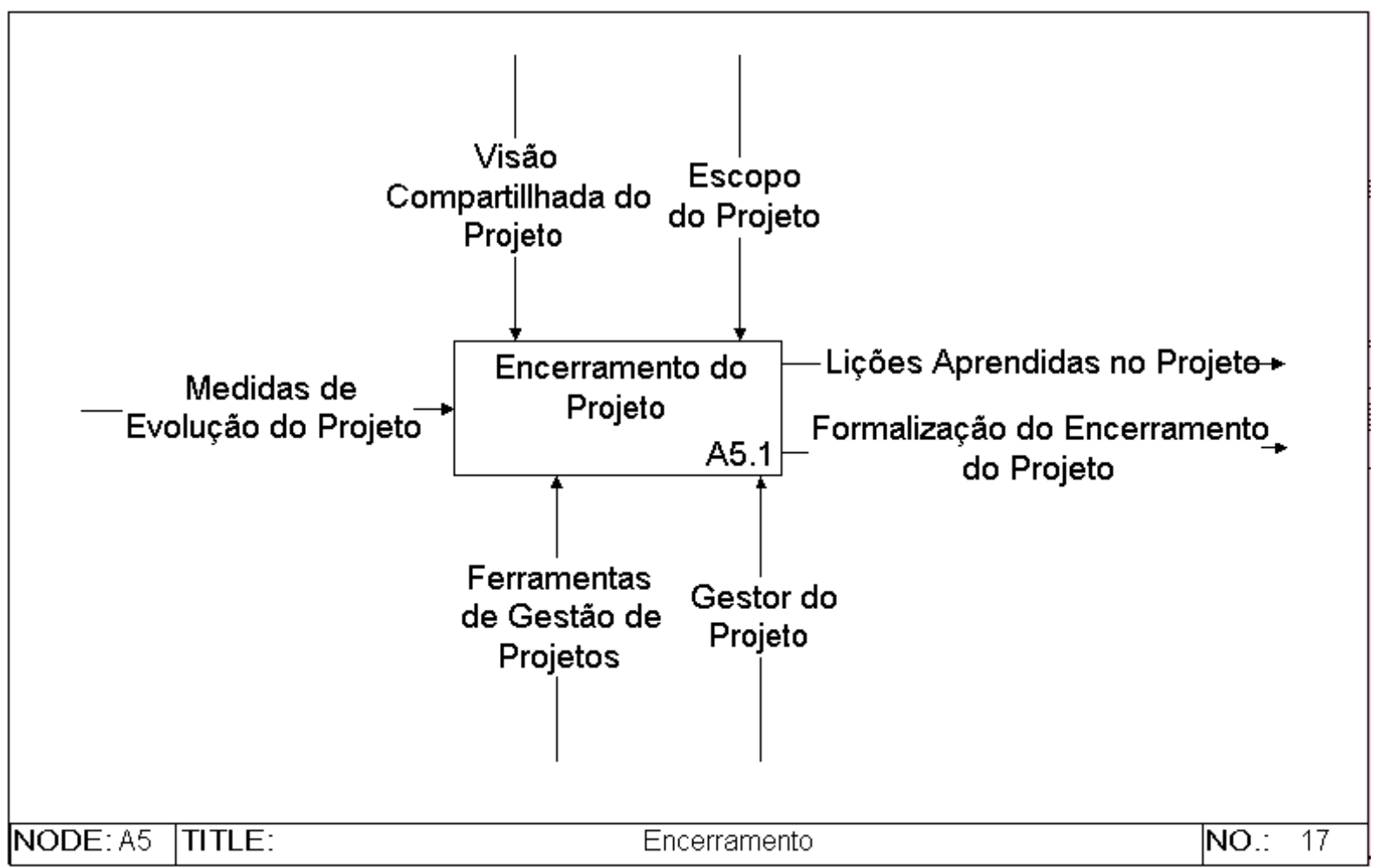

Figura 33. A5 - Encerramento.

\subsubsection{Encerramento do Projeto}

O subprocesso de "Encerramento do Projeto" é inspirado no modelo PMBoK (2000) e tem como objetivo formalizar o encerramento do projeto. Este subprocesso é muito importante, pois existe uma tendência natural nas pessoas de prolongar a execução de uma determinada atividade a que se está acostumado. Além disso, o subprocesso de Encerramento do Projeto também é importante para formalização da aceitação do produto final pelo cliente. A Tabela 12 apresenta os atributos do subprocesso.

Tabela 12. Atributos do Encerramento do Projeto.

\begin{tabular}{|l|l|}
\hline Objetivos do subprocesso: & Formalizar o encerramento do projeto. \\
\hline Limites do processo: & $\begin{array}{l}\text { Início: Após a identificação do cumprimento das metas } \\
\text { do projeto. } \\
\text { Fim: Dissolução da Organização Virtual. }\end{array}$ \\
\hline Indicadores de Desempenho: & - Esforço dispendido no encerramento do projeto. \\
\hline
\end{tabular}


As entradas desse subprocesso são o indicador de progresso do projeto e o conjunto de produtos entregues ao cliente. A partir deste indicador e da comparação dos produtos entregues ao cliente com o Escopo do Projeto, é possível identificar o momento de encerramento do projeto.

As saídas deste subprocesso são as lições aprendidas que serão armazenadas através do subprocesso de "Gestão do Conhecimento Colaborativo" e também a formalização do encerramento do projeto.

O Encerramento do Projeto é conduzido pelo Gestor do Projeto com o suporte de ferramentas de gestão de projetos para registro e divulgação do encerramento e também tem como controle a Visão Compartilhada do Projeto e o Escopo do Projeto.

A Figura 34 apresenta o detalhamento do subprocesso.

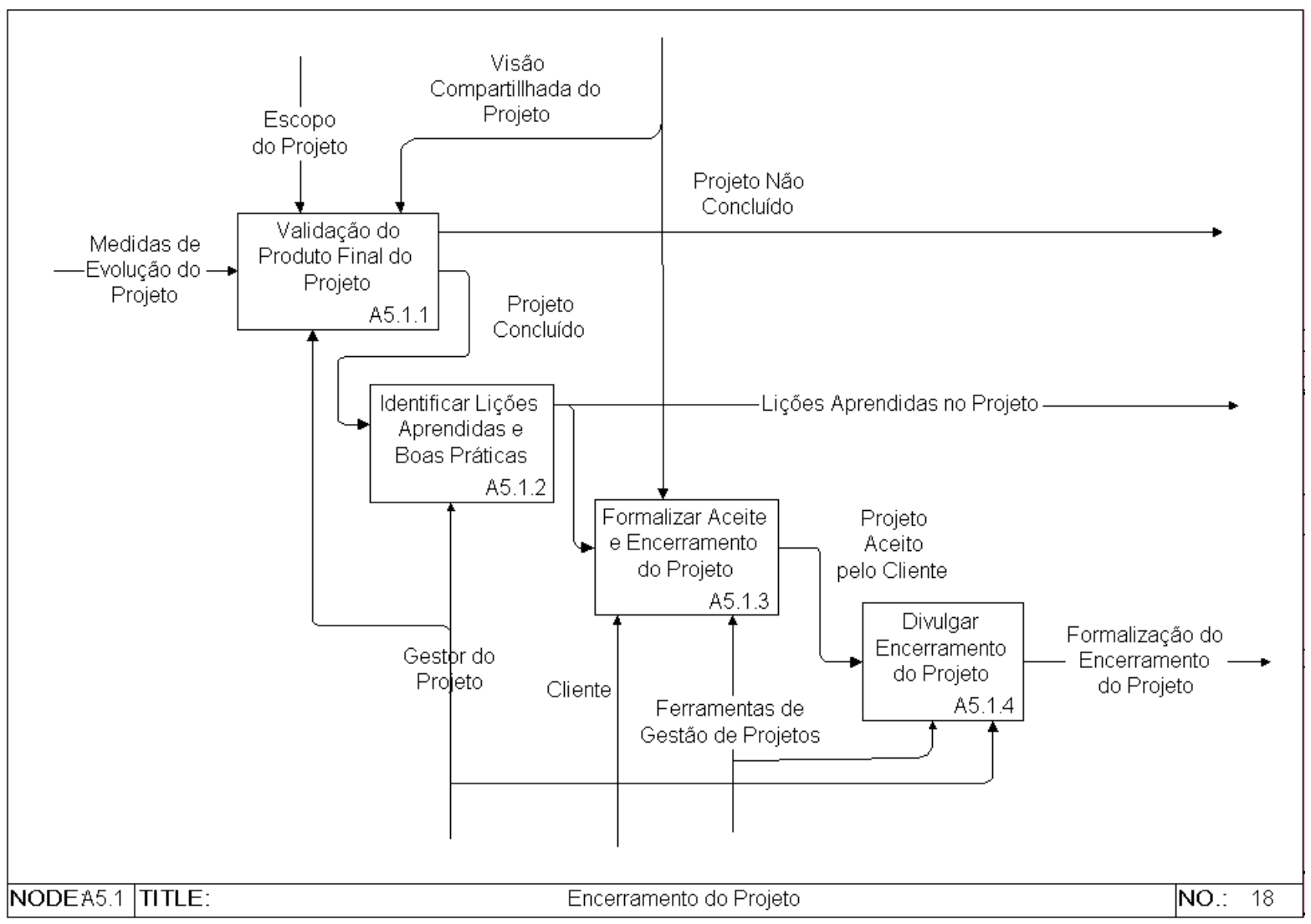

Figura 34. A5.1 - Encerramento do Projeto. 
O processo de Encerramento do Projeto inicia-se com a monitoração do progresso do projeto. O produto a ser entregue ao cliente no final do projeto é validado conforme o Escopo do Projeto. Esta atividade tem como objetivo identificar se o produto gerado tem todas as características especificadas no Escopo do Projeto. O Encerramento do Projeto não se caracteriza por uma atividade de teste de um produto, mas por uma validação de que o que deveria ser feito já está concluído. Após a identificação da conclusão do produto a ser entregue ao cliente, inicia-se uma atividade de identificação de boas práticas e lições aprendidas. Este conhecimento adquirido é entrada para o processo de "Gestão do Conhecimento Colaborativo".

Após esta atividade, tem início o encerramento formal do projeto. A aceitação formal do cliente é registrada e os contratos com as Equipes Virtuais são encerrados. O projeto é encerrado formalmente.

Por fim, o encerramento do projeto é divulgado a todos os interessados no projeto conforme subprocesso de "Gestão da Distribuição de Informações do Projeto".

\subsection{Avaliação do Modelo GesProDS}

O GesProDS, modelo proposto neste trabalho, tem como objetivo servir de referência para implantação e refinamento de processos de gestão para Organizações Virtuais que desejam executar projetos GSD.

O modelo proposto pode ser aplicado para projetos das categorias dois, três, quatro, cinco ou sete da classificação de Evaristo e Fenema (1999).

Os subprocessos descritos neste trabalho têm como objetivo amenizar e diminuir os problemas existentes em projetos GSD independentemente da complexidade dos projetos, da quantidade de projetos associados (projeto ou programa) e do nível de distribuição dos 
projetos (quantidade de locais de execução do projeto). O aumento do número de projetos associados e locais de execução aumenta a complexidade de gerenciamento de um projeto. Entretanto, os processos descritos neste trabalho constituem uma infra-estrutura básica que precisa existir independentemente destas características.

Os subprocessos de Gestão do Conhecimento Colaborativo e de Suporte ao Entendimento de Conceitos do Projeto têm como objetivo unificar o conhecimento de todos os membros das Equipes Virtuais do projeto. A Gestão do Conhecimento Colaborativo permite o acúmulo de experiências e aprendizados que são partilhados por todos envolvidos. O Suporte ao Entendimento de Conceitos do Projeto diminui as barreiras impostas pela distância na medida em que mantém uma Visão Compartilhada do Projeto com as principais diretrizes da organização e os conceitos mais importantes. Desta forma, aumenta-se o entendimento das características importantes do projeto. Além disso, esses processos também auxiliam a diminuir os problemas de comunicação do projeto, pois fornecem visibilidade a conceitos importantes evitando mal entendidos na comunicação entre os membros do projeto.

Os subprocessos de Iniciação do Projeto, Gestão da Distribuição de Informações do Projeto e Encerramento do Projeto atuam na melhoria da comunicação entre as Equipes Virtuais, destacando pontos de controle aos envolvidos, coletando informações importantes do projeto e identificando os destinatários e canais de distribuição da informação. Esses processos são muito importantes, pois em um contexto de projetos GSD, a falta ou incoerência de informações pode levar as Equipes Virtuais a caminhos diferentes do estabelecido para o projeto.

Os subprocessos de Meta-Planejamento do Tempo do Projeto, Controle do Cronograma e Controle de Mudança de Escopo atuam principalmente na coordenação das atividades das Equipes Virtuais. Os dois primeiros subprocessos estão focados na coordenação do planejamento de tempo do projeto. Esses indicam boas práticas para aumentar 
o nível de relacionamento e coordenação entre as atividades dos planos distribuídos do projeto.

Atrasos de uma Equipe Virtual ou alterações nas decisões de um projeto podem ter impactos significativos em um projeto. As técnicas descritas apóiam na identificação dos impactos e no replanejamento do projeto em virtude de problemas na execução, ocorridos nas atividades de uma Equipe Virtual. O subprocesso de Controle de Mudança de Escopo também auxilia na coordenação na medida em que gerencia mudanças de escopo, analisa os impactos e gera entradas para o replanejamento do projeto.

O subprocesso de Gestão do Ambiente Físico de Desenvolvimento Distribuído atua na integração entre as Equipes Virtuais. Apesar de não estar focado diretamente na integração dos produtos do projeto, ele apóia na manutenção da infra-estrutura física de hardware, software e telecomunicações das Equipes Virtuais de forma a unificar o ambiente e diminuir os problemas de integração.

A integração é um problema bastante sério neste contexto, pois a falta de padronização dos ambientes pode levar a geração de subprodutos incompatíveis. Este tipo de situação pode levar a grandes retrabalhos e atrasos no projeto.

O subprocesso de Gestão da Colaboração entre as Equipes Virtuais, atua na colaboração entre os membros do projeto. Este subprocesso tem grande importância para o modelo, pois disponibiliza meios para aumentar a produtividade do projeto. As atividades que demandam maior colaboração são identificadas, e o processo e as ferramentas para estas atividades são definidos, de forma a aumentar o grau de interação entre os membros das Equipes Virtuais e propiciar um aumento de produtividade.

O subprocesso de Avaliação de Riscos de Distribuição de Projetos e de Equipes Virtuais tem como objetivo auxiliar na identificação de riscos relacionados ao Desenvolvimento Distribuído de Software. Esse subprocesso atua como um suporte a tomada 
de decisão já que identifica os possíveis riscos da utilização do GSD. Em muitos casos, devido a restrições e características do projeto, o GSD pode não ser a opção mais adequada.

O GesProDS foi elaborado com base em modelos tradicionais de grande utilização no mercado como o PMBoK (2000) e o CMMI (2002) e também com base em modelos de gestão de projetos focados no GSD. Estes modelos foram identificados através de pesquisa bibliográfica de artigos de revistas especializadas como IEEE e ACM e são bastante referenciados em outros artigos relacionados ao tema.

O modelo MuNDDoS, proposto por Zanoni e Audy (2003) e Prikladnicki e Audy (2002, 2003), foi desenvolvido com base em estudos de caso conduzidos na Dell Computer Corporation com Equipes Virtuais a partir de Porto Alegre no Brasil e em Austin nos Estados Unidos da América.

O modelo MILOS, proposto por Goldmann et al. (1999a, 1999b, 1999c, 1999d, 2002), está em evolução desde 1992 e foi aplicado e refinado em projetos de grandes empresas como a Volkswagen Foundation.

O modelo CPMA, proposto por Chen, Romano e Nunamaker (2002, 2003a, 2003b), também é fruto de parcerias entre universidade e a iniciativa privada. Os conceitos descritos no modelo foram observados a partir de estudos de caso.

Desta forma, o modelo apresentado neste trabalho reúne processos e boas práticas coletados em modelos experimentados. O GesProDS consolida processos e boas práticas de uma forma coerente e facilita a implementação de processos de gestão de projetos para empresas que desejam desenvolver projetos de Desenvolvimento Distribuído de Software. 


\section{Conclusões}

Este capítulo apresenta as conclusões deste trabalho. Primeiramente são discutidas as principais contribuições e posteriormente os trabalhos futuros que poderão ser conduzidos a partir dos resultados apresentados.

\subsection{Contribuições}

Este trabalho discute os principais problemas identificados na literatura a respeito de projetos GSD. Alguns modelos de gestão de projetos conhecidos foram pesquisados como CMMI (2002) e o PMBOK (2000). Também foram identificados modelos focados na gestão de projetos GSD como o CPMA proposto por Chen, Romano e Nunamaker (2002, 2003a, 2003b), MunDDoS proposto por Prikladnick e Audy (2002, 2003) e MILOS proposto por Goldmann et al. (1999a,1999b, 1999c, 1999d, 2002). A partir dos problemas identificados para ambientes GSD e dos processos descritos nos modelos conhecidos e nos focados em GSD, foi elaborada uma tabela comparativa entre os modelos para identificação do nível de atendimento de cada um em relação aos problemas.

O modelo CMMI (2002) apresentou o maior nível de atendimento aos problemas descritos. Vários processos e práticas das áreas de processo do modelo foram utilizados e adaptados para composição do modelo proposto GesProDS.

A análise da Tabela 1 também permitiu evidenciar boas práticas descritas nos modelos para projetos GSD. Estas boas práticas são utilizadas como referência para composição do modelo de gestão de projetos GSD apresentado neste trabalho.

O GSD é um modelo de execução de projetos de software que está em franca expansão na indústria de software. O GesProDS pode ser utilizado como referência em 
organizações que desejam utilizar esta forma de desenvolvimento em seus projetos. Ele apresenta os principais processos de gestão para este contexto e o detalhamento das atividades de cada processo.

O modelo GesProDS não apresenta uma estrutura de papéis e responsabilidades completa para projetos GSD. Entende-se que dependendo do tipo de seção (vertical ou horizontal) a ser adotada e do ciclo de vida de desenvolvimento do projeto, diferentes papéis são necessários. Desta forma, os papéis apresentados são os necessários apenas para os processos descritos no modelo e devem ser complementados de acordo com o processo de desenvolvimento de software completo da organização que o utilizar.

O GesProDS não substitui os modelos tradicionais e focados na gestão de projetos GSD discutidos ao longo do trabalho. Ele apresenta os principais processos a serem adotados para minimizar os problemas identificados no contexto GSD. Entretanto, não foi objetivo deste trabalho cobrir todos os processos do modelo PMBoK (2000), nem do CMMI (2002).

Os processos mais importantes destes modelos para o contexto de projetos GSD foram analisados e serviram como referência para o modelo apresentado. Os processos de Iniciação, Controle de Cronograma, Controle de Mudança de Escopo e Encerramento de Projetos são inspirados no PMBoK (2000).

Os processos de Gestão do Ambiente Físico de Desenvolvimento Distribuído e Suporte ao Entendimento de Conceitos do Projeto utilizam alguns conceitos e boas práticas descritos em processos do CMMI (2002).

Estes modelos, PMBoK (2000) e CMMI (2002), devem ser utilizados no apoio à elaboração de processos complementares de desenvolvimento de software e de gestão de projetos GSD para uma Organização Virtual. O modelo apresentado deve ser utilizado como referência inicial para ajudar a desenvolver os processos e boas práticas mais críticos em um 
contexto GSD. O modelo apresentado também pode ser utilizado para refinamento de processos tradicionais.

Espera-se também que o modelo apresentado neste trabalho possa ser utilizado como referência para empresas que desejam participar de projetos GSD e que desta forma possa fomentar uma maior participação do Brasil no mercado mundial de software.

\subsection{Trabalhos Futuros}

Inicialmente, este trabalho possuía dois focos diferentes, mas dependentes. O primeiro foco consistia na elaboração de um modelo de gestão de projetos GSD. Este tema foi desenvolvido neste trabalho. O segundo foco envolvia o desenvolvimento de uma arquitetura e uma ferramenta baseada em agentes de software para automação de processos existentes em organizações com pontos de trabalho distribuídos geograficamente. Esta ferramenta teria como objetivo suportar a implantação dos processos descritos no modelo de gestão de projetos. Este é um possível futuro trabalho que poder ser gerado a partir dos resultados desse trabalho.

Esse trabalho teve como resultado a elaboração de um modelo de gestão para projetos GSD. O GesProDS reúne boas práticas e processos coletados em uma pesquisa bibliográfica no contexto de projetos GSD e também em modelos de gestão tradicionais. O GesProDS não foi aplicado em um estudo de caso. Desta forma, espera-se poder aplicar futuramente este modelo em um contexto GSD com objetivo de verificar e validar a utilidade e importância dos processos descritos. Os resultados do estudo de caso seriam utilizados para refinamento dos processos e boas práticas descritos e também na identificação de outras boas práticas e processos para o contexto de projetos de Desenvolvimento Distribuído de Software. 


\section{Referências}

BRIGGS, R. O.; ROMANO, N. C. Jr.; NUNAMAKER, J. F. Jr. A Framework for Collaboration and Knowledge Management. In: HAWAII INTERNATIONAL CONFERENCE ON SYSTEM SCIENCES, 34. , Hawaii, 2001. Proceedings. IEEE Computer Society Press, 2001.

BURLTON, R. Business Process Management: Profiting From Process. Indianapolis: Sams Publishing, 2001, 416p.

CARMEL, E. Global Software Teams. Collaborating Across Borders and Time Zones. Upper Saddle River: Prentice Hall PTR, 1999, 269p.

CHEN F.; ROMANO, N. C. Jr.; NUNAMAKER, J. F. Jr. Collaborative Project Management Software. In: HAWAII INTERNATIONAL CONFERENCE ON SYSTEM SCIENCES, 35., Hawaii, 2002. Proceedings. IEEE Computer Society Press, 2002.

CHEN F.; ROMANO, N. C. Jr.; NUNAMAKER, J. F. Jr.; BRIGGS, R. O. A Collaborative Project Management Architecture. In: HAWAII INTERNATIONAL CONFERENCE ON SYSTEM SCIENCES, 36., Hawaii, 2003. Proceedings. IEEE Computer Society Press, 2003a, p. 15-26.

CHEN, F.; ROMANO, N. C. Jr.; NUNAMAKER, J. F. Jr. An Overview of a Collaborative Project Management Approach and Supporting Software. In: AMERICAS CONFERENCE ON INFORMATION SYSTEMS,9., Tampa, 2003. Proceedings. Association for Information Systems, 2003b, p. 1303-1313.

CMMI-SE. Capability Maturity Model for Software Engineering. CMU/SEI, 2002.

CYRILLO, L. C., HIRAMA, K. Problemas, Desafios e Boas Práticas para o Processo de Gestão em Desenvolvimento Distribuído de Software. In: OBSERVATÓRIO - SESSÕES TÉCNICAS DE INFORMÁTICA DA UNOCHAPECÓ, 2., Chapecó, 2005. Anais. 2005.

EVARISTO, R.; FENEMA, P. C. V. A Typology of Project Management: Emergence and Evolution of New Forms. International Journal of Project Management, v.17, n.5, p.275, 1999.

GOLDMANN, S.; MÜNCH, J.; HOLZ, H. A Meta-Model for Distributed Software Development. In: WORKSHOP ON ENABLING TECHNOLOGIES (WETICE 1999), 8., USA, 1999. Proceedings. IEEE Computer Society, 1999a. p. 48-53.

GOLDMANN, S.; MÜNCH, J.; HOLZ, H. Distributed Process Planning Support with MILOS. In: INTERNATIONAL SOFTWARE \& ENGINEERING AND KNOWLEDGE ENGINEERING CONFERENCE (SEKE 1999), 11., Germany, 1999. International Journal of Software Engineering and Knowledge Engineering, 1999b. v. 10, n. 4 p. 511-525. 
GOLDMANN, S.; MÜNCH, J.; HOLZ, H.; MAURER, F.; SUCCI, G. Software Process Support over the Internet. In: INTERNATIONAL CONFERENCE ON SOFTWARE ENGINEERING (ICSE 1999), 21., USA, 1999. Proceedings. IEEE Computer Society, 1999c. p. 642-645.

GOLDMANN, S.; MÜNCH, J.; HOLZ, H. MILOS: A Model of Interleaved Planning, Scheduling and Enactment. In: WORKSHOP ON SOFTWARE ENGINEERING OVER THE INTERNET (ICSE 1999), 21., Los Angeles, 1999. Anais eletrônicos. 1999d.

Disponível em: http://sern.cpsc.ucalgary.ca/ maurer/ICSE99WS/Program.htm. Acesso em: 07/09/2004.

GOLDMANN, S. A Model of Planning and Enactment Support in Software Development Projects. In: INTERNATIONAL CONFERENCE AUTOMATED SOFTWARE ENGINEERING (ASE 2002), 17, Edinburgh, UK, 2002. Proceedings. IEEE Computer Society, 2002. p. 48-53.

HAYWOOD, M. Managing Virtual Teams. Practical Technique for High-Tecnology Project Managers. Boston: Artech House Publishers, 1998, 199p.

ISO. International Organization for Standardization. Concepts and introductory guide. IEC TR 15504 Part1 (SPICE), 1998.

ISO. International Organization for Standardization. A reference model for process capability. IEC TR 15504 Part2 (SPICE), 1998.

JACOBSON, I.; BOOCH, G.; RUMBAUGH, J. The Unified Software Development Process. Massachusetts: Addison-Wesley Longman Inc, 1998, 163p.

KAROLAK, D. W. Global Software Development. Los Alamitos: IEEE Computer Society, 1998, 158p.

NUNAMAKER, J. F. Jr., The MIS research program at the University of Arizona. In: HAWAII INTERNATIONAL CONFERENCE ON SYSTEM SCIENCES, 22., Hawaii, 1989. Proceedings. 1989a. p. 852-862.

NUNAMAKER, J. F. Jr.; VOGEL, D. R.; HEMINGER, A.; MARTZ, B.; GROHOWSKI, R.; McGOFF, C. Experiences at IBM with group support systems: a field study. Decision Support Systems, v. 5, n. 2, 1989b, p. 183-196.

OPPENHEIMER, H. L. Project Management Issues in Globally Distributed Development. In: WORKSHOP ON GLOBAL SOFTWARE DEVELOPMENT (ICSE 2002), 24., Florida, 2002. Anais eletrônicos. 2002. Disponível em: http://www.cse.ohiostate.edu/ nsridhar/ICSE02/GSD/ Acesso em: 07/09/2004.

PMBoK. A guide to the project management body of knowledge. Newtown Square: Project Management Institute, 2000. p. 380.

PRIKLADNICKI, R.; AUDY, J. L. N. Towards a Model of Software Development Process for a Physically Distributed Environment. In: CONGRESSO ARGENTINO DE CIENCIAS DE LA COMPUTACION (CACIC 2002), 8., Buenos Aires, 2002, Anales. 2002. v.1. p.798-809 
PRIKLADNICKI, R.; AUDY, J. L. N. Um Modelo de Referência para Desenvolvimento Distribuído de Software. In: WORKSHOP DE TESTES EM ENGENHARIA DE SOFTWARE (WTES 2003), 8., 2003, Manaus. Anais. Manaus: EDUA - Editora da Universidade Federal do Amazonas, 2003. v.1. p.89-94

RICHTER, M. M.; MAURER, F. MILOS and MASE. Past and Present. Anais eletrônicos do Ebe Group. 2003. Disponível em:

http://ebe.cpsc.ucalgary.ca/ebe/Wiki.jsp?page=Root.Publications. Acesso em: 01/10/2005.

ZANONI, R.; AUDY, J. L. N. Project Management Model for a Physically Distributed Software Development Environment. In: HAWAII INTERNATIONAL CONFERENCE ON SYSTEM SCIENCES, 36., Hawaii, 2003. Proceedings. IEEE Computer Society Press, 2003.

ZESAR, K. D.; ZECHNER, M.; SALHOFER, P.; SCHUSTER, G. MUELLEITNER, G. Performance and Quality Aspects of Virtual Software Enterprises. In: EUROMICRO CONFERENCE (EUROMICRO 1998), 24., Sweden, 1998. Proceedings. IEEE Computer Society, 1998. p. 20824-20829. 